\title{
LESS IS MTOR: REGULATION OF PROTEIN SYNTHESIS VIA THE INSULIN SIGNALING PATHWAY IN THE ANOXIA- TOLERANT RED-EARED SLIDER TRACHEMYS SCRIPTA ELEGANS
}

\author{
BY \\ KAMA E. SZERESZEWSKI \\ B.Sc. Hons. Carleton University, 2012
}

A THESIS SUBMITTED TO THE FACULTY OF GRADUATE AND POSTDOCTORAL AFFAIRS IN PARTIAL FULFILLMENT OF THE REQUIREMENTS FOR THE DEGREE OF MASTER OF SCIENCE

DEPARTMENT OF BIOLOGY

CARLETON UNIVERSITY

OTTAWA, ONTARIO, CANADA

(C) COPYRIGHT 2014

KAMA SZERESZEWSKI 
The undersigned hereby recommend to the Faculty of Graduate Studies and Research acceptance of this thesis

\title{
LESS IS MTOR: REGULATION OF PROTEIN SYNTHESIS VIA THE INSULIN SIGNALING PATHWAY IN THE ANOXIA- TOLERANT RED-EARED SLIDER TRACHEMYS SCRIPTA ELEGANS
}

\author{
Submitted by \\ Kama Szereszewski, B.Sc. Hons. \\ In partial fulfillment of the requirements for the degree of Masters of Biology
}

Chair, Department of Biology

Thesis Supervisor

Carleton University 


\begin{abstract}
The red-eared slider turtle, Trachemys scripta elegans, can survive 3-4 months of anoxic submergence in cold water during the winter. The effect of hypoxia/anoxia on protein synthesis in red-eared sliders was investigated with a focus on the insulin-signaling pathway and analysis of the mammalian target of rapamycin (mTOR) and its upstream and downstream effectors in liver and white muscle. Expression of mTORC1 did not change in muscle but increased significantly in liver after 5 and 20 hours of anoxic submergence. Upstream effectors, AKT and RAPTOR, were also elevated in liver but suppressed in muscle. PRAS40 and TSC2 inhibitors of mTOR were differentially regulated in both tissues but generally suppressed. Downstream targets of mTOR signaling (eIF4E, 4E-BP1, P70S6K, S6) as well as the poly(A) binding protein also showed differential responses to anoxia. Overall, the data indicate that the early response to anoxia by turtles is maintenance of protein synthesis in liver but suppression in white muscle.
\end{abstract}




\section{ACKNOWLEDGEMENTS}

First and foremost, I would like to thank my thesis supervisor, Dr. Kenneth Storey for accepting me into his lab. I am eternally grateful for his advice and persistence in pushing me to work harder than I ever have in order to become the molecular biologist I am today. I have learned so much more than new molecular techniques from Dr. Storey. He has helped me develop on a personal level and pursue higher levels of achievement. I must also thank Janet Storey for her extensive knowledge and hours of work put into helping me write this thesis. Furthermore, the continued amount of work put into keeping the lab running. We would be lost without you.

I would like to thank my family and friends without whom I would not be where I am today. To my parents for causing me to push myself towards higher academic achievement, to my lab mates: Dr. Barb Katzenback and Dr. Shannon Tessier for teaching me everything I know, Sanoji Wijenayake for her endless guidance and support, as well as Kyle Biggar, Mike Wu, and Bryan Luu for their countless hours of training and tutelage. Finally, I would like to thank the rest of the lab for guiding me along the way and for our endless scientific discussions.

Most importantly, I would like to thank Avery, without you, I would not have gotten where I am today. I thank you for your endless support, wisdom and guidance. You have been there for me from the beginning and continuously throughout this journey. 
TABLE OF CONTENTS

Page

Title page $\quad$ i

Acceptance Sheet ii

Abstract $\quad$ iii

Acknowledgements iv

Table of Contents $\quad \mathrm{v}$

List of Abbreviations $\quad$ vi

List of Figures vii

List of Appendices viii

Chapter $1-$ General Introduction 1

$\begin{array}{lr}\text { Chapter } 2 \text { - Materials and Methods } & 18\end{array}$

Chapter 3 - Upstream of mTORC1 23

Chapter 4 - Downstream of mTORC1 50

$\begin{array}{ll}\text { Chapter } 5 \text { - General Discussion } & 71\end{array}$

$\begin{array}{lr}\text { Appendices } & 80\end{array}$

References $\quad 83$ 


\section{LIST OF ABBREVIATIONS}

$\begin{array}{ll}\text { 4E-BP1 } & \text { 4E-binding protein-1 } \\ \text { AKT } & \text { Protein kinase B } \\ \text { eIF4E } & \text { Eukaryotic translation initiation factor-4E } \\ \text { GßL } & \text { G-protein beta-subunit-like } \\ \text { mTOR } & \text { Mammalian target of rapamycin } \\ \text { p70 S6K } & \text { Ribosomal protein S6 kinase, 70kDa } \\ \text { PABP } & \text { Poly-A-binding protein } \\ \text { PDK-1 } & \text { Phosphoinositide-dependent kinase-1 } \\ \text { PI3K } & \text { Phosphoinositide-3-kinase } \\ \text { PRAS40 } & \text { Proline-rich Akt substrate, } 40 \mathrm{kDa} \\ \text { PTEN } & \text { Phosphatase and tensin homolog } \\ \text { RAPTOR } & \text { Regulatory associated protein of mTOR } \\ \text { Rheb } & \text { Ras homolog enriched in brain } \\ \text { S6 } & \text { Ribosomal protein S6 } \\ \text { TSC2 } & \text { Tuberous sclerosis factor-2 }\end{array}$




\section{LIST OF FIGURES}

FIG 1.1 Down-regulation of the 5 most energy-consuming metabolic processes in hepatocytes of the anoxia-tolerant red-eared slider turtle Trachemys scripta elegans.

FIG 1.2 Anoxia duration in days at temperatures of $20^{\circ} \mathrm{C}, 15^{\circ} \mathrm{C}, 10^{\circ} \mathrm{C}$ and $3^{\circ} \mathrm{C}$ of the red-eared slider Trachemys scripta elegans.

FIG 1.3 North American distribution of the anoxia tolerant turtle Trachemys scripta elegans.

FIG 1.4 Transitions to and from a hypometabolic state in the anoxic turtle.

FIG 1.5 The mTOR signaling pathway.

FIG 3.1 The mTOR pathway

FIG 3.2 Immunoblots of upstream mTOR signaling pathway proteins in (A) white skeletal muscle and (B) liver tissues.

FIG 3.3 Regulation pattern of mTOR in white skeletal muscle and liver of Trachemys scripta elegans determined by Western Immunoblotting.

FIG 3.4 Regulation pattern of RAPTOR in white skeletal muscle and liver tissues of Trachemys scripta elegans determined by Western Immunoblotting.

FIG 3.5 Regulation pattern of PTEN in white skeletal muscle and liver tissues of Trachemys scripta elegans determined by Western Immunoblotting.

FIG 3.6 Regulation pattern of PDK1 in white skeletal muscle and liver tissues of Trachemys scripta elegans determined by Western Immunoblotting.

FIG 3.7 Regulation pattern of AKT in white skeletal muscle and liver tissues of Trachemys scripta elegans determined by Western Immunoblotting.

FIG 3.8 Regulation pattern of TSC2 in white skeletal muscle and liver tissues of Trachemys scripta elegans determined by Western Immunoblotting.

FIG 3.9 Regulation pattern of PRAS40 in white skeletal muscle and liver tissues of Trachemys scripta elegans determined by Western Immunoblotting.

FIG 3.10 Regulation pattern of G $\beta L$ in white skeletal muscle and liver tissues of Trachemys scripta elegans determined by Western Immunoblotting. 
FIG 4.1 The downstream mTOR signaling pathway.

FIG 4.2 Immunoblots of downstream mTOR signaling pathway proteins in white skeletal muscle (A) and liver (B) tissues.

FIG 4.3 Regulation pattern of p70 S6K in white skeletal muscle and liver tissues of Trachemys scripta elegans determined by Western Immunoblotting.

FIG 4.4 Regulation pattern of S6 in white skeletal muscle and liver tissues of Trachemys scripta elegans determined by Western Immunoblotting.

FIG 4.5 Regulation pattern of 4E-BP1 in white skeletal muscle and liver tissues of Trachemys scripta elegans determined by Western Immunoblotting.

FIG 4.6 Regulation pattern of eIF4E in white skeletal muscle and liver tissues of Trachemys scripta elegans determined by Western Immunoblotting.

FIG 4.7 Regulation pattern of PABP in white skeletal muscle and liver tissues of Trachemys scripta elegans determined by Western Immunoblotting.

\section{LIST OF APPENDICES}

Appendix A1 List of Antibodies

Appendix A2 Immunoblotting conditions 
CHAPTER 1

\section{GENERAL INTRODUCTION}




\subsection{General Introduction}

\section{Lack of oxygen}

Many organisms must endure some type of environmental stress throughout the year. Animals that live in the northern hemisphere experience drastic changes in temperature from summer to winter months and during the winter are also faced with challenges including limited food availability and low/freezing temperatures. As a result, animals develop adaptations that enable them to promote their survival. Adaptations to the cold can come in many forms. Some species move to warmer environments to avoid winter cold; many birds, for example, migrate to warmer climates. Others do shorter movements to retreat underground or under water where they are thermally buffered against very cold air temperatures. Many small mammals like ground squirrels seek refuge in underground burrows and then enter hibernation, during which they cycle through long periods of torpor that are interspersed with short periods of arousal (Storey, 1997). Amphibian species exhibit multiple strategies - some go underground (toads, salamanders), some winter underwater (many frogs) and some frogs winter on the forest floor (e.g. the wood frog Rana sylvatica) where they have developed freeze-tolerance to endure the freezing of their internal body fluids when temperatures fall below $0^{\circ} \mathrm{C}$ (Storey and Storey, 1984). Many turtles winter underwater where they are generally safe from freezing but, as lungbreathing vertebrates, they have issues with oxygen supply while submerged. A number of species (mainly soft-shelled turtles) can get all of the oxygen they need by taking oxygen up across epithelial surfaces (buccal, cloacal or skin) (Ultsch, 2006, Jackson and Ultsch, 2010). This extrapulmonary mode of oxygen acquisition works well in cold water because (a) turtle metabolic rate is very low in the cold, and (b) dissolved oxygen content 
is highest in cold water. Other turtles such as the red-eared sliders (Trachemys scripta elegans) have developed excellent tolerance to long term oxygen deprivation (anoxia) in order to survive.

\section{Anoxia-tolerance}

Well-developed anoxia tolerance occurs in a number of vertebrate species such as: the carp (Carassius carassius), goldfish (Carassius auratus), and turtles (Trachemys scripta and Chrysemys picta), among others. For example, fish such the crucian carp and the epaulette shark (Hemiscyllium ocellatum) are able to tolerate very low-oxygen conditions for long periods of time ranging from weeks to months (Wise et al., 1998). Many invertebrates, particularly marine intertidal species, are also good facultative anaerobes; these include many gastropod and bivalve molluscs, annelid worms and barnacles (Bickler and Buck, 2007, Lutz and Nilsson, 2004, Larade and Storey, 2002a).

Red-eared slider turtles are champions of facultative anaerobiosis in that they are highly tolerant of low-oxygen conditions and can survive for days at $16^{\circ} \mathrm{C}$ and $12-18$ weeks at $3^{\circ} \mathrm{C}$ with oxygen concentrations below $0.02 \%$ (Herbert and Jackson, 1985; Storey and Storey, 2004b; Biggar, et al., 2011 and Pi et al., 2013). Anaerobic metabolism may be employed during short-term oxygen deprivation when turtles dive for food or to escape from prey. However, longer term oxygen deprivation occurs in the winter months during underwater hibernation when animals are restricted from surfacing to breathe by ice cover. Sliders must then turn to one of two modes of survival; either by using an extrapulmonary method of oxygen uptake from the water (sliders are relatively poor at 
this), or by utilizing anaerobic metabolism combined with strong suppression of metabolic demand (hypometabolism) (Biggar et al., 2011).

\section{Metabolic rate depression and protein synthesis}

Organisms utilizing aerobic metabolism are able to use carbohydrates, lipids and proteins as sources of fuel for ATP generation. However, when oxygen levels become limiting, animals are restricted almost solely to the use of carbohydrates as their major source of fermentable fuel (Storey and Storey, 2004b). As the final electron acceptor for the electron transport chain, oxygen supports the generation of 36 moles of ATP per mole of glucose catabolized. However, under anoxic conditions, animals must rely on anaerobic glycolysis, which only produces a net of 2 mol of ATP per mol of glucose. Therefore, although most organisms can run glycolysis at high rates for short periods of time (e.g. burst sprint running), over the longer term ATP demand soon outstrips the ability to supply ATP from glycolysis alone. This has disastrous consequences for anoxia intolerant animals since glucose/glycogen stores become depleted, ATP levels fall and metabolic processes become dysregulated while toxic acidic waste products such as lactic acid accumulate (Jackson, 2002). For example, without oxygen, irreversible metabolic damage to the human brain can occur within only about 4 minutes. To achieve long term survival, facultative anaerobes such as the red-eared slider turtle have developed a number of adaptive strategies to avoid these negative effects. These mechanisms include: (1) maintaining high levels of fermentable fuel stores (glycogen), primarily in the liver, (2) buffering the acidic by-products of anaerobic glycolysis, and (3) depressing their metabolic demand to ensure homeostasis between ATP supply and demand (FIG 1.1) (Storey and Storey, 1990). Several ATP-utilizing metabolic processes are therefore 
reprioritized or suppressed under anoxia so that long-term viability can be sustained. For example, a previous study showed a $94 \%$ decrease in overall ATP turnover in isolated turtle hepatocytes when exposed to anoxic conditions (Hochachka et al., 1996). The most dramatic effects were observed in five main ATP consuming processes: $\mathrm{Na}^{+} \mathrm{K}^{+}$-ATPase activity, protein synthesis, protein degradation, gluconeogenesis and urea biosynthesis which, respectively, consumed 28, 36, 17, 17 and 3\% (Hochachka et al., 1996) of ATP turnover under aerobic conditions. Each of these was strongly but differentially suppressed under anoxia by 75, 93, 94, 100 and 70\%, respectively (Storey and Storey, 2004b) (FIG 1.2) As a result, $\mathrm{Na}^{+} \mathrm{K}^{+}$-ATPase activity was reprioritized to be the major consumer of ATP under anaerobic conditions. Hence, the turtle redirects available energy to vital processes in order to endure a long-term period of anoxic hypometabolism.

However, although multiple metabolic processes are significantly downregulated, turtles must still remain at-the-ready so that normal function can be rapidly restored when oxygen is again available. Therefore, reversible controls are applied in order to regulate metabolic processes so that they may be suppressed during anoxia, while allowing for rapid return to normal metabolic functioning when oxygen is again available (Storey and Storey, 2004).

\section{Post-translational modifications: Phosphorylation}

Reversible protein phosphorylation is a major mechanism for post-translational modification and general regulatory control of enzymes and proteins involved in virtually every cellular process (Storey and Storey, 2007; Storey, 2007). Phosphorylation and dephosphorylation reactions catalyzed by protein kinases and protein phosphatases can 
govern the function of a protein in multiple ways; for example by regulating biological activity, protein stability, movement between subcellular compartments, protein-protein interactions, or marking a protein for destruction (Cohen, 2002). This flexibility explains why phosphorylation is one of the most general regulatory devices that have been adopted by eukaryotic cells. Multiple studies in our lab have demonstrated that reversible phosphorylation is an important regulatory mechanism in animal responses to several types of environmental stress (Storey and Storey, 2004b, 2007) as well as specifically during turtle anaerobiosis (Krivoruchko and Storey, 2013a,b; Zhang et al., 2013). The present study investigates the role of reversible phosphorylation in controlling protein synthesis in response to anoxia in the fresh water red-eared slider turtle Trachemys scripta elegans.

\section{Animal model: Red-eared slider}

Red-eared slider turtles are an excellent animal model for anoxia tolerance as they are one of the champion vertebrate facultative anaerobes capable of enduring long periods of time with little to no oxygen (painted turtles, Chrysemys picta, are the other main model). They are able to survive under anoxic conditions for up to two weeks at temperatures around $16^{\circ} \mathrm{C}$ and up to 18 weeks around $3^{\circ} \mathrm{C}$ (FIG 1.3). Red-eared sliders are native to the southeastern and mid-eastern United States but have been introduced to many other parts of the United States as well as Southern Canada due to animals released from the pet trade (FIG 1.4). Typical body size for an adult slider carapace is at most 30$40 \mathrm{~cm}$ however the average is around $12-20 \mathrm{~cm}$. Females are generally larger than the males and both sexes can live between 20 to 30 years although some can live as long as 40 years. The red-eared slider is an omnivore that generally feeds on aquatic plants and 
crustaceans. Sliders are poikilotherms and are unable to regulate body temperature by internal means and are therefore strongly influenced by the temperature of their environment (Kroese and Rooijen, 1982). During summer and autumn, turtles greatly increase their liver glycogen stores to prepare for winter months and eat little or nothing during the winter when the metabolic rate of submerged turtles is depressed to only about $10 \%$ of normoxic rates (Herbert and Jackson, 1985). Studies have shown that the western painted turtle may accumulate plasma lactate levels as high as $150-200 \mathrm{mM}$ over the winter months (Jackson, 2000, Nilsson and Renshaw, 2004). The average human may only accumulate lactate levels of around 15-20 mM after strenuous exercise (Wasserman, 1999). These extreme lactate levels (and the acidosis that accompanies lactate production) would be highly injurious to most animals but turtles have developed specialized coping mechanisms. They mobilize $\mathrm{Mg}^{2+}$ and $\mathrm{Ca}^{2+}$ carbonates from their shell and bone to buffer acidosis and also move large amounts of lactate into their shell and store it there (Jackson, 2002).

\subsection{Objectives and Hypotheses}

Protein synthesis is an energy-expensive metabolic process which can consume a high proportion of overall ATP use in cells; for example, in normoxic turtle hepatocytes, $\sim 36 \%$ of total ATP turnover was devoted to protein synthesis (Hochachka et al., 1996). However, during anoxic submergence in cold water, freshwater turtles have been shown to depress whole body metabolism to around $10 \%$ of normoxic levels and protein synthesis in liver cells was reduced to $\sim 6 \%$ of normoxic levels during anoxia (Hochachka et al., 1996). This type of stress-induced metabolic rate depression is seen in many other 
animals employing various mechanisms for survival, such as: the freeze-tolerant wood frogs (Rana sylvatica), hibernating squirrels (Ictidomys tridecemlineatus), estivating snails (Otala lactea) and many more (Storey and Storey, 1984; Storey, 1997; HermesLima et al., 1998). Overall, then, metabolic rate depression seems to be quite well conserved across the animal kingdom. Therefore, given that strong suppression of protein synthesis was demonstrated for turtle liver in response to anoxia, I chose to explore the metabolic mechanisms underlying this suppression. Hence, this thesis examines the insulin signaling pathway and mammalian target of rapamycin (mTOR) (FIG 1.5) regulated control of protein synthesis in the anoxia-tolerant red-eared slider Trachemys scripta elegans. Two tissues were chosen for study, liver and white skeletal muscle. The liver has a major role to play under anoxic conditions, containing the central store of glycogen that is slowly catabolized to sustain the supply of blood glucose to all other organs. It is also a major organ involved in detoxification and antioxidant defense as well as biosynthesis of proteins that are exported into plasma. The white muscle used is the neck retractor, a fast twitch muscle that is used to rapidly pull in the turtle's head.

The current thesis addressed the subject of protein synthesis by examining regulatory responses by the insulin signaling pathway that is involved in mediating cellular growth and proliferation by responding to various extracellular signals. Specifically, the focus was on the portion of the insulin signaling pathway that regulates protein synthesis and is mediated by mTOR. Amino acids, cytokines, hormones and growth factors stimulate several protein kinase cascades which all integrate into the mTOR pathway in order to initiate and regulate protein synthesis. This is achieved through mTOR-mediated activation of p70 S6 kinase (p70 S6K) and the inhibition of the 
eukaryotic translation initiation factor 4E-binding protein 1 (4E-BP1). Through the action of these downstream targets, p70 S6K and 4E-BP1, control over mRNA binding and ribosomal complex assembly is exerted (Hay and Sonenberg, 2004).

The pathway commences when insulin binds to the receptor thus activating the PI3K pathway. Upon phosphorylation, the insulin receptor protein interacts with phosphoinositide-3-kinase (PI3K) leading to its activation. PI3K then generates the lipid product phosphatidylinositol $(3,4,5)$-trisphosphate $\left(\mathrm{PIP}_{3}\right)$ from phosphatidylinositol $(4,5)$ bisphosphate ( $\left.\mathrm{PIP}_{2}\right)$ (Hay and Sonenberg, 2004; Chang et al., 2004). The increase in $\mathrm{PIP}_{3}$ levels can be attenuated by dephosphorylation of $\mathrm{PIP}_{3}$ back to $\mathrm{PIP}_{2}$ by the phosphatase PTEN (phosphatase and tensin homolog). Insulin-stimulated increases in $\mathrm{PIP}_{3}$ result in the activation of the downstream phosphoinositide-dependent kinase-1 (PDK-1) which phosphorylates and activates subsequent downstream kinases including AKT (Chang et al., 2004). AKT goes on to phosphorylate and inactivate protein inhibitors of the mTOR complex, PRAS40 (proline-rich Akt substrate $40 \mathrm{kDa}$ ) and TSC2 (tuberous sclerosis factor-2), which results in the activation of mTOR. Once active, mTOR phosphorylates its downstream targets. mTOR-mediated phosphorylation activation of p70 S6K subsequently leads to activation of the ribosomal protein S6 which stimulates translation initiation by facilitating ribosomal complex assembly. mTOR also phosphorylates 4EBP1 which releases eIF4E from inhibitory binding and allows the eukaryotic initiation factor to initiate cap-dependent translational initiation (Chang et al., 2004, Hay and Sonenberg, 2004). 


\section{Objective 1: Regulation of the mTOR complex}

In response to anoxia, synthesis of new proteins has been shown to be strongly down-regulated (Hochachka et al., 1996; Storey and Storey, 2004b). The activation of the mTOR complex occurs when inhibitors PRAS40 and TSC2 are inactivated. Under anoxic conditions, relative levels of active phosphorylated mTOR would be expected to decrease thus suppressing protein synthesis.

Hypothesis 1: The regulatory role of mTOR signaling to promote protein synthesis will be suppressed during anoxia in order to reduce energy expenditure in the anoxic state. Hence, the active form of the mTOR complex will be downregulated under anoxia.

Chapter 3 tests this hypothesis by assessing the regulation of the mTOR signaling pathway in turtle white skeletal muscle and liver during anoxia. The mTOR complex is composed of several proteins, which upon phosphorylation form the active mTOR complex. Chapter 3 analyzes the responses to anoxia by mTOR components including mTOR and phosphorylated mTOR ${ }^{\text {Ser2448. }}$.

\section{Objective 2: Regulation of upstream targets.}

Upstream of mTOR, various protein kinases function to activate subsequent factors which relieve inhibition on the mTOR complex. Once PI3K is activated, it catalyzes the 
conversion of $\mathrm{PIP}_{2}$ to $\mathrm{PIP}_{3}$, and then $\mathrm{PIP}_{3}$ as a second messenger activates PDK-1. Active PDK-1 then activates another central protein kinase of the mTOR pathway, AKT (or protein kinase B). AKT is responsible for controlling cell survival and apoptosis and with respect to $\mathrm{mTOR}$ control phosphorylates downstream targets in order to release mTOR from inhibition by TSC2 and PRAS40. The upstream protein phosphatase, PTEN, also contributes to PDK-1 control by catalyzing the dephosphorylation of $\mathrm{PIP}_{3}$ back to $\mathrm{PIP}_{2}$, acting in opposition to $\mathrm{P} 13 \mathrm{~K}$.

Hypothesis 2: Upstream factors that control mTORC1 will be slowed or inhibited in response to anoxia in order to suppress energy expenditure on protein synthesis. mTORC1 inhibitors will be activated and mTORC1 activators suppressed. Upstream regulators of the pathway, such as PTEN, will be activated in order to help turn-off the mTOR pathway.

Chapter 3 also analyzes the upstream regulators of the mTORC1 complex by examining the regulation of upstream targets PTEN, PDK-1, AKT, TSC2 and PRAS40 in turtle liver and white muscle tissues.

Objective 3: Regulation of downstream effectors.

The active mTORC1 complex contributes to regulating cell protein synthesis and ribosomal complex assembly via the activation of p70 S6 Kinase (p70 S6K) and inhibition of the eukaryotic 4E-binding protein 1 (4E-BP1). p70 S6K subsequently 
stimulates translation initiation through the activation of the S6 protein of the $40 \mathrm{~S}$ ribosomal subunit whereas the hyperphosphorylation of 4E-BP1 releases its inhibition of the eukaryotic initiation factor 4E (eIF4E) thus promoting cap-dependent translation.

Hypothesis 3: Downstream targets of mTOR, p70 S6K and 4E-BP1, as well as subsequent targets under p70 S6K control, will be suppressed under anoxic conditions contributing to the down-regulation of cap-dependent protein synthesis in anoxia.

Chapter 4 tests this hypothesis by examining the protein expression of downstream targets of mTOR signaling including p70 S6K, S6, 4E-BP1, eIF4E and other ribosomal proteins eIF4A and eIF4B in liver and white muscle tissues in response to anoxic stress. 


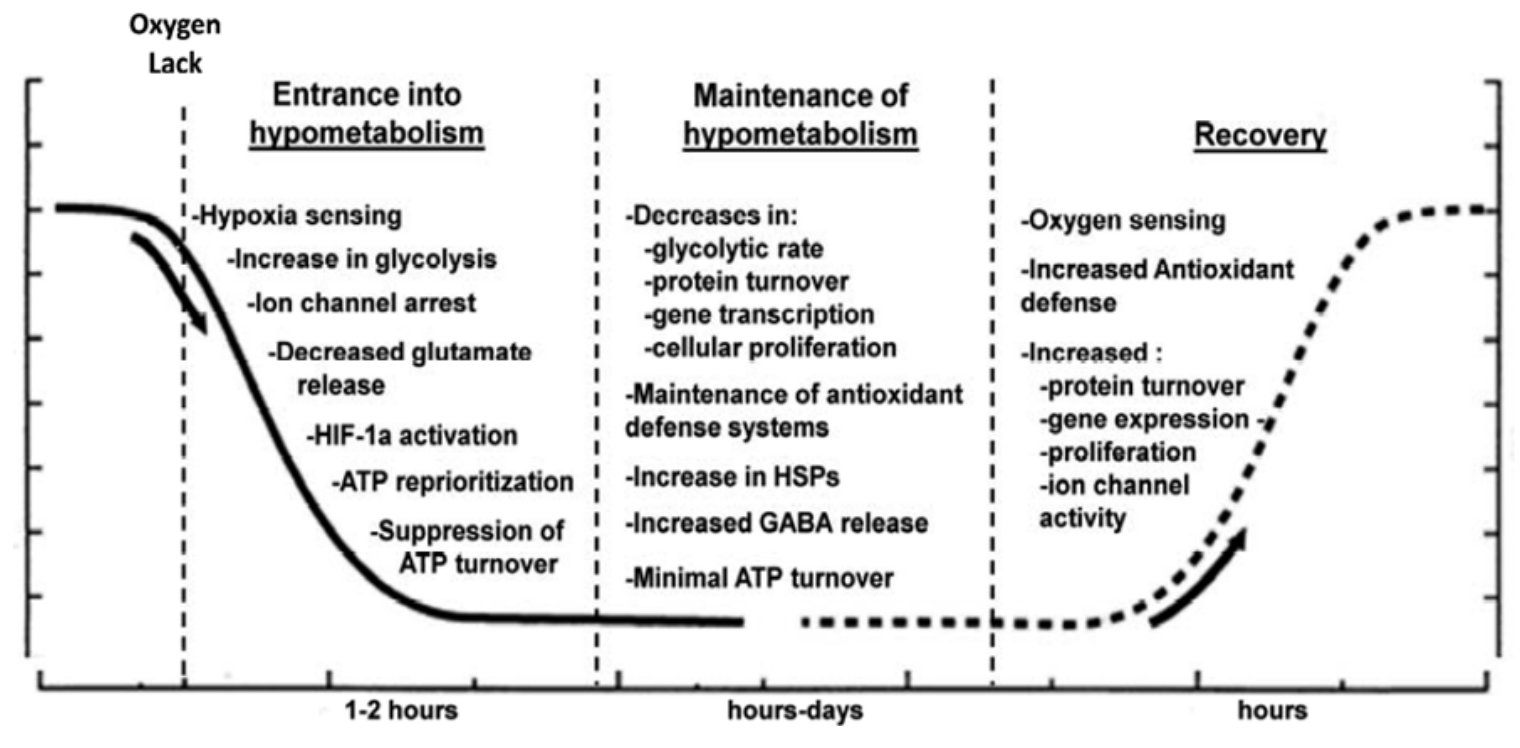

Figure 1.1 Transitions to and from a hypometabolic state in the anoxic turtle. Upon initial sensing of oxygen lack, ATP-requiring metabolic processes are reprioritized in order for cells to endure long term oxygen deprivation and protect themselves against oxidative damage upon oxygen reperfusion. From Biggar et al. (2011). 


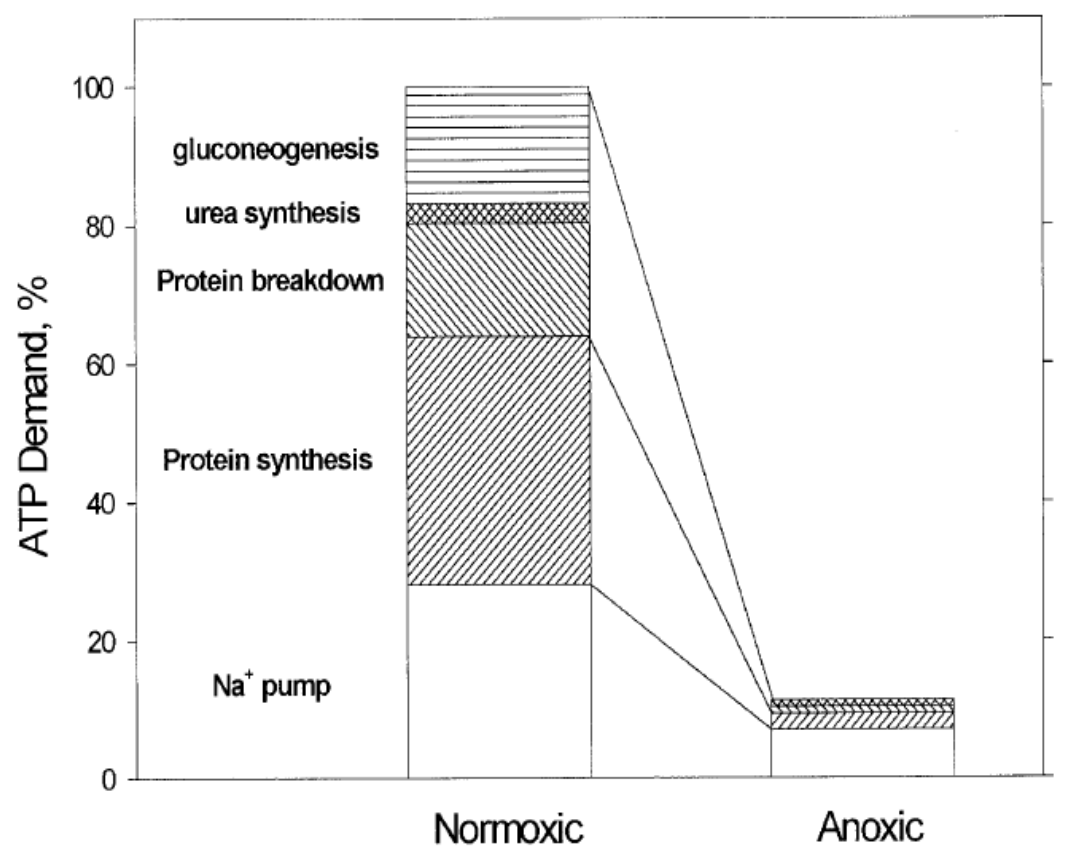

\begin{tabular}{lccc}
\hline & $\begin{array}{c}\text { Normoxia } \\
(\%)\end{array}$ & $\begin{array}{c}\text { Anoxia } \\
(\%)\end{array}$ & $\begin{array}{c}\text { Suppression in } \\
\text { Anoxia }(\%)\end{array}$ \\
\hline $\mathrm{Na}^{+} \mathrm{K}^{+}-$ATPase & 28.5 & 62.3 & 75 \\
Protein synthesis & 36.1 & 20.8 & 93 \\
Protein degradation & 16.6 & 9.1 & 94 \\
Urea synthesis & 3.0 & 7.8 & 70 \\
Gluconeogenesis & 17.0 & 0 & 100 \\
\hline
\end{tabular}

Figure 1.2 Down-regulation of the 5 most energy-consuming metabolic processes in hepatocytes of the anoxia-tolerant red-eared slider turtle Trachemys scripta elegans. The suppression of gluconeogenesis, urea synthesis, protein synthesis, protein breakdown and ion-motive ATP pumps results in a 90\% decrease in ATP-consumption under anoxia. From Hochachka et al. (1996). 


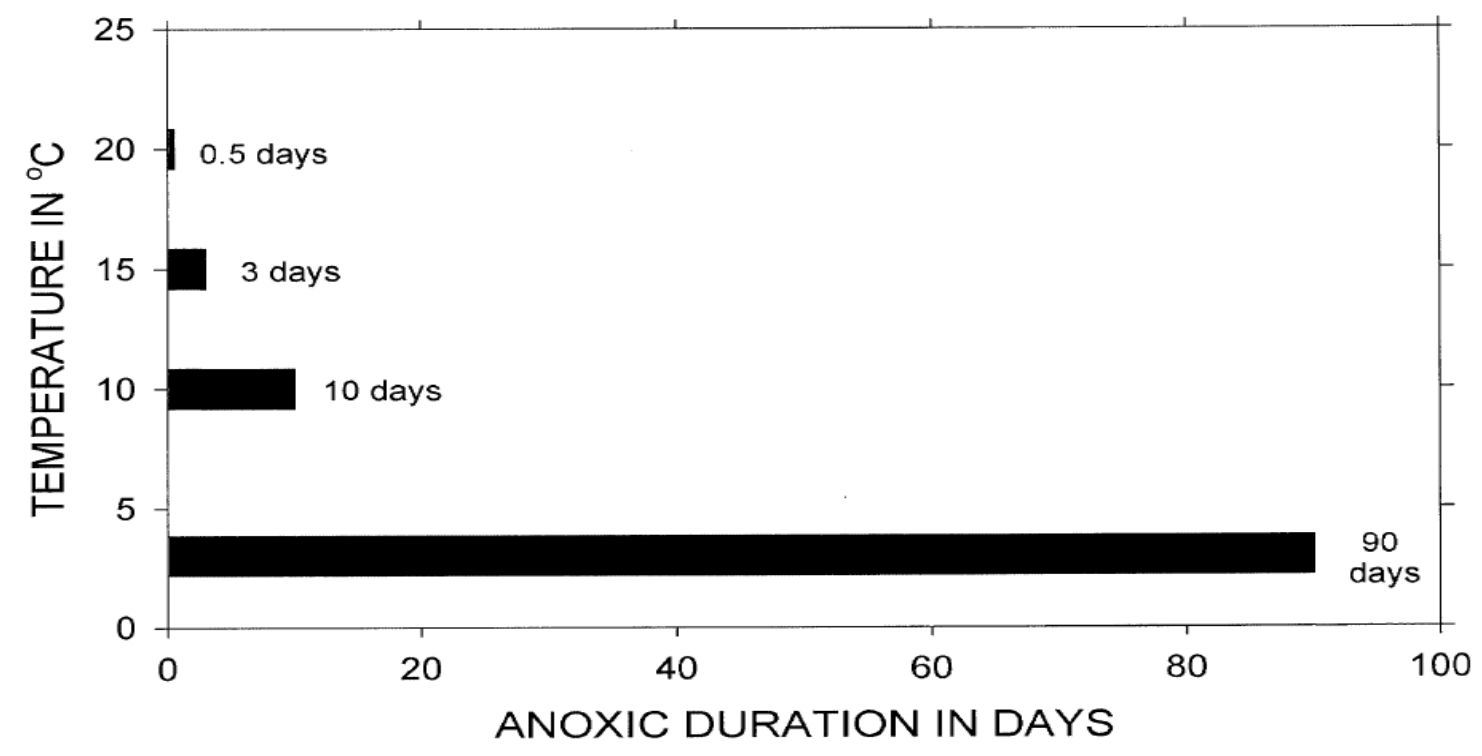

Figure 1.3 Anoxia duration in days at temperatures of $20^{\circ} \mathrm{C}, 15^{\circ} \mathrm{C}, 10^{\circ} \mathrm{C}$ and $3^{\circ} \mathrm{C}$ of the red-eared slider Trachemys scripta elegans. Figure obtained from Jackson (2002). 


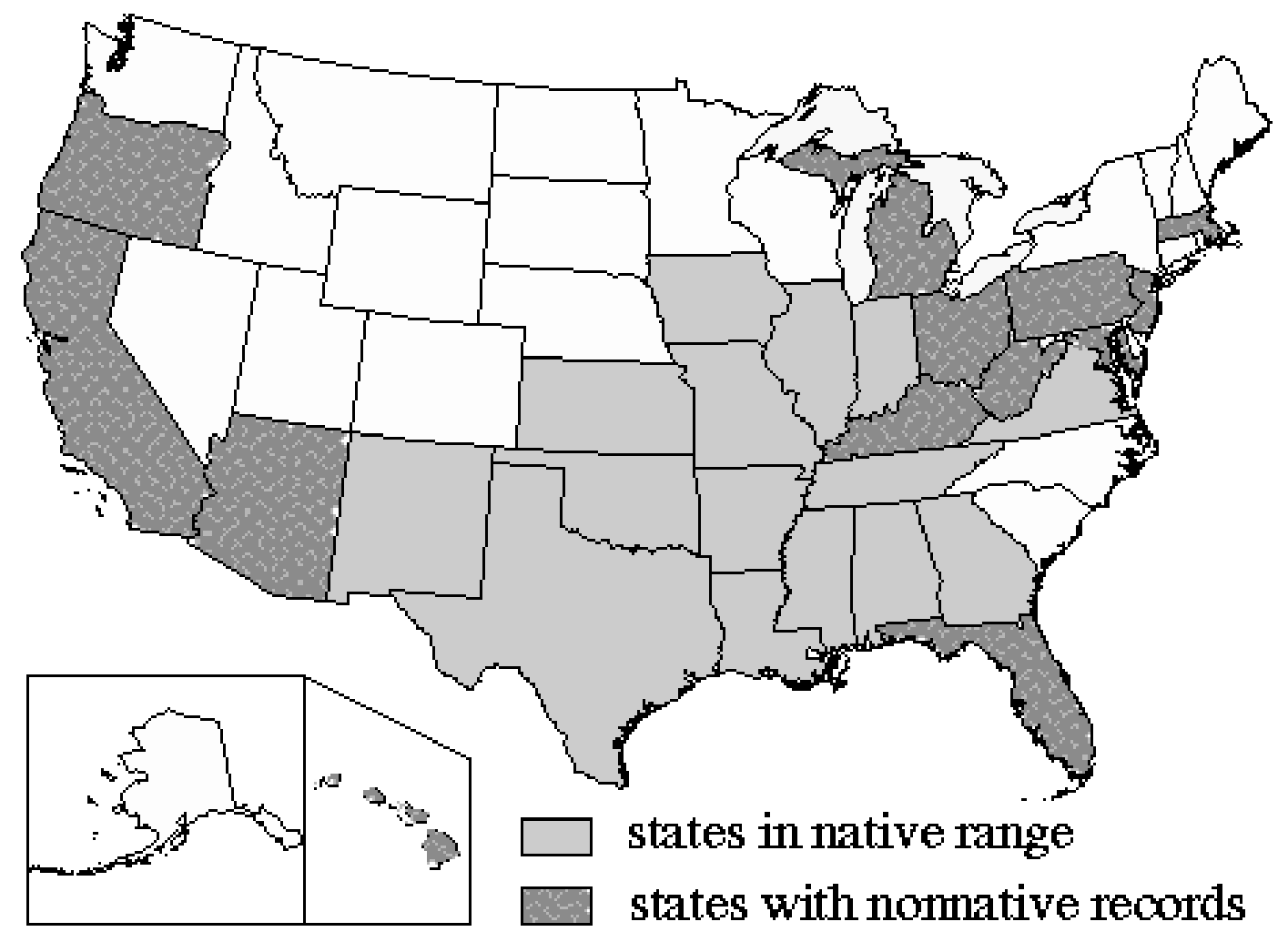

Figure 1.4 North American distribution of the anoxia tolerant turtle Trachemys scripta elegans. Distribution map supplied from the United States Geological Survey. (http://mbreiding.us/ert/Arizona/Sweetwater/photo011.html) 


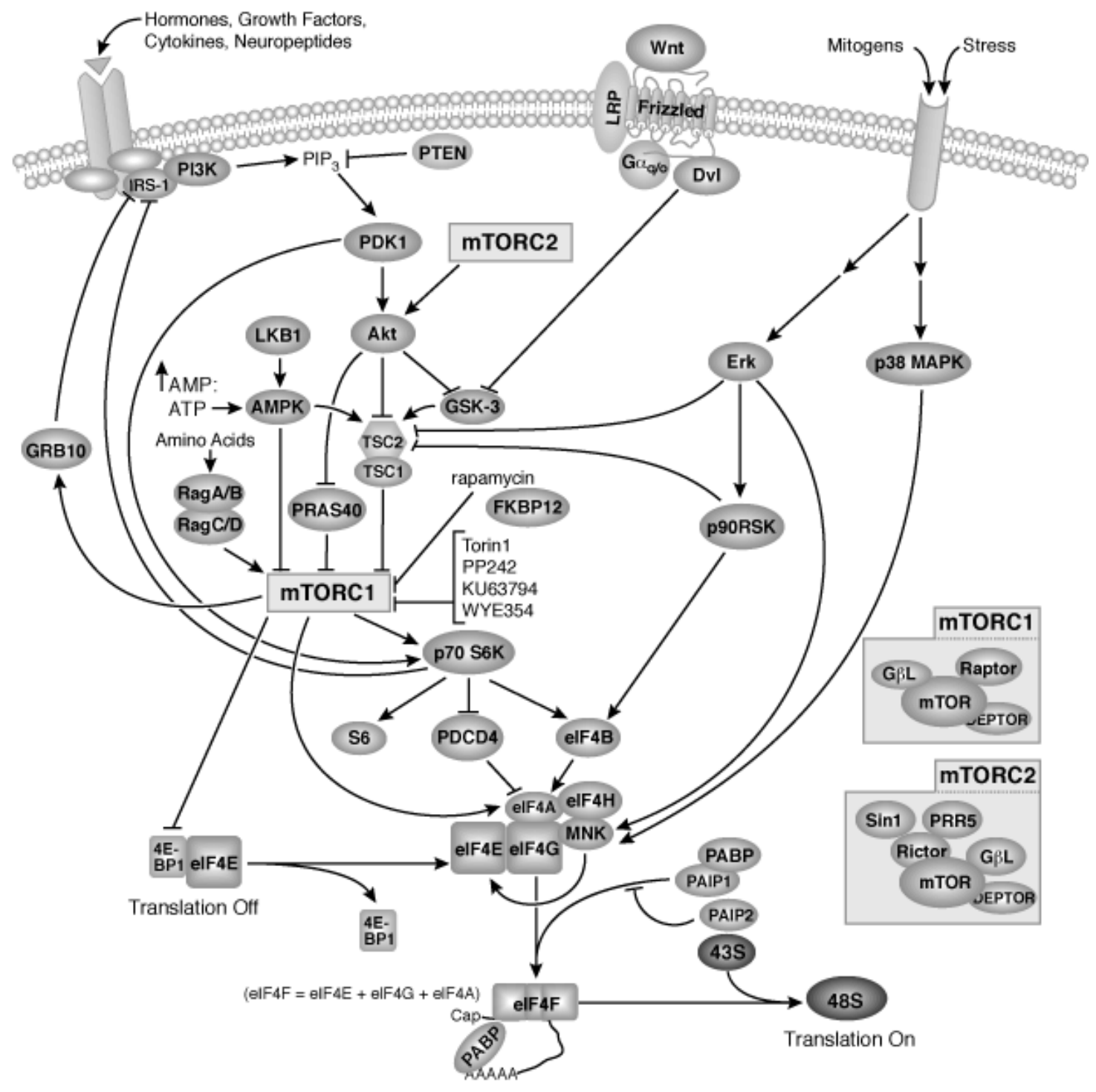

Figure 1.5 The mTOR signaling pathway. Akt activates mTORC1 by phosphorylating TSC2 to relieve its inhibitory effects on mTORC1. In addition, Akt-mediated phosphorylation of PRAS40 inhibits activation of $\mathrm{mTORC} 1$ which subsequently prevents the activation downstream substrates p70 S6K and 4E-BP1. The inability of mTOR to phosphorylate downstream substrates prevents the formation of the active translational complex (Hay and Sonenberg, 2004). Figure obtained from Cell Signaling (2014), www.cellsignal.com). 


\section{CHAPTER 2}

\section{MATERIALS AND METHODS}




\section{Materials and Methods}

\subsection{Animal care and experiments}

Adult red-eared slider turtles (Trachemys scripta elegans), weighing 700-1500g, were purchased from local suppliers and experiments were conducted as in Zhang et al. (2013). The turtles had been previously kept at $5 \pm 1{ }^{\circ} \mathrm{C}$ in large holding tanks filled with dechlorinated tap water for at least one week before use. Control turtles were taken from this condition. For anoxia exposure, the turtles were transferred to large buckets at $5 \pm 1^{\circ} \mathrm{C}$ that had been previously bubbled with nitrogen gas for 1 hour; 2-3 turtles were added per bucket in 30 minute intervals. Bubbling was continued for 1 hour after the last turtle was added and was reinitiated again during sampling of the animals. A wire mesh was fitted into the tank about $5 \mathrm{~cm}$ below the water surface so that the turtles remained submerged throughout the 5 and 20 hour experimental anoxia exposure. All animals were killed by decapitation and then tissues were rapidly dissected, frozen in liquid nitrogen and stored at $-80^{\circ} \mathrm{C}$ until use. All animals were cared for in accordance with the guidelines of the Canadian Council on Animal Care and experimental procedures had the prior approval of the Carleton University Animal Care Committee.

\subsection{Total protein isolation}

Total protein was extracted from turtle liver and white skeletal muscle samples from control, 5 hour and 20 hour anoxia treated turtles. Frozen tissues (approx. 0.5 g) were crushed under liquid nitrogen and homogenized in $1 \mathrm{~mL}$ of buffer $(20 \mathrm{mM}$ Hepes $\mathrm{pH} 7.5$, $200 \mathrm{mM} \mathrm{NaCl}, 0.1 \mathrm{mM}$ EDTA, $10 \mathrm{mM}$ NaF, $1 \mathrm{mM} \mathrm{Na} \mathrm{VO}_{4}, 10 \mathrm{mM} \quad \beta-$ glycerophosphate) with a few crystals of phenylmethysulfonyl fluoride (PMSF) and $1 \mu \mathrm{L}$ 
of protease inhibitor cocktail (104 mM AEBSF, $80 \mu \mathrm{M}$ aprotinin, $4 \mathrm{mM}$ bestatin, $1.4 \mathrm{mM}$ E-64, $2 \mathrm{mM}$ leupeptin, $1.5 \mathrm{mM}$ pepstatin A) (Sigma-Aldrich, Oakville, ON) added immediately before use. After homogenization the samples were centrifuged at 10,000 x $g$ for 15 minutes at $4^{\circ} \mathrm{C}$ and the supernatant was collected. Soluble protein concentration was determined using the BioRad Protein Assay (Cat\# 500-0006) using Bovine Serum Albumin as the standard. Sample concentrations were then adjusted to $10 \mu \mathrm{L} / \mu \mathrm{g}$ by addition of small volumes of homogenization buffer. Samples were then mixed 1:1 v:v with SDS loading buffer (100 mM Tris Base, 4\% w/v SDS, $20 \% \mathrm{v} / \mathrm{v}$ glycerol, $0.2 \% \mathrm{w} / \mathrm{v}$ bromophenol blue, $10 \% \mathrm{v} / \mathrm{v} 2$-mercapthoethanol) for a final protein concentration of 5 $\mu \mathrm{L} / \mu \mathrm{g}$. Samples were boiled for 5 minutes to denature the proteins and stored at $-40^{\circ} \mathrm{C}$ until use.

\subsection{Immunoblotting}

Aliquots of control and anoxic samples containing 20-30 $\mu \mathrm{g}$ of protein were loaded onto $10 \%$ polyacrylamide gels along with pre-stained molecular weight standards (Gene Direx PiNK Plus Prestained Protein Ladder PM005-0500) and separated on a discontinuous buffer system (Laemmli, 1970). Electrophoresis was carried out in a BioRad miniProtean III apparatus at $180 \mathrm{~V}$ for 45 minutes at room temperature (RT) with $1 \mathrm{X}$ Trisglycine running buffer (Tris base, Glycine, SDS, $\mathrm{ddH}_{2} \mathrm{O}$ ). Proteins were electroblotted onto polyvinyl difluoride (PVDF) membranes (Millipore; Cat\# IPVH00010) in a BioRad mini Trans-Blot cell at $160 \mathrm{~mA}$ constant amperage for 90 minutes at $4^{\circ} \mathrm{C}$. Membranes were then washed in 1X Tris-Buffered-Saline with Tween-20 (TBST) $(10 \mathrm{mM}$ Tris $\mathrm{pH}$ 7.5, $150 \mathrm{mM} \mathrm{NaCl}, 0.05 \% \mathrm{v} / \mathrm{v}$ Tween-20) three times for 5 minutes each. Membranes 
were then blocked in TBST and 5\% milk for 30 minutes. After blocking, membranes were washed again and then probed overnight at $4^{\circ} \mathrm{C}$ in antigen-specific antibody on a rocking platform (see Appendix A1). All membrane washes, after both primary and secondary antibody probing (see Appendix A2) consisted of three washes for 5 minutes each in TBST at RT. Subsequently, blots were developed using enhanced homemade chemiluminescent reagents: Luminol reagent [250 mM Luminol (Sigma), $90 \mathrm{mM}$ pCoumaric acid (Sigma), dimethylsulfoxide (DMSO), 1.5M Tris buffer pH 8.8 (BioShop), in $\mathrm{ddH}_{2} \mathrm{O}$ ] and Hydrogen Peroxide reagent [30\% Hydrogen Peroxide (BioShop), 1.5M Tris buffer $\mathrm{pH} 8.8$, in $\left.\mathrm{ddH}_{2} \mathrm{O}\right]$.

Bands were visualized using a ChemiGenius bio-imaging system and band densities were quantified using the associated GeneTools software (Syngene, Frederick, MD). After imaging of immune-reactive bands, blots were restained with Coomassie blue to visualize all protein bands as per Zhang et al. (2013). The protein molecular weight of the immunoreactive band was confirmed as being the expected size by running separate lanes, one containing $5 \mu \mathrm{L}$ of protein ladder and another mammalian sample (control liver from thirteen-lined ground squirrel) as a positive control. Immunoblots of the proteins of interest were individually adjusted for loading irregularities by standardizing the band intensity of immune-reactive material in each lane against the combined density of a group of Coomassie-stained protein bands in the same lane according to the procedure performed in Eaton et al (2013) (that remained constant over all lanes of the gel and was well separated from the immunoblot band of interest). 


\subsection{Statistics}

Detection of bands on gels and blots used a ChemiGenius Bio-Imager (Syngene, Frederick, MD) and densitometric analysis was performed with the associated Gene Tools software. Immunoblot band intensity in each lane was normalized against a group of Coomassie blue stained bands in the same lane to correct any minor variations in sample loading; the Coomassie stained band chosen showed constant intensity across all samples and was well-separated from the area of the gel containing the immunoreactive protein. Mean normalized band densities \pm SEM were calculated for control and anoxic samples; all data are derived from $n=4$ independent tissue extracts from different animals. Significance testing used a one-way analysis of variance followed by a post-hoc Tukey test to identify significant differences among the three groups (control, 5 anoxic, $20 \mathrm{~h}$ anoxic). Statistical difference was accepted if $P<0.05$. Significant differences between control and experimental ( $5 \mathrm{~h}$ or $20 \mathrm{~h}$ ) values are denoted with an ' $\mathrm{a}$ ' above the appropriate experimental bar. Significant differences between the 5 and 20 hour experimental groups are denoted with a ' $b$ ' above the $20 \mathrm{~h}$ bar. 


\section{CHAPTER 3}

\section{UPSTREAM OF mTORC1}




\subsection{Introduction}

Various intracellular and extracellular signals must be relayed to the appropriate targets in order for cellular metabolism, proliferation and/or development to occur. Examples of these are growth signals, hormones, cytokines and amino acid availability. One of the pathways through which nutrient availability is transmitted is via the Target of Rapamycin (TOR) protein kinase. In mammalian tissues, the TOR kinase pathway activates cell growth or apoptosis through the regulation of protein synthesis.

Protein synthesis is one of the most energy-expensive metabolic processes in cells and is therefore a significant target for suppression during hypometabolism (Storey, 1996). For example, under anoxic conditions, protein synthesis may be greatly reduced to less than $10 \%$ of normoxic levels (Storey and Storey, 2004a). One of the main signaling pathways with inputs on mTOR regulated control of protein translation is the PI3K/AKT pathway, typically responding to insulin signaling (Hemmings and Restuccia, 2012). When the appropriate signals are relayed, activation of the PI3K pathway will promote protein translation. Other signaling inputs on the mTOR pathway include the AMPactivated protein kinase (AMPK) that mediates cellular responses to changes in energy status, although it was not the subject of this work.

The mTOR pathway is regulated through two different complexes: mTORC1 and mTORC2, each with distinct functions. The mTORC1 complex plays a major role in the regulation of cell growth and proliferation by promoting anabolic processes such as biosynthesis of proteins, lipids and organelles. In contrast, mTORC2 is not as well defined but has been shown to be involved in cell survival, metabolism and mostly cytoskeletal organization (Laplante and Sabatini, 2009). The regulation of mTORC1 was 
the focus of this thesis due to its ability to control protein translation in response to nutrient availability. Under anoxic conditions both amino acid availability (from food intake) and energy (ATP) supply are often very limited and hence protein synthesis must be closely controlled.

Signaling via mTOR is initiated when upstream signals such as insulin activate receptors which, in turn, initiate a signaling cascade. The cascade is initiated from signal reception at the cell surface where growth factors, hormones, cytokines etc, activate the insulin receptor. This results in the activation of $\mathrm{PI} 3 \mathrm{~K}$ which phosphorylates $\mathrm{PIP}_{2}$ into $\mathrm{PIP}_{3}$. PIP 3 then recruits AKT from the cytosol to the plasma membrane where it binds to $\mathrm{PIP}_{3}$ via the pleckstrin homology domain. $\mathrm{PIP}_{3}$ also enables the co-localization of AKT with its activating kinase, PDK-1, which phosphorylates AKT on a conserved threonine (Thr308). This phosphorylation event leads to a second phosphorylation by mTORC2 (Ser473) which potentiates its kinase activity (Dunn and Connor, 2010). The function of AKT is to inactivate mTOR inhibitors: TSC2 and PRAS40. When growth is suppressed, the TSC1:TSC2 complex forms a GTPase activating protein (GAP) which catalyzes the cleavage of Rheb:GTP into Rheb:GDP (Brugarolas et al., 2004). This conversion results in the loss of GTPase activity and thus inactivates mTORC1.

Conversely, when growth is promoted, AKT inhibits the TSC1:TSC2 complex via phosphorylation at Thr-1462 which destabilizes the complex and allows for mTOR activation (Brugarolas et al., 2004). AKT activation of mTORC1 is also mediated through the phosphorylation of PRAS40 which catalyzes its dissociation from RAPTOR thus relieving inhibition on mTOR (Kim et al., 2003). By forming a complex with 
RAPTOR, PRAS40 inhibits mTOR activation and prevents mTOR from interacting with its downstream targets, p70 S6K and 4E-BP1.

Previous studies have shown that protein synthesis is strongly reduced in anoxiatolerant species (Brooks and Storey, 1994; Hochachka et al., 1996; Storey, 1996; Larade and Storey, 2002) and the current study analyzes the potential mechanisms by which the mTOR pathway is regulated in turtle organs to facilitate anoxia-induced inhibition of translation. To gain a better understanding of the adaptive changes occurring in response to anoxia, the mechanisms regulating protein synthesis were examined in liver and white muscle tissues of Trachemys scripta elegans analyzing the responses to 5 hour of anoxic submergence, which represents the hypoxic transition state, and to 20 hours of anoxia submergence, a time by which anoxia-induced metabolic rate depression is well developed.

This chapter evaluates mTOR as well as several of its upstream regulators in response to anoxia in turtle white skeletal muscle and liver.

\subsection{Results}

\subsubsection{Activation of the mTOR complex}

mTOR is a key player in a kinase cascade that promotes ribosome assembly for protein synthesis in response to various stimuli (FIG 3.1) (Dunlop and Tee, 2009). Figure 3.2 shows representative western blots with immunoreactive bands which reveal consistency of metabolic response by upstream proteins in response to anoxia. Antibodies recognizing $\mathrm{mTOR}$ and $\mathrm{p}-\mathrm{mTOR}^{\mathrm{Ser} 2448}$ (Appendices A1-A2) cross-reacted with a protein 
band of $\sim 289 \mathrm{kDa}$, the expected size of mTOR. The effects of 5 and 20 hours of anoxia exposure on total mTOR protein levels and the relative change in phospho-mTOR content were evaluated in white skeletal muscle and liver tissues of turtles. Total mTOR expression levels did not change significantly in white skeletal muscle after either 5 or 20 hours of anoxia exposure (FIG 3.3A). However, a significant decrease to $0.43 \pm 0.01$ of the control was seen after 20 hours of anoxia in liver (FIG 3.3B). Active p-mTOR ${ }^{\text {Ser2448 }}$ in muscle decreased significantly to $0.59 \pm 0.01$ after 5 hours of hypoxia but rebounded at 20 hours of anoxia, whereas liver mTOR showed a strong increase in phosphorylation by approximately 6 -fold $(5.66 \pm 0.28)$ after 5 hours of hypoxia, that rose to $13 \pm 2.13$ fold over control levels after 20 hours of anoxia.

\subsubsection{Inhibition by PTEN}

The PI3K pathway can be inhibited by causing the dephosphorylation of the second messenger $\mathrm{PIP}_{3}$. PTEN is the phosphatase responsible for this conversion that interrupts the phosphorylation cascade. Antibodies that recognized non-phospho-PTEN detected the peptide only if the phospho-sites (Ser-380/ Thr-382/ Thr-383) were not phosphorylated and conversely phospho-PTEN antibodies recognized the peptide when the sites were phosphorylated. Both antibodies cross-reacted with a protein band of $\sim 54 \mathrm{kDa}$, the expected size of PTEN. The effects of 5 and 20 hours of anoxia exposure on nonphospho-PTEN and phospho-PTEN ${ }^{\text {Ser-380/Thr-382/Thr-383 }}$ can be seen in FIGs 3.4A and 3.4B, for muscle and liver, respectively. No significant change was seen in white muscle in non-phosphorylated PTEN content, whereas a significant decrease was observed after 20 hours of anoxia in phosphorylated PTEN to $0.62 \pm 0.03$ of the control value $(P<0.05)$. 
The relative amount of non-phospho-PTEN increased in liver to $1.89 \pm 0.03$-fold higher than controls after 5 hours of anoxic submergence $(P<0.05)$ but was reduced somewhat by 20 hours and not significantly different from controls. No significant change was observed in liver phospho-PTEN values.

\subsubsection{Phosphorylation of PDK1}

PDK-1 is a kinase responsible for the activation of downstream targets such as AKT. It is activated by the second messenger $\mathrm{PIP}_{3}$ produced by PI3K. PDK-1 showed an immunoreactive band of $\sim 64 \mathrm{kDa}$. No significant changes in the levels of total PDK-1 were seen in white skeletal muscle under anoxia (FIG 3.5A) whereas liver revealed a significant increase of $5.25 \pm 0.24$-fold after 5 hours of anoxia, with a subsequent decrease to $3.34 \pm 0.25$-fold after 20 hours of anoxia, compared to control values $(P<$ 0.05) (FIG 3.5B). A significant decrease was seen in both white skeletal muscle and liver for p-PDK $1^{\text {Ser241 }}$ (Schick et al., 2007). In liver, a decrease in expression was seen only after 20 hours of anoxia to $0.59 \pm 0.05$, as compared to control values $(P<0.05)$ whereas white skeletal muscle showed a decrease after 5 hours of hypoxia $(0.84 \pm 0.01)$ that remained at the same level after 20 hours of anoxia $(0.84 \pm 0.03)$.

\subsubsection{Activation of $A K T$}

The relative phosphorylation of AKT was examined at Ser-473. Antibodies recognizing both total $\mathrm{AKT}$ and $\mathrm{p}-\mathrm{AKT}^{\mathrm{Ser} 473}$ cross-reacted with a protein band of $\sim 60$ $\mathrm{kDa}$, the expected size of AKT. AKT is phosphorylated on two sites, Ser473 and Thr308. Ser473 is phosphorylated by mTORC2 and Thr308 by PDK1 (Wan and Helman, 2003). The effects of 5 and 20 hours of anoxia exposure on AKT and phospho-AKT in white 
skeletal muscle and liver are shown in FIG 3.6A and 3.6B. No significant changes were seen in total AKT expression levels in white skeletal muscle as compared with controls; however, liver showed a strong significant increase in total AKT expression to $5.38 \pm$ 0.18 -fold after 5 hours of anoxic submergence that remained high after 20 hours $(4.74 \pm$ 0.54 -fold over control values) $(P<0.05)$. Levels of $\mathrm{p}-\mathrm{AKT}^{\mathrm{Ser} 473}$ increased in white skeletal muscle and liver after 5 hours of anoxia. White skeletal muscle showed an increase in expression of $1.88 \pm 0.09$-fold after 5 hours of anoxia but this then decreased significantly to just $0.17 \pm 0.02$ compared to controls after 20 hours of anoxia. PhosphoAKT levels also increased in liver by $3.14 \pm 0.08$-fold after 5 hours of anoxia and remained high at $3.66 \pm 0.13$-fold after 20 hours.

\subsubsection{Phosphorylation of TSC2}

Phosphorylation of TSC2 by AKT at multiple sites (Thr-1462, Thr-389, Thr-421 and Ser424) (Inoki et al., 2002) relieves the inhibitory effects of the TSC1-TSC2 complex on mTOR, allowing mTOR to be activated (Huang and Manning, 2009). Antibodies recognizing $\mathrm{p}$-TSC2 ${ }^{\mathrm{Thr} 1462}$ cross-reacted with a protein band of $\sim 200 \mathrm{kDa}$, the expected size of TSC2. Relative levels of p-TSC2 $2^{\mathrm{Thr} 1462}$ in liver and white skeletal muscle tissues are shown in FIG 3.7. Neither tissue revealed a change in phospho-protein levels after 5 $\mathrm{h}$ of hypoxia. However, in white skeletal muscle, phospho-TSC2 ${ }^{\mathrm{Thr} 1462}$ content decreased to $0.50 \pm 0.04$ after 20 hours of anoxia as compared with controls. Liver tissues showed no significant change after 20 hours of anoxia. 


\subsubsection{Release from inhibition of PRAS40}

In order to assess the state of the mTOR complex, two components of the complex were examined PRAS40 and G $\beta$ L. PRAS40 inhibits the mTOR complex when not phosphorylated. When PRAS40 is phosphorylated at Thr-246 by AKT this relieves inhibition of mTOR (Wang et al., 2007). Antibodies recognizing the phosphorylated form

of the protein, p-PRAS40 ${ }^{\text {Thr246 }}$ (Haar et al., 2007) cross-reacted with a protein band of $\sim 40 \mathrm{kDa}$, the expected size of PRAS40. The effects of 5 and 20 hours of anoxia exposure on p-PRAS40 in white skeletal muscle and liver were evaluated and can be seen in FIG 3.8. No significant change was seen in the phosphorylation state of PRAS40 in the liver, whereas a significant decrease in p-PRAS40 was detected in white muscle after 5 hours of anoxia where levels dropped to $0.61 \pm 0.08$. However, relative phosphorylation of PRAS40 in muscle rose again to control values after 20 hours of anoxia $(1.09 \pm 0.04)(P<$ $0.05)$.

\subsubsection{Activation of the mTOR complex by RAPTOR}

A kinase complex forms between mTOR and RAPTOR with RAPTOR acting as a scaffold to bind and present substrates to mTOR (Wang et al., 2007). RAPTOR may also be phosphorylated by AMPK on Ser-722/792 in order to inhibit the Raptor-containing mTOR complex 1 (mTORC1) (Gwinn et al., 2008). An immunoreactive band for RAPTOR was produced at $\sim 150 \mathrm{kDa}$, the expected size of RAPTOR. Contrasting results were seen in white skeletal muscle and liver for relative RAPTOR levels (FIG 3.9). In skeletal muscle, no significant change in total RAPTOR expression was observed after 5 hours of anoxia, however after 20 hours, a significant decrease in RAPTOR content was 
observed, with relative levels falling to $0.49 \pm 0.09$, as compared with controls. In liver, a significant decrease in RAPTOR occurred after 5 hours of anoxia, levels falling to $0.43 \pm$ 0.07, compared with controls but levels returned to control values after 20 hours of anoxia. The 20 hour value was significantly different from the 5 hour time point $(P<$ 0.05 ) but not from control values.

\subsubsection{Activation by $G \beta L$}

Along with mTOR, PRAS40 and RAPTOR, G $\beta$ L is another member of the mTORC1 complex which stabilizes the interaction between RAPTOR and mTOR (Wang et al., 2007; Kim et al., 2003). Antibodies recognizing G $\beta$ L produced an immunoreactive band of $\sim 37 \mathrm{kDa}$, the expected size of G $\beta \mathrm{L}$. Opposing responses to anoxia were also seen in white skeletal muscle and liver for protein G $\beta$ L. In white skeletal muscle, a significant increase of $1.54 \pm 0.08$-fold occurred after 5 hours of anoxia that then decreased again after 20 hours of anoxia to $0.66 \pm 0.05$-fold as compared with controls ( $P$ $<0.05$ ) (FIG 3.10). In contrast, liver showed a very strong significant decrease in G $\beta L$ expression after 5 hours of anoxia to $20 \%$ of aerobic control levels $(0.19 \pm 0.03)(P<$ $0.05)$ and remained low after 20 hours of anoxia $(0.34 \pm 0.05)$.

\subsection{Discussion}

The regulation of protein synthesis is of particular interest to the study of anoxia tolerance because translation can account for a high percentage of total energy expenditure in the anoxia tolerant turtle; for example, in aerobic liver cells of turtles, 
protein synthesis consumed 36\% of total ATP turnover (Hochachka et al. 1996; Buck et al., 1993). To better understand the regulation of protein synthesis, the present study investigated the mTORC1 signaling pathway and its implications for metabolic rate suppression. The mTOR pathway regulates mammalian 5' cap-dependent protein synthesis via controls over downstream targets eIF4E and 4E-BP1 which are involved in translation initiation, the eIF4E initiation factor being responsible for bringing the mRNA into the assembling ribosome. Within this study, an emphasis was placed on the comparison between regulatory mechanisms between white skeletal muscle and liver tissues.

Selected actions of the insulin signaling pathway are directly mediated by activation of mTORC1, a central protein kinase which acts as an ATP and amino acid sensor in order to balance nutrient availability and cell biosynthesis for export (Laplante and Sabatini, 2009). In response to the appropriate growth/nutrient signals, mTOR signals downstream effectors to activate protein synthesis.

In response to anoxic submergence, neither total mTOR protein nor its active phosphorylated form, $\mathrm{mTOR}^{\mathrm{Ser} 248}$ showed significant changes in skeletal muscle, however interestingly, a significant activation of mTOR was seen in liver. Although total mTOR decreased by about $60 \%$ after 20 hours of anoxia, the relative phosphorylation of the remaining mTOR increased very strongly, suggesting activation of protein synthesis. Under conditions of biosynthesis or growth promotion, the activation of the positive regulator G $\beta \mathrm{L}$ and inhibition of the inhibitors TSC2 and PRAS40 would lead to a net activation of protein synthesis. Under anoxic conditions, we would expect the opposite to 
be true. Interestingly, the results of this study showed contrasting results between the two tissues.

The pathway begins with signaling at the cell membrane which upon formation of $\mathrm{PIP}_{3}$, results in activation of the signaling cascade. Upon sensing an oxygen lack, the pathway will be immediately suppressed upstream of all PI3K pathway proteins. PTEN is a protein phosphatase that acts as a negative regulator this cascade and, ultimately, of mTOR. PTEN functions as a major 'on' / 'off' switch controlling the effects of many cellular pathways including carbohydrate metabolism, protein synthesis, transcription, cell proliferation and others (Chagpar et al., 2010). Active (non-phosphorylated) PTEN functions to inhibit the PI3K/AKT pathway by dephosphorylating $\mathrm{PIP}_{3}$ into $\mathrm{PIP}_{2}$, and thus prevents the activation of PDK-1. In this study, the relative amount of active PTEN showed no significant change in white muscle after 5 hours of anoxia however an increase was observed in liver (FIG 3.4). However, inactive phosphorylated PTEN decreased significantly after 20 hours of anoxia in muscle which suggests suppression of protein translation. Overall, inhibition of the mTOR pathway by PTEN was suggested, probably as a result of reduced insulin signaling under anoxia. Previous studies showed a similar effect in ground squirrels where PTEN was strongly reduced during torpor and therefore inhibited insulin signaling (Wu and Storey, 2012; Wu, 2014).

Consequently, a decrease in the phosphorylation state of PDK-1 might be attributed to changes in PTEN activity. A lack of significant change in nonphosphorylated PTEN as seen in the muscle is indicative of a maintenance of PTEN activity and therefore of continuing breakdown of $\mathrm{PIP}_{3}$. Therefore, this continuing inhibitory input on the insulin signaling pathway may combine with the specific 
suppression of various other loci in the mTOR pathway to provide a net reduction in protein synthesis in muscle under anoxia. In contrast, in the liver, non-phosphorylated PTEN increases after 5 hours of anoxia which suggests increased inhibition upstream of the mTOR pathway by increasing PTEN activity and thereby dephosphorylating $\mathrm{PIP}_{3}$ into $\mathrm{PIP}_{2}$. By decreasing the levels of PIP 3 , PDK-1 activation would be reduced and thereby suppress active PDK-1 as seen in the muscle and liver (FIG 3.5).

PDK-1, an upstream regulator of the mTOR signaling pathway, is a kinase responsible for the activation of a central mTOR pathway regulator, the AKT protein kinase. FIG 3.5A shows that the amount of active phosphorylated-PDK-1 ${ }^{\text {Ser241 }}$ was reduced in white muscle and liver tissues after 5 hours and 20 hours of anoxia, respectively. However, a strong significant increase in total PDK1 was found in liver but not in white muscle in response to anoxia (FIG 3.5B). The suppression of active PDK-1 would therefore suggest a reduction of AKT activity during anoxia. Interestingly, this was confirmed in muscle, but not liver.

An initial increase in phosphorylated active AKT was in fact observed in white muscle after 5 hours of anoxia (FIG 3.6A) however, levels decreased below control values after 20 hours of anoxia. In liver, strong increases in both total AKT protein phosphorylated $\mathrm{AKT}^{\mathrm{Ser} 473}$ content were detected in liver after 5 hours and remained high after 20 hours of anoxia (FIG 3.6). This increase in phospho-AKT is consistent with the results for mTOR since mTOR phosphorylates AKT at Ser-473 and our results revealed an increase in active phosphorylated mTOR. As no significant change was observed in white muscle p-mTOR, this could support the data showing a decrease in phosphorylated AKT in muscle as well. 
Studies have shown that phosphorylation of AKT at Thr308 will result in the development of certain cancers whereas activation at Ser473 does not (Fayard et al., 2005). Furthermore, other factors such as AMPK also activate AKT on Ser473 and therefore it can be speculated that a lack of activation of protein synthesis in muscle tissue could be due to lack of phosphorylation of AKT by AMPK. During anoxia, ATP levels drop and AMP rise, this leads to an activation of AMPK, a major energy sensor of the cell. Under hypoxic conditions, AMPK will shut down energy expensive cell processes which include protein synthesis (Leclerc et al., 2010). Therefore, the results seen here may be partially due to AMPK. Overall, an increase in active phosphorylated AKT as seen in liver could possibly be attributed to a need to increase the synthesis of select proteins required for maintenance of long-term survival under anoxic conditions.

The phosphorylation state of TSC2 decreased in muscle by $50 \%$ after prolonged (20 h) anoxic submergence but no significant change occurred in liver (FIG 3.7). TSC2 inhibits the mTOR complex in two ways; mTORC1 is inhibited by non-phosphorylated TSC2 by preventing the conversion of Rheb:GTP to Rheb:GDP and also by preventing mTORC1 activation by phosphorylation at Ser2448 by AKT (Rosner et al., 2009). Therefore, the reduced level of phospho-TSC2 after $20 \mathrm{~h}$ anoxia suggests that increased inhibition of the mTORC1 complex could occur in white muscle with prolonged anoxia by preventing the phosphorylation of mTORC1. Indeed, levels of phosphorylated mTOR did not increase in muscle tissues under anoxia (FIG 3.7). In liver, however, the situation was different. A strong increase in the relative phosphorylation of mTOR was observed under anoxia, although total mTOR decreased by one-half after $20 \mathrm{~h}$. Hence, there is evidence of an initial activation of mTOR in liver which could indicate a need for some 
continued (or enhanced) level of protein synthesis in the liver over the early hours of anoxic submergence. However, the lack of change in phospho-TSC2 ${ }^{\text {Thr1462 }}$ levels in liver suggests that this regulator was not involved in mTOR control in anoxic liver.

Next, the phosphorylation state of PRAS40 along with expression of G $\beta L$ are two components of the mTOR complex responsible for its activation (Wang et al., 2007) and their modifications under anoxia will also influence the state of mTOR and of protein synthesis. Relative phosphorylation levels of p-PRAS $40^{\text {Thr2 } 246}$ showed no significant change in liver but decreased by $40 \%$ in muscle after 5 h of hypoxia (FIG 3.8). Studies have shown that AKT mediated phosphorylation of PRAS40 induces its binding with 143-3, a chaperone protein, thus sequestering PRAS40 and preventing it from inhibiting mTOR (Wang et al., 2007; Wang et al., 2008). The observed decrease in phosphoPRAS40 ${ }^{\text {Thr246 }}$ in muscle suggests an increase in the inhibitory effects of PRAS40 on mTOR that would contribute to preventing mTOR from accessing its downstream targets under anoxia.

Next, another component of the mTOR complex was assessed. RAPTOR is the mTORC1 binding partner responsible for the recruitment of downstream substrates (4EBP1 and P70S6K1) to the mTORC1 complex. RAPTOR can be sequestered by PRAS40 thus inhibiting the interaction of mTOR with its downstream targets. When PRAS40 is phosphorylated by AKT, PRAS40 releases RAPTOR to allow the restoration of the full mTORC1 complex. In white skeletal muscle, RAPTOR protein levels decreased by about one-half after $20 \mathrm{~h}$ of anoxia which would be consistent with reduced functioning of the mTORC1 complex. Incidentally, phospho-PRAS40 levels also decreased after 5 hours of anoxia despite a strong increase in the amount of active phosphorylated AKT, which 
would be predicted to elevate PRAS40 phosphorylation. However, levels of phosphoPRAS40 did return to control values after 20 hours of anoxia.

RAPTOR behaved differently in liver with an initial strong suppression seen after 5 hours of anoxia (FIG 3.4B) which suggests an initial suppression of mTOR activity. However, levels returned to control values after 20 hours of anoxia. Phospho-PRAS40 levels remained unchanged throughout the anoxic duration which contrasts with the strong increases in both total AKT and active phosphorylated AKT under anoxia. Hence, both tissues seem to show a disconnect between AKT signaling and PRAS40 response in anoxic turtles. This may suggest that activation of AKT seen in both turtle liver and muscle under anoxia has little influence on protein synthesis under these conditions.

The expression of G $\beta$ L (FIG 3.10) showed a significant decrease by $\sim 80 \%$ after 5 hours of anoxia in liver but not in white muscle. Instead, white skeletal muscle revealed an almost 1.5-fold increase during hypoxia and then a subsequent decrease back to control levels after 20 hours of anoxia. G $\beta \mathrm{L}$ is a subunit of the mTORC1 complex which acts as a positive regulator of the signaling pathway to promote mTORC1 activation (Haar et al., 2007). The down-regulation in liver would help to abort mTORC1 activity in liver during hypoxia and anoxia. However, these findings are in opposition to those obtained for anoxia-tolerant crayfish and hibernating 13-lined ground squirrels (Lant, 2011; Wu and Storey, 2012) in which activation in phospho-PRAS40 and G $\beta$ L were indicated and suggested an activation of $\mathrm{mTORC} 1$ and stimulation of proteins critical to survival under anoxic conditions and torpor, respectively. Therefore, an unexpected decrease in translational activity can be seen in the liver due to lack of increase in $G \beta L$ expression levels. 
Overall, the data in this chapter were consistent with a down-regulation of mTOR in white skeletal muscle but activation in liver in response to anoxic submergence. The red-eared slider turtle is largely inactive under anoxic conditions. Therefore, it might be expected that there could be disuse of the white muscle during extended periods of anoxia accompanied by suppressed protein synthesis. In contrast, the liver is the main source of glycogenolysis and would therefore have to remain active in order to supply turtle tissues with enough glucose to maintain all basal metabolic processes. This model is in fact supported by examining other organisms undergoing metabolic rate depression. In African clawed frog (Xenopus laevis), muscle tissue such as the cardiac muscle showed an overall suppression of AKT expression whereas liver tissues demonstrated some maintenance of activity during estivation (Luu, 2011). This study noted similar results where liver AKT expression, among others, was maintained during anoxia-induced hypometabolism whereas muscle tissues revealed significant decreases in expression.

In summary, the present study elucidates important mechanisms for the regulation of expression of upstream mTOR targets contributing to maintenance of a hypometabolic state in liver and white skeletal muscle tissues. Modulation of the components of the insulin-signaling pathway play a role in the regulation of translational suppression thus allowing for the reprioritization of energy-dependent metabolic processes allowing the red-eared slider to endure long-term anoxia. These results reflect their physiological states during anoxia where disuse results in the suppression of cellular proliferation, versus maintenance of basal levels of translation in the liver in order to endure long-term hypometabolism. In conclusion, this study provides new insights into the mechanism of 
upstream mTOR regulation in the red-eared slider turtle during long term anoxiatolerance. 


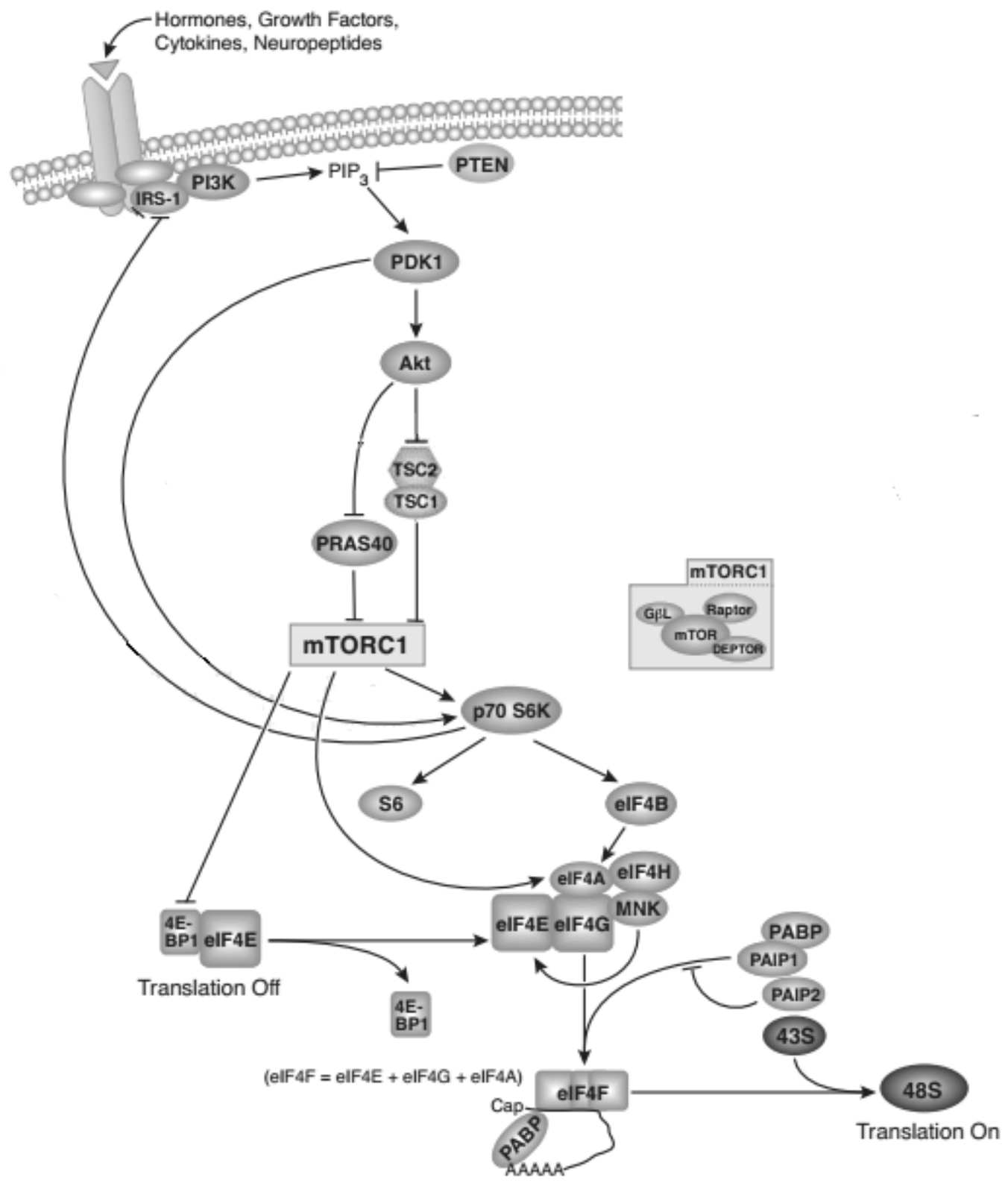

Figure 3.1 - mTOR pathway - adapted from cellsignal.com 
(A)

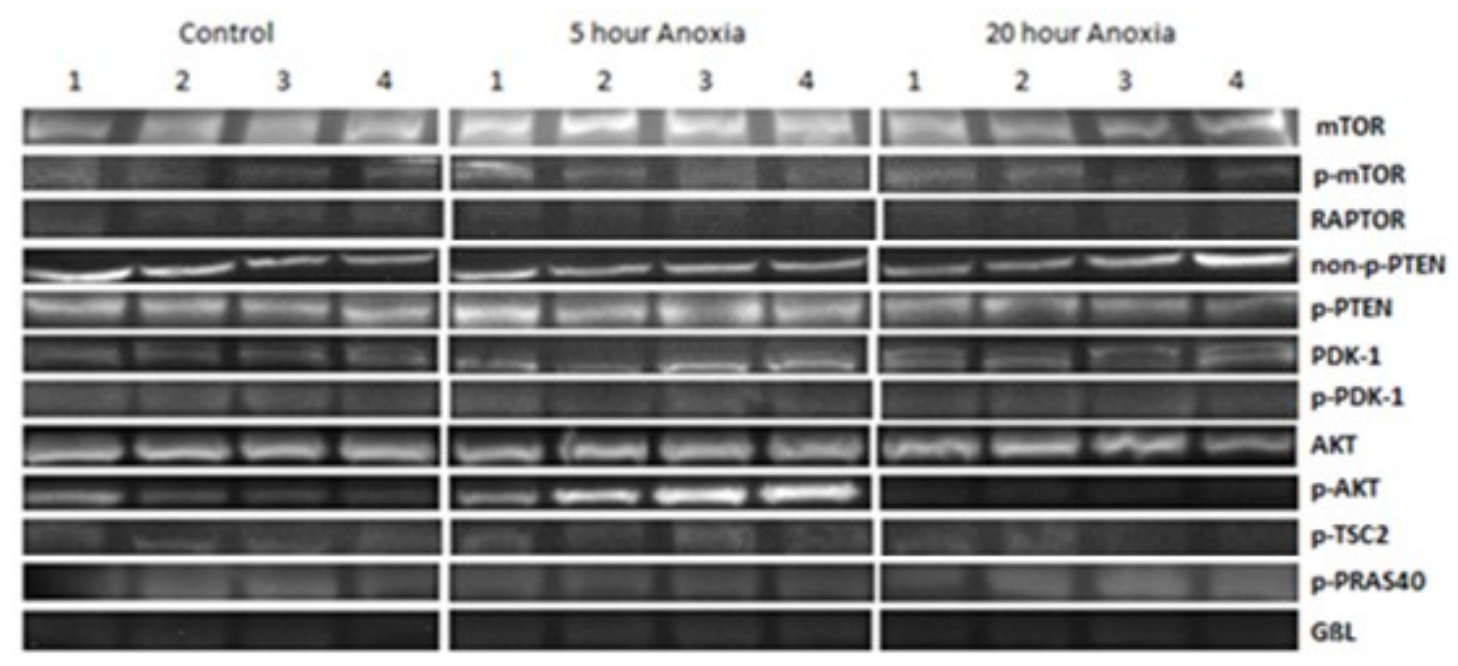

(B)

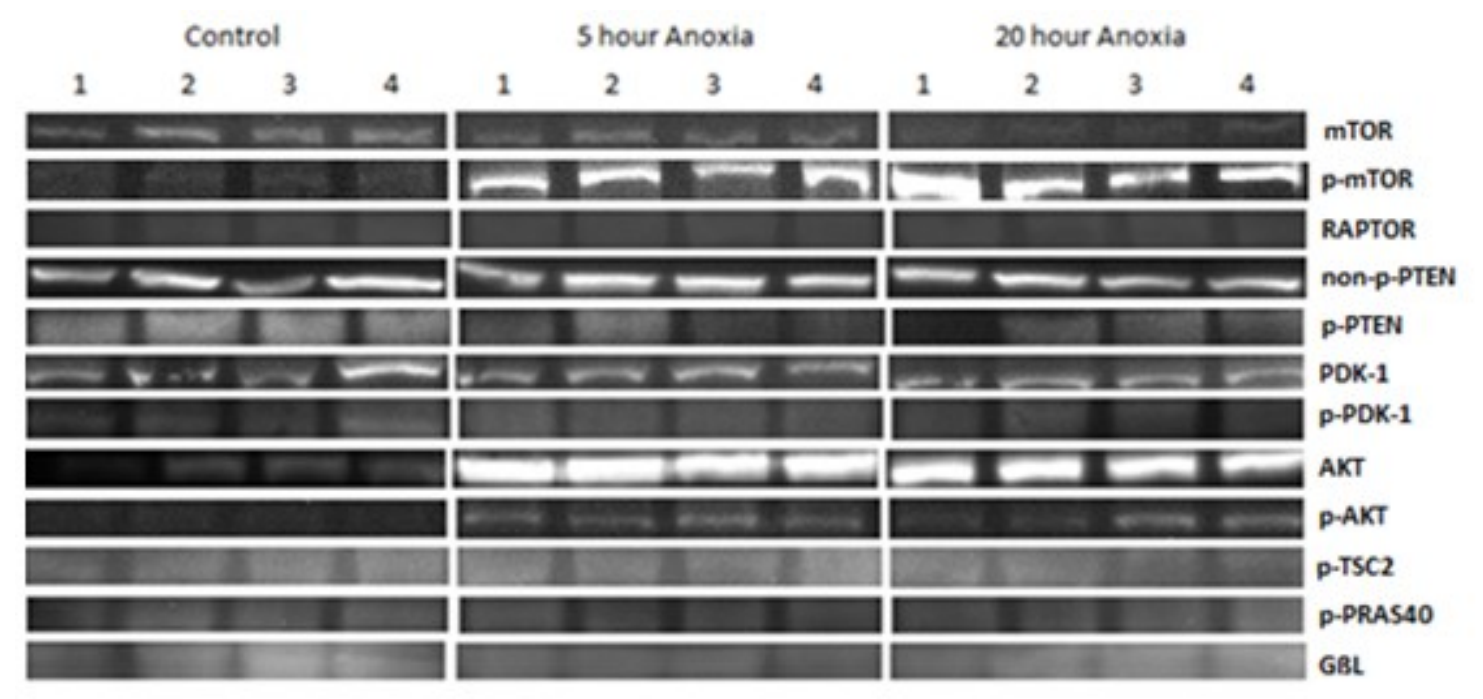

Figure 3.2. Immunoblots of upstream mTOR signaling pathway proteins from (A) white skeletal muscle and (B) liver tissues 
(A)

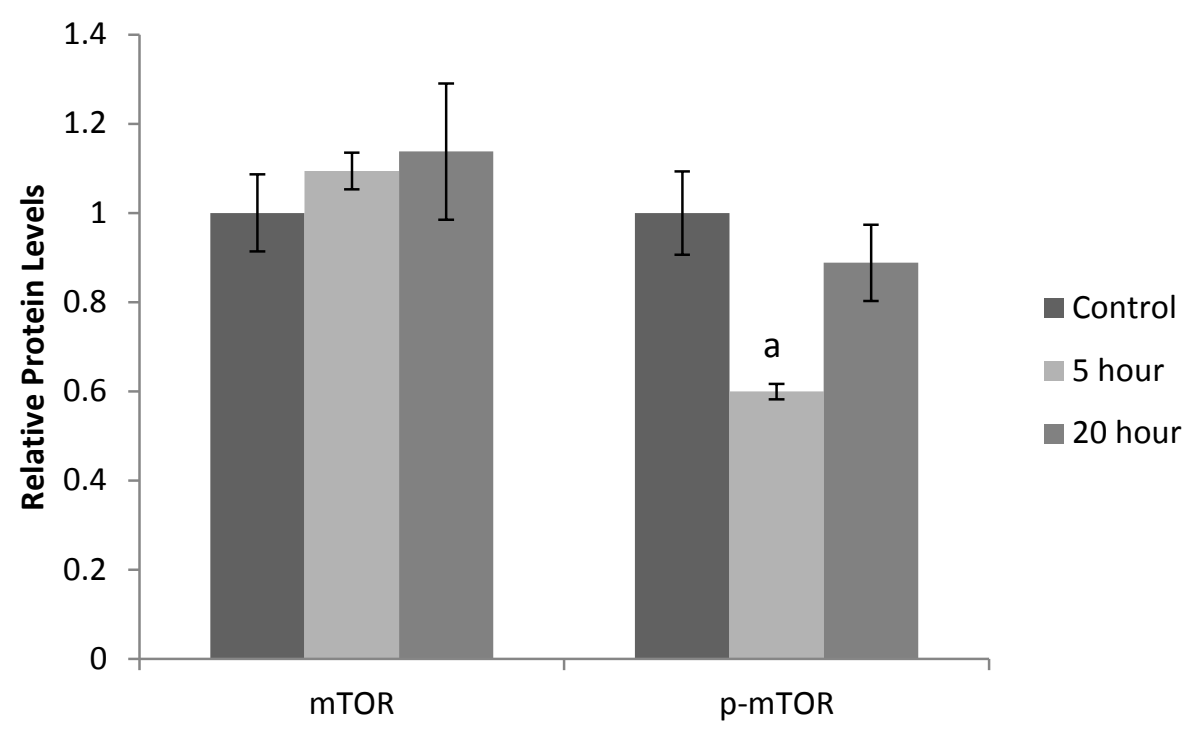

(B)
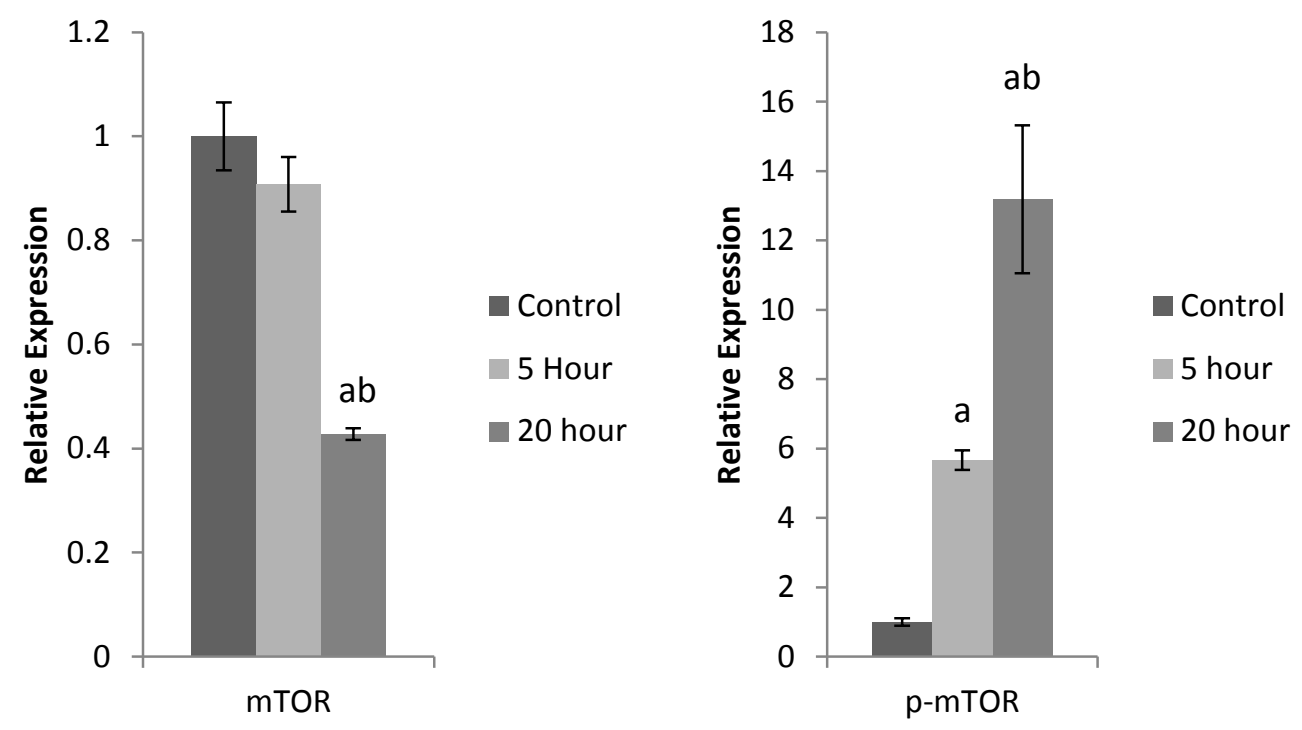

Figure 3.3. Regulation pattern of mTOR in white skeletal muscle and liver of Trachemys scripta elegans determined by Western Immunoblotting.

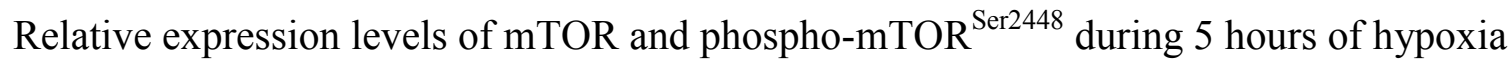
and 20 hours of anoxia in white muscle (A) and liver (B) of the red-eared slider turtle. Representative bands were detected at $\sim 289 \mathrm{kDa}$. a- significantly different from corresponding control value, b- significantly different from corresponding 5 hour value. $(P<0.05$, ANOVA, Tukey post hoc test $)$. 
(A)

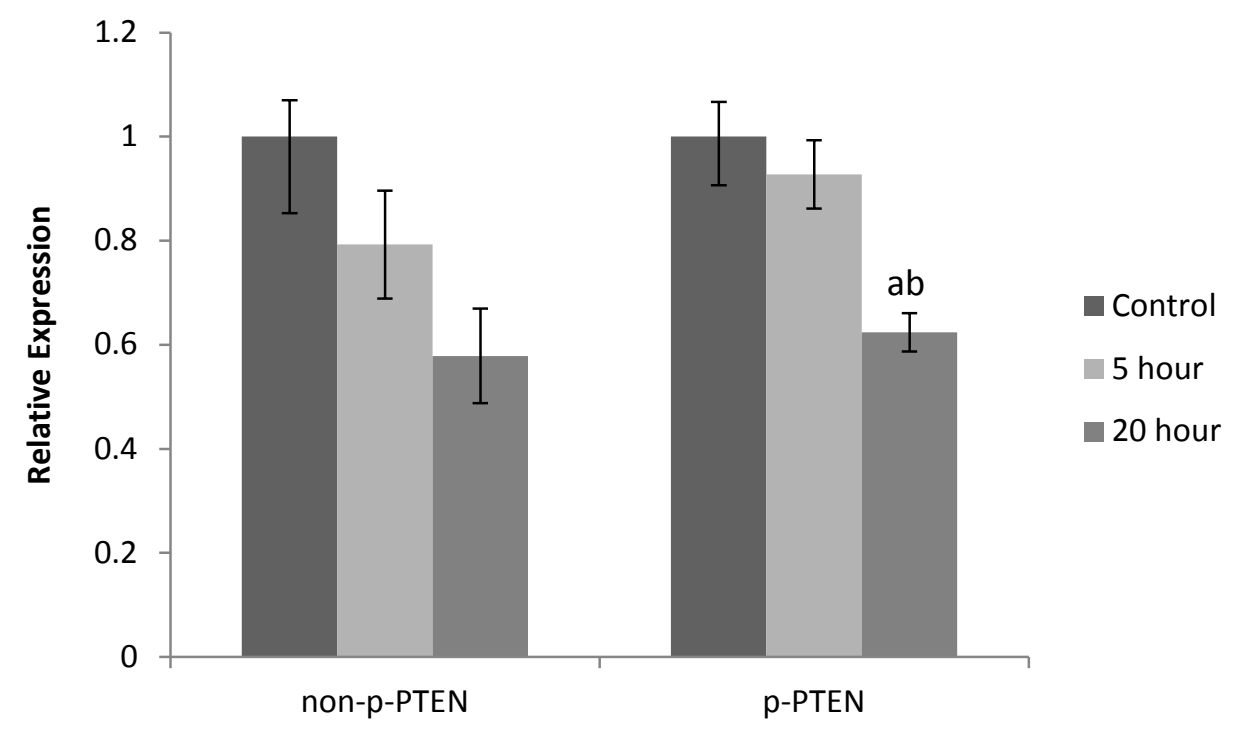

(B)

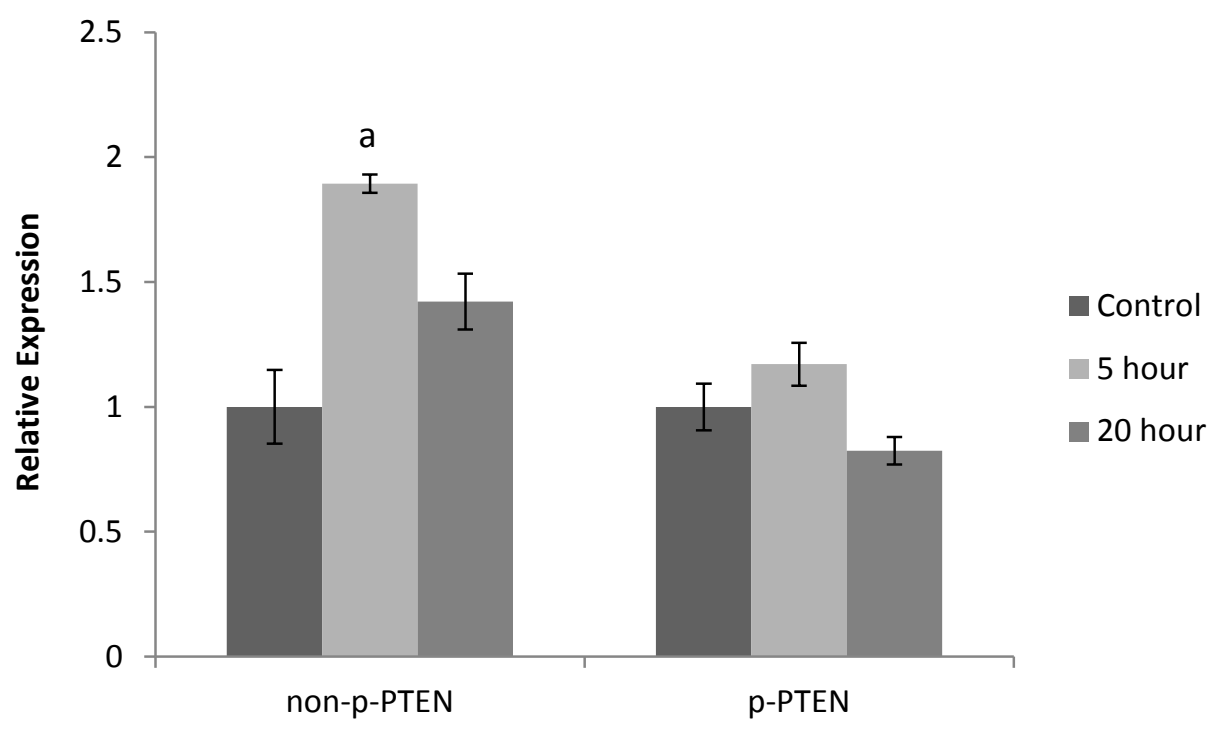

Figure 3.4 Regulation pattern of PTEN in white skeletal muscle and liver tissues of Trachemys scripta elegans determined by Western Immunoblotting.

Relative expression levels of non-phospho-PTEN and phospho-PTEN ${ }^{\text {Ser380/Thr382/thr383 }}$ during 5 hours of hypoxia and 20 hours of anoxia in white muscle (A) and liver (B) of the red-eared slider turtle. Representative bands were detected at $\sim 54 \mathrm{kDa}$. a- significantly different from corresponding control values, $\mathrm{b}$ - significantly different from corresponding 5 hour values. $(P<0.05$, ANOVA, Tukey post hoc test). 
(A)

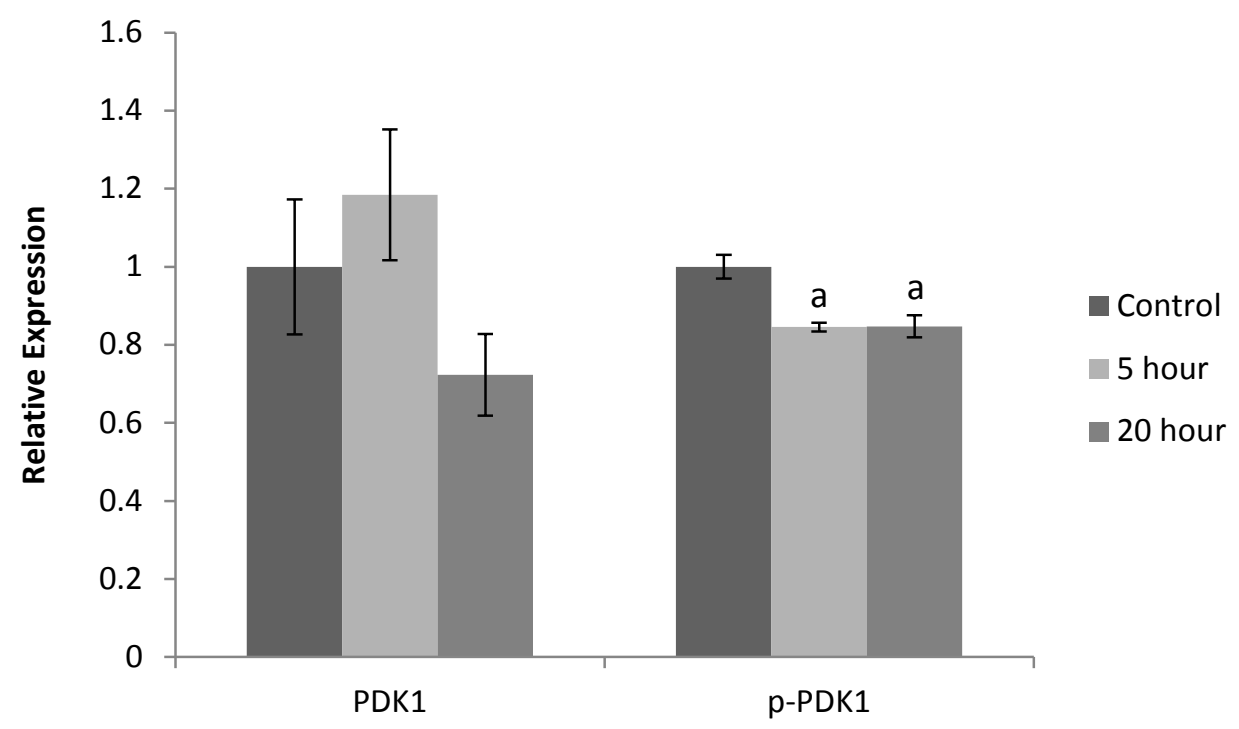

(B)

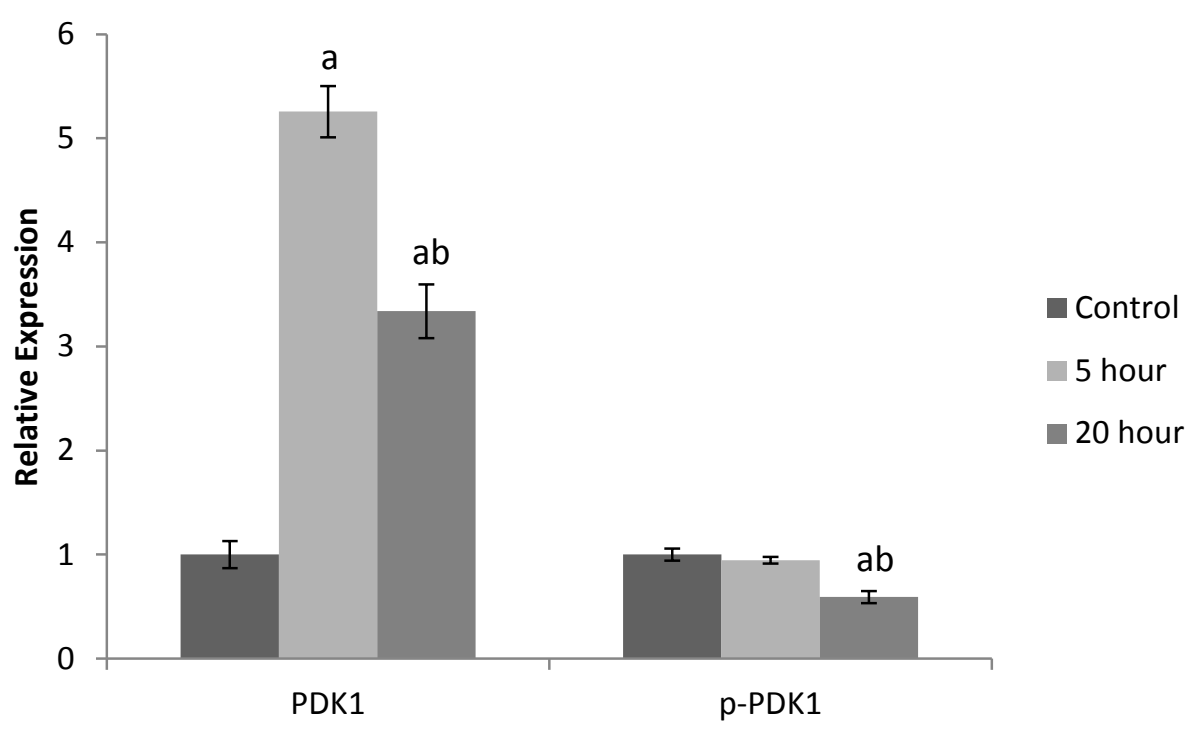

Figure 3.5 Regulation pattern of PDK1 in white skeletal muscle and liver tissues of Trachemys scripta elegans determined by Western Immunoblotting.

Relative expression levels of PDK1 and phospho-PDK1 ${ }^{\text {Ser241 }}$ during 5 hours of hypoxia and 20 hours of anoxia in white muscle (A) and liver (B) of the red-eared slider turtle. Representative bands were detected at $\sim 64 \mathrm{kDa}$. a- significantly different from corresponding control values, b- significantly different from corresponding 5 hour values. $(P<0.05$, ANOVA, Tukey post hoc test $)$. 
(A)

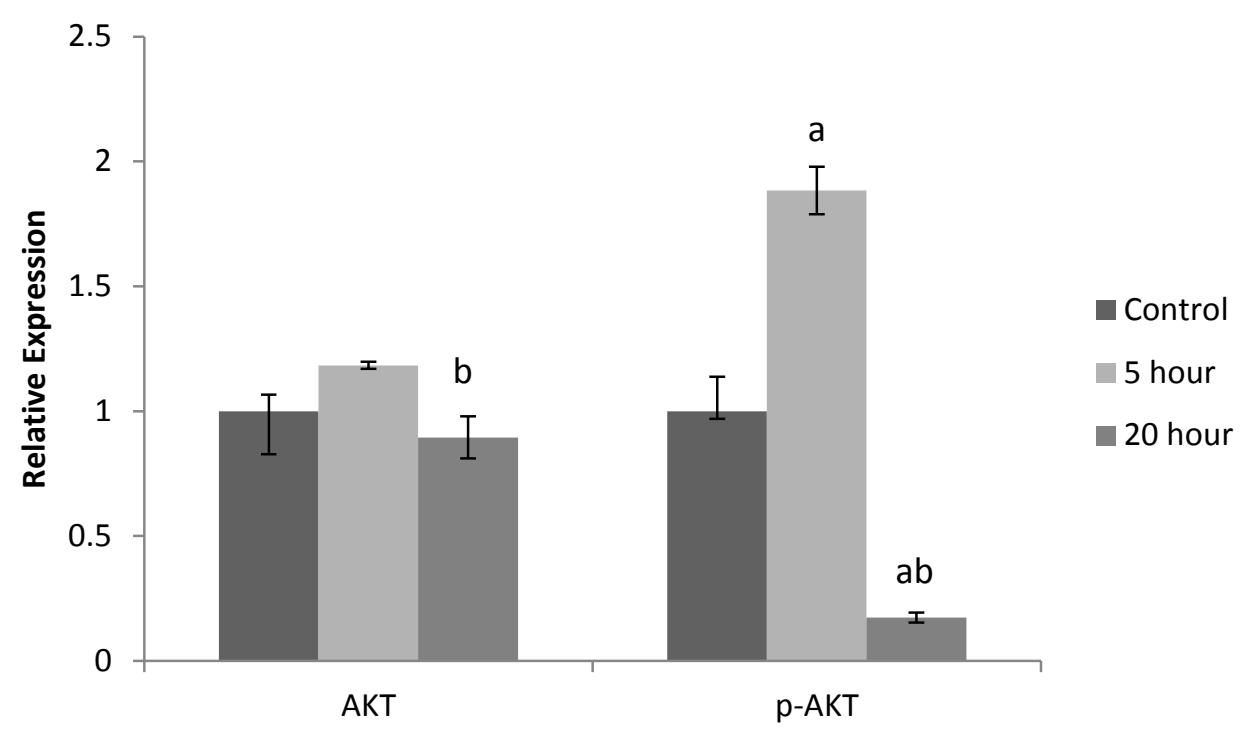

(B)

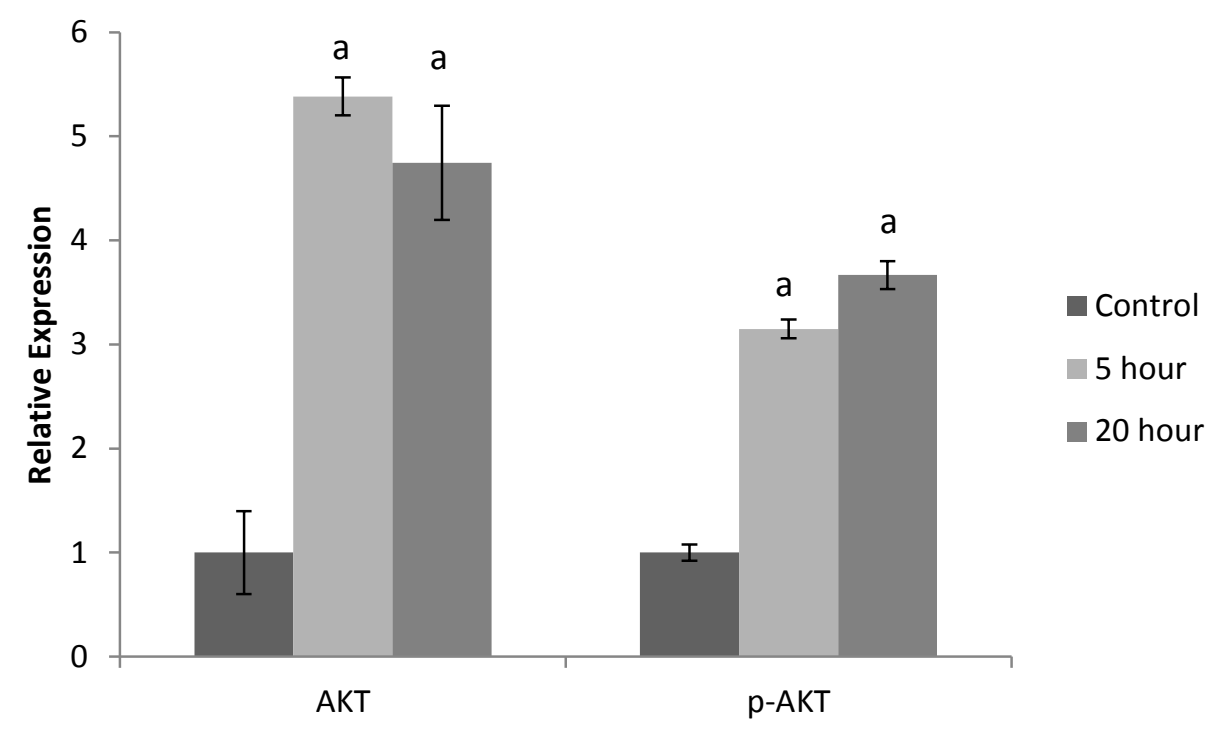

Figure 3.6 Regulation pattern of AKT in white skeletal muscle and liver tissues of Trachemys scripta elegans determined by Western Immunoblotting.

Relative expression levels of AKT and phospho-AKT ${ }^{\text {Ser473 }}$ during 5 hours of hypoxia and 20 hours of anoxia in white muscle (A) and liver (B) of the red-eared slider turtle. Representative bands were detected at $\sim 60 \mathrm{kDa}$. a- significantly different from corresponding control values, b- significantly different from corresponding 5 hour values. $(P<0.05$, ANOVA, Tukey post hoc test $)$. 


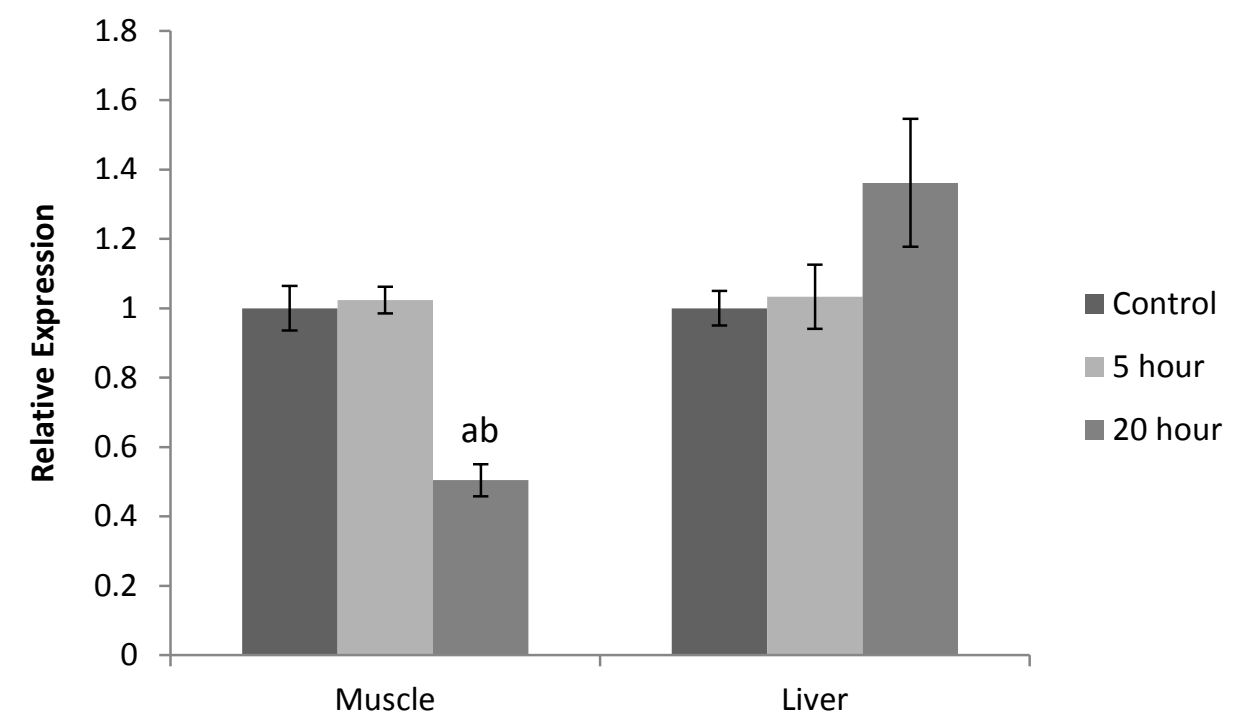

Figure 3.7 Regulation pattern of TSC2 in white skeletal muscle and liver tissues of Trachemys scripta elegans determined by Western Immunoblotting.

Relative expression levels of phospho-TSC2 $2^{\text {Thr1462 }}$ during 5 hours of hypoxia and 20 hours of anoxia in white muscle and liver of the red-eared slider turtle. Representative bands were detected at $\sim 200 \mathrm{kDa}$ a- significantly different from corresponding control values, $b$ - significantly different from corresponding 5 hour values. $(P<0.05$, ANOVA, Tukey post hoc test). 


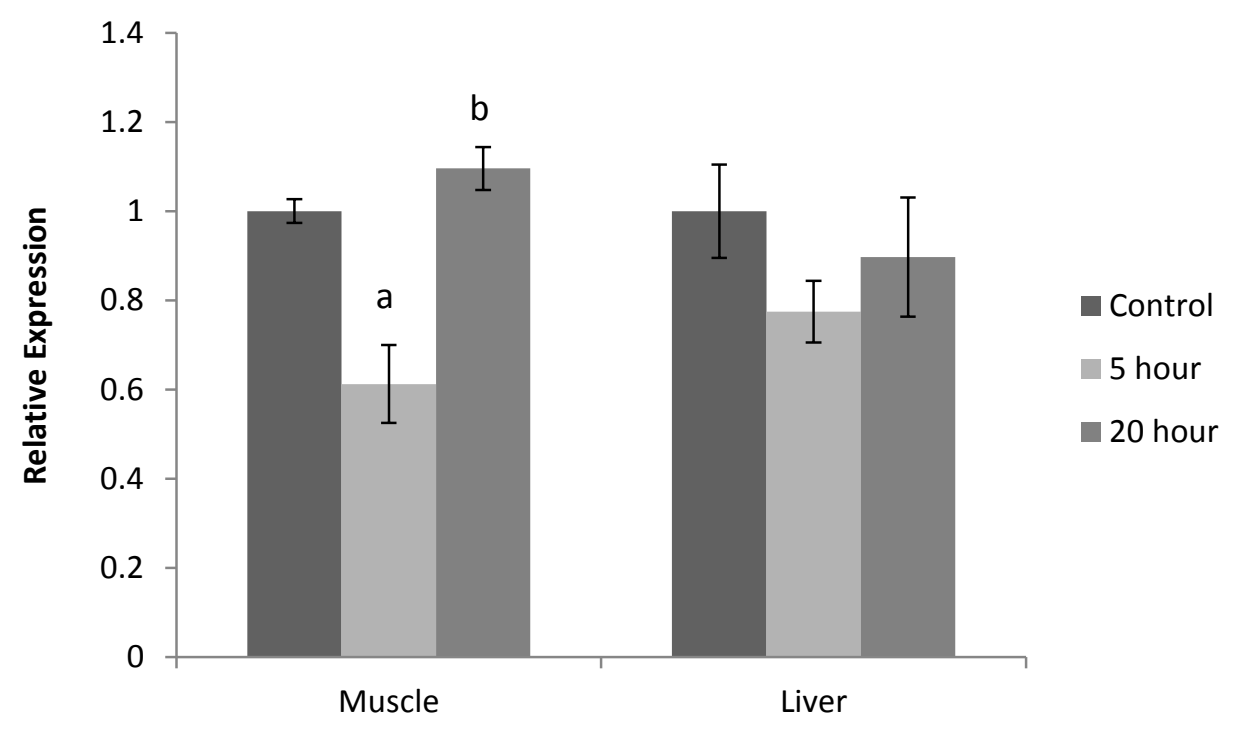

Figure 3.8 Regulation pattern of PRAS40 in white skeletal muscle and liver tissues of Trachemys scripta elegans determined by Western Immunoblotting.

Relative expression levels of phospho-PRAS $40^{\text {Thr246 }}$ during 5 hours of hypoxia and 20 hours of anoxia in white muscle and liver of the red-eared slider turtle. Representative bands were detected at $\sim 40 \mathrm{kDa}$. a- significantly different from corresponding control values, $b$ - significantly different from corresponding 5 hour values. $(P<0.05$, ANOVA, Tukey post hoc test). 


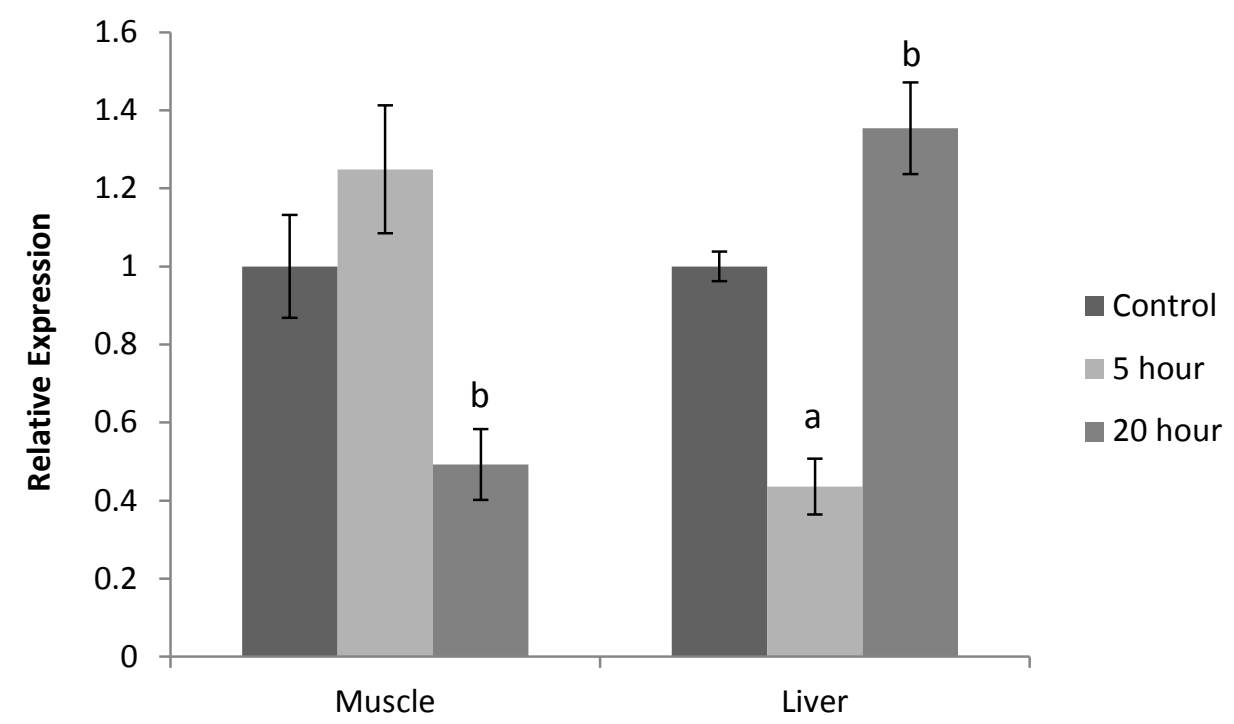

Figure 3.9 Regulation pattern of RAPTOR in white skeletal muscle and liver tissues of Trachemys scripta elegans determined by Western Immunoblotting.

Relative expression levels of RAPTOR during 5 hours of hypoxia and 20 hours of anoxia in white muscle and liver of the red-eared slider turtle. Representative bands were detected at $\sim 150 \mathrm{kDa}$. a- significantly different from corresponding control values, bsignificantly different from corresponding 5 hour values. $(P<0.05$, ANOVA, Tukey post hoc test). 


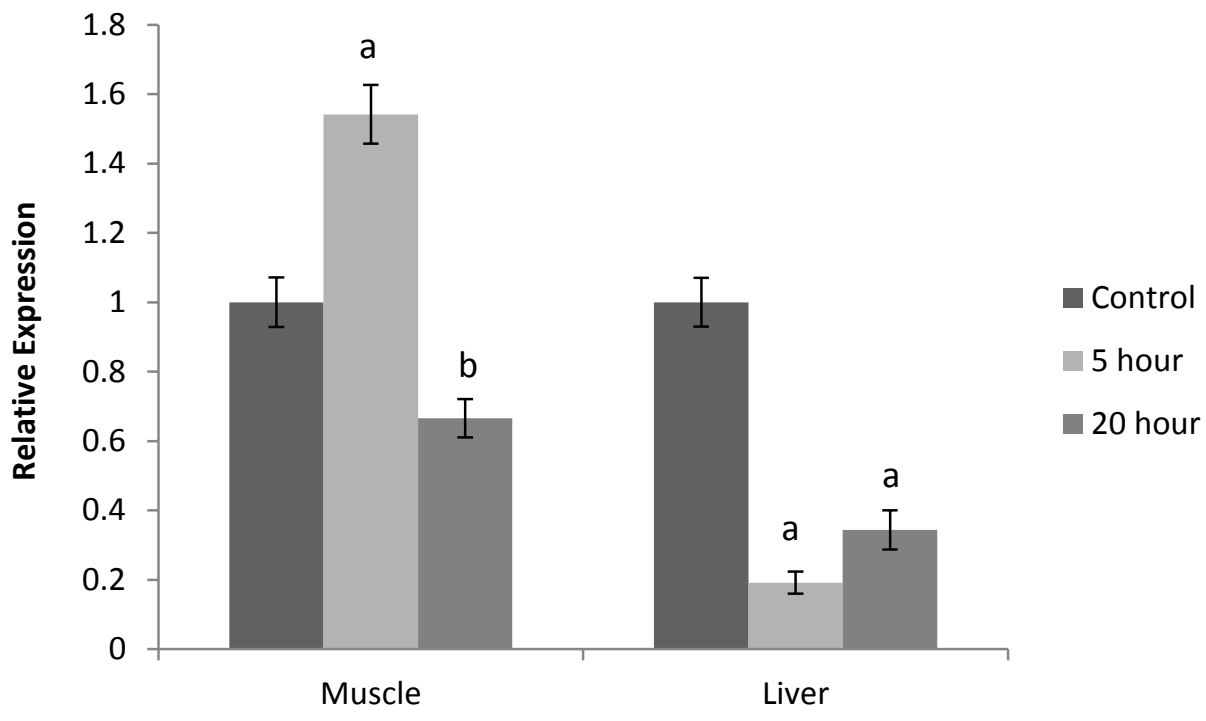

Figure 3.10 Regulation pattern of $G \beta L$ in white skeletal muscle and liver tissues of Trachemys scripta elegans determined by Western Immunoblotting.

Relative expression levels of G $\beta$ L during 5 hours of hypoxia and 20 hours of anoxia in white muscle and liver the red-eared slider turtle. Representative bands were detected at $\sim 37 \mathrm{kDa}$. a- significantly different from corresponding control values, b- significantly different from corresponding 5 hour values. $(P<0.05$, ANOVA, Tukey post hoc test). 


\section{CHAPTER 4}

DOWNSTREAM OF mTORC1 


\subsection{Introduction}

Gene expression leads to the formation of a gene product, most often a protein but also various RNA products such as transfer RNAs, ribosomal RNAs, microRNAs and other non-coding RNAs. All life forms undergo gene expression to produce the proteins required for survival. The process of gene expression leading to the synthesis of functional proteins includes: transcription, post-transcriptional processing of mRNA, translation, and post-translational modifications of proteins (Schwanhäusser et al., 2011). Translation converts mRNA into protein via the ribosomal complex. Translation initiation and ribosomal complex assembly are mitigated through the activation of several downstream targets of the mTOR pathway including: p70 S6 kinase (p70 S6K), ribosomal protein $\mathrm{S} 6(\mathrm{rpS} 6)$, eukaryotic initiation factor 4E-binding protein 1 (4E-BP1) and the eukaryotic initiation factor (eIF4E) (FIG 4.1).

P70 S6K is phosphorylated and thereby activated by mTOR and PDK-1. The p70 S6 Kinases, S6K1 and S6K2 play a major role in S6 phosphorylation. Both isoforms phosphorylate the ribosomal protein S6, a component of the 40S ribosome (Long et al., 2004). Once active, S6 facilitates translation by regulating the biosynthesis of a variety of translational components (Dufner and Thomas, 1999; Ruvinsky and Meyuhas, 2006). RpS6 is responsible for the selective translation of a family of mRNAs that encode components of the translational apparatus, including ribosomal proteins and translational elongation factors whose expression is essential for cell growth and proliferation (Dufner and Thomas, 1999). RpS6 undergoes inducible phosphorylation on a cluster of five serine residues at the carboxyl terminus: Ser-235, Ser -236, Ser -240, Ser -244 and Ser -247. 
The sequential phosphorylation of S6 enhances its affinity for the $\mathrm{m}^{7} \mathrm{G}$ cap which implies that phosphorylation enhances mRNA translation initiation (Hutchinson et al., 2011); an increase in S6 protein phosphorylation increases the rate of translation initiation (Nielsen et al, 1982; Hershey, 1989). Under anoxic conditions, translation is inhibited via the dephosphorylation of the S6 protein.

Translation is also initiated by the binding of translation initiation proteins such as eIF4E. Through its interaction with the mRNA cap structure and eIF4G, eIF4E physically brings the ribosome to the $5^{\prime}$ extremity of the capped mRNA $\left(\mathrm{m}^{7} \mathrm{G}\right)$ (Müller et al., 2013). The mRNA 5' cap is bound by eIF4F of which eIF4G is a component. eIF4G interacts with eIF4A and 4E which facilitate ribosomal binding and its passage along the untranslated region (UTR) towards the initiation codon. Translation initiation occurs when the $40 \mathrm{~S}$ ribosome is recruited to the 5 , end through the interaction with the eukaryotic initiation factors. However, sequestration of eIF4E by binding to 4E-BP1 prevents eIF4E from joining the initiation complex and thereby disrupts translation initiation (Hershey, 1989; Richter and Sonenberg, 2005).

MAPK-Interacting Protein Kinase (MNK) activates eIF4E on a Serine-209 residue. This phosphorylation has implications for eIF4E involvement in tumorigenesis (Müller et al., 2013). Incidentally, a mutation in either MNK isoforms MNK-1 or MNK-2 has been shown to delay tumorigenesis (Müller et al., 2013). Protein synthesis initiation is facilitated through the inactivation of $4 \mathrm{E}-\mathrm{BP} 1.4 \mathrm{E}-\mathrm{BP} 1$ acts as a negative inhibitor of eIF4E by competing with eIF4G for the binding site. Overexpression of 4E-BP1 has been shown to prevent eIF4E-induced oncogenic properties (Müller et al., 2013). This target is activated through phosphorylation by mTOR thus cancelling its inhibitory effects on 
eIF4E, releasing it so that it may form the translation initiation complex. Upon aminoacid starvation, or under anoxic conditions, 4E-BP1 may not be phosphorylated and protein synthesis is suppressed (Müller et al., 2013, Storey, 2005).

The function of the poly(A) tail has much to do with stimulating translation. Even though the $5^{\prime}$ cap $\left(\mathrm{m}^{7} \mathrm{G}\right)$ and poly $(\mathrm{A})$ tail are located at opposite ends of the mRNA, they act synergistically to initiate translation (Wilkie et al., 2003). The poly(A) binding protein $(\mathrm{PABP})$ is a protein suggested to play a pivotal role in poly(A)-mediated translation. PABP interacts with the eukaryotic initiation factor eIF4G and eIF4B. The PABP-eIF4G interaction circularizes the mRNA and the PABP-eIF4B interaction has been suggested to enhance PABP binding to the poly(A) tail and to stimulate eIF4A helicase activity (Wilkie et al., 2003). The sum of these interactions encourages the recruitment of the $40 \mathrm{~S}$ ribosome to the mRNA to initiate translation. Studies have shown that in general, a longer poly(A) tail will lead to translational activation whereas shorter poly(A) tails will not (Sachs and Davis, 1989; Jackson and Standart, 1990; Brown and Sachs, 1998).

Previous studies have shown comparable modes of suppression of translation and ribosomal complex assembly under anoxic conditions (Storey, 1996, Hochachka et al., 1996, Storey, 2005). The studies in this chapter show contrasting results as downstream mTOR pathway proteins responsible for activation of protein synthesis revealed tissuespecific regulation. Some downstream mTOR pathway proteins were down-regulated, whereas others were upregulated in response to anoxia. I show here that protein synthesis is differentially regulated in two tissues, liver and white muscle. These results reflect the biochemical changes occurring during anoxia where translation is suppressed in order to 
reduce energy expenditure to basal levels in order for the turtle to survive over the longterm in a hypometabolic state. Overall, the current work provides new insights into the molecular mechanisms that control protein synthesis in a facultative anaerobe through downstream mTOR regulation in the red-eared slider turtle during anoxia.

\subsection{Results}

\subsubsection{Phosphorylation status of mTOR during anoxia}

The mTOR signaling pathway regulates protein synthesis in response to various stimuli such as hormones, growth factors and amino acid availability and is impaired by nutrient deficiency. The mTOR kinase cascade initiates protein synthesis through the activation of downstream factors responsible for initiation of translation and ribosomal biogenesis (Wang and Proud, 2006).

Recall from Chapter 3 that the analysis of mTOR indicated that protein synthesis was negatively regulated in muscle in response to anoxia but positively regulated in liver. Western blots revealed no significant changes in total or phosphorylated mTOR $^{\text {Ser2448 }}$ protein levels in skeletal muscle. Mean normalized values of total mTOR were $1.09 \pm$ 0.04 and $1.13 \pm 0.15$ after 5 hours and 20 hours of anoxia, respectively, but revealed a significant decrease in phospho-mTOR after 5 hours of hypoxia to $0.60 \pm 0.01$ before returning to control values after 20 hours of anoxia $(0.88 \pm 0.08)(P<0.05)$ (FIG 3.3A Chapter 3). In contrast, liver tissues revealed a strong suppression of total mTOR protein levels after 20 hours of anoxia to $0.42 \pm 0.01$ as well as a strong increase in phosphorylated mTOR protein levels after 5 and 20 hours of anoxia with mean 
normalized values rising by $5.66 \pm 0.28$-fold and $13.18 \pm 2.13$-fold, respectively, compared to controls $(P<0.05)$ (FIG 3.3B - Chapter 3).

\subsubsection{Phosphorylation of downstream targets p70 S6K and S6}

The downstream effects of mTOR signaling during anoxia were examined by assessing the phosphorylation status of specific mTOR targets. Formation of the ribosomal complex is activated by the phosphorylation of the ribosomal protein S6 by p70 S6 Kinase. Antibodies recognizing phosphorylated p70 S6K ${ }^{\text {Thr389 }}$ cross-reacted with a protein band of $\sim 70 \mathrm{kDa}$, the expected size of $\mathrm{p} 70 \mathrm{~S} 6 \mathrm{~K}$ and those recognizing $\mathrm{S} 6$ and $\mathrm{p}$ $\mathrm{S} 6^{\text {Ser235 }}$ cross-reacted with a protein band of $\sim 32 \mathrm{kDa}$, the expected size of S6. Western blots seen in FIG 4.2 reveal consistency of metabolic responses of downstream proteins in response to anoxia.

FIG 4.3 shows that in skeletal muscle, the relative levels of phospho-p70 S6K were reduced after 5 hours of hypoxia to approximately $60 \%$ of control values $(0.59 \pm$ $0.07)$ and decreased further after 20 hours of anoxia to $30 \%(0.30 \pm 0.08)$ of controls $(P<$ 0.05). However, the phosphorylation state of $\mathrm{p} 70 \mathrm{~S} 6 \mathrm{~K}$ in the liver was unchanged after either length of anoxic submergence (FIG 4.3).

To determine if changes in the phosphorylation state of p70 $\mathrm{S} 6 \mathrm{~K}^{\mathrm{Th} 389}$ had any effect on the translational complex, the phosphorylation state of the ribosomal protein $\mathrm{S6}^{\mathrm{Ser} 235}$ was also examined. Total S6 showed an increase in expression in skeletal muscle after 20 hours of anoxia by $1.53 \pm 0.17$-fold (FIG 4.4A) whereas liver tissue revealed an even higher increase to over 7 -fold $(7.31 \pm 0.86)$ after 5 hours of hypoxia which remained high at $5.66 \pm 0.95$-fold after 20 hours of anoxia $(P<0.05)\left(\right.$ FIG 4.4B). Phospho-S6 ${ }^{\text {Ser235 }}$ 
expression levels decreased in white skeletal muscle by $65 \%(0.45 \pm 0.05)$ and remained low at $0.50 \pm 0.10$ after 20 hours of anoxia $(P<0.05)\left(\right.$ FIG 4.4A). Liver phospho-S6 ${ }^{\text {Ser235 }}$ levels increased significantly by 2.5 fold $(2.57 \pm 0.40)$ after 5 hours of anoxia exposure but returned to control values after 20 hours $(1.12 \pm 0.18)(P<0.05)$ (FIG 4.4B).

\subsubsection{Phosphorylation of downstream targets $4 E-B P 1$ and eIF4E}

Another important mTOR downstream target is 4E-BP1. 4EBP is a translational repressor protein, which upon hyper-phosphorylation, disrupts the interaction between itself and eIF4E. Antibodies recognizing 4E-BP1 cross-reacted with a protein band of $\sim 15-20 \mathrm{kDa}$, the expected size of 4E-BP1. FIG 4.5 shows that in response to 5 and 20 hours of anoxia, the relative levels of total 4E-BP1 in skeletal muscle decreased by about $40 \%$ to $0.59 \pm 0.09$ and $60 \%$ to $0.37 \pm 0.05$ after 5 hours and 20 hours of anoxia, respectively $(P<0.05)$ (FIG $4.5 \mathrm{~A})$. Liver exhibited a very strong decrease in total 4EBP1 after 20 hours of anoxia by $94 \%$ to $0.06 \pm 0.01$ (FIG 4.5B). Relative levels of phosphorylated 4E-BP1 showed a different pattern with no change in phospho-4E$\mathrm{BPa}^{\mathrm{Tre} 37 / 46}$ in white muscle during anoxia whereas phosphorylation of the liver protein strongly increased by $2.07 \pm 0.12$ and $2.91 \pm 0.05$-fold $(P<0.05)$ in hypoxia and anoxia, respectively.

To determine the effect of the phosphorylation state of 4E-BP1 on the translational complex, the phosphorylation of eIF4E was also examined. eIF4E assists the eIF4F complex during translation initiation by binding the 5 ' cap of the cytoplasmic mRNA and forming the pre-initiation complex (Hay and Sonenberg, 2004). eIF4E is inhibited when bound by 4E-BP1 thus preventing translation initiation. Antibodies 
recognizing eIF4E cross-reacted with a protein band of $\sim 25 \mathrm{kDa}$, the expected size of eIF4E. FIG 4.6A shows that eIF4E expression decreased significantly to $70 \%$ of control values $(0.70 \pm 0.04)$ after 5 hours of hypoxia but returned to control values during anoxia. By contrast, liver showed an almost 3 -fold increase in eIF4E content $(2.89 \pm 0.04$ fold $)$ after 5 hours and then a subsequent decrease back to near-control levels after 20 hours of anoxia $(1.43 \pm 0.27)(P<0.05)\left(\right.$ FIG 4.6B). The phosphorylation state of $4 \mathrm{E}-\mathrm{BP} 1^{\mathrm{Thr} 37}$ revealed no significant change in the white muscle but a strong increase in liver by $2.59 \pm$ 0.15 -fold and $4.23 \pm 0.45$-fold after 5 hours and 20 hours of anoxic submergence, respectively $(P<0.05)$ (FIGs 4.6A,B).

\subsubsection{Regulation of the poly(A) binding protein}

The poly(A)-binding protein (PABP) interacts with the eukaryotic initiation factor 4G (eIF4G) to promote translation initiation. Phosphorylated PABP exhibits cooperative binding to poly(A) RNA as well as increased binding to eIF4G (Storey, 2005). An immunoreactive band recognizing PABP cross-reacted with a protein band of $\sim 71 \mathrm{kDa}$, the expected size of PABP. In skeletal muscle, total PABP showed a significant increase after 5 hours of hypoxia to $1.87 \pm 0.10$-fold and remained high after 20 hours at $1.50 \pm$ 0.10-fold above control values $(P<0.05)$ (FIG 4.7A). In liver, similar results were seen after 5 hours of hypoxia as a 3 -fold increase $(3.00 \pm 0.19)$ was observed followed by a return to control values after 20 hours of anoxia $(1.16 \pm 0.16)$ (FIG 4.7B). 


\subsection{Discussion}

Studies of translational regulation under hypoxic conditions have shown great potential to elucidate the mechanisms through which long term survival may be achieved. Many studies have shown that in response to the appropriate growth factors, downstream mTOR targets will initiate ribosomal complex assembly and cap-dependent protein synthesis (Sonenberg and Gingras, 1998; Fingar et al., 2004; Stensløkken et al., 2008; Fähling, 2009). Some of these studies have employed various hypoxia tolerant animal models in order to examine the mechanisms through which translation may be suppressed under hypoxic conditions such as the brine shrimp, crucian carp, crayfish and others. The focus of this chapter was to elucidate the mechanisms by which downstream effectors of the mTOR pathway employ in order to suppress protein translation in a premier vertebrate facultative anaerobe, the red-eared slider turtle Trachemys scripta elegans.

Both p70 S6K and 4E-BP1 are important regulatory players in the formation of the ribosomal complex and initiation of cap-dependent translation. p70 S6K phosphorylates the downstream ribosomal protein S6 a component of the 40S ribosomal subunit (Weng, et al., 1995), whereas 4E-BP1 is a translational repressor which, in its dephosphorylated form, inhibits the eukaryotic initiation factor 4E (eIF4E). This prevents eIF4E from binding with other initiation factors such as eIF4G and thereby inhibits the cap-dependent translational complex formation (Fingar et al., 2004).

Active mTORC1 phosphorylates downstream targets to initiate protein translation. The first target to be activated is p70 S6K, a downstream kinase that in turn activates ribosomal protein S6 by phosphorylation on Ser-235. Activation of S6 
influences protein synthesis by increasing the rate of initiation and elongation (Nielsen et al., 1982). FIG 4.3 shows the phosphorylation state of p70 S6K at Thr-389 and shows an approximate $50 \%$ decrease phosphorylated protein in white muscle in response to 5 hours of hypoxia followed by a further decrease to $30 \%$ of control values after 20 hours of anoxia. In contrast, no significant change was seen in liver. This would suggest that levels of translation are maintained in the liver, but repressed in the muscle, at least over the early hours of anoxia exposure. Hence, these data immediately indicate that there may be organ-dependent responses in the timing of translational suppression under anoxia.

Since, P70 S6K goes on to phosphorylate S6, it would be assumed that the response of S6 to hypoxia/anoxia would mirror response by P70 S6K. Indeed, the phosphorylation status of the ribosomal protein S6 at Ser-235 correlated well with p70 S6K in white muscle where the significant decrease in p70 S6K phosphorylation in white muscle correlated with an accompanying $\sim 50 \%$ decrease in muscle $\mathrm{p}-\mathrm{S} 6^{\mathrm{Ser} 235 / 236}$ levels (Fig. 4.4). Oppositely, maintenance of p70 S6K expression levels in the liver were accompanied by an increase in phosphorylated S6 content after $5 \mathrm{~h}$ hypoxia. Both the change in phospho-S6 levels and the increase in total S6 levels seen in liver further support a state of relative translational activation in liver, particularly in the short term (5 h) but showing signs of reversal by $20 \mathrm{~h}$.

Studies have shown that the phosphorylation of p70 at Thr-389 is the first phosphorylation of several, required for the full activation of p70 S6K (Long et al., 2004). Also, the strong increase in mTORC1 activation in liver would suggest an activation of S6 in this organ, which was shown by the data in FIG 3.3 (Chapter 3). There an initial 6-fold increase in liver mTOR activity after 5 hours of hypoxia was 
followed by a further increase to 13 -fold higher than control levels after 20 hours of anoxia. These results correlate with those observed in FIG 4.4 where levels of activated p-S6 in liver increased after 5 hours of anoxia to 2.56-fold of control values before returning to control levels by 20 hours. S6 activation is controlled by the phosphorylation of five sites including: Ser-235, -236, -240 -244 and -247 (Hutchinson et al., 2011). Since S6 is phosphorylated by mTOR and the p70 S6 Kinases, it is possible that S6 was not fully activated and is the cause of the decrease in expression after 20 hours of anoxia. Because Ser-235 is was the only residue examined in this study, and the first phosphorylation event in the series of five phosphorylations, it is likely that the rate of translation was much lower than it would have been if RpS6 had been fully activated by the S6 Kinases.

The results for the white muscle correlate with what would be expected, as the turtle is largely inactive during anoxic submergence in cold water. Therefore, white muscle should not require much protein synthesis during the hypometabolic state. On the other hand, the liver could be expected to continue some level of protein synthesis because liver is responsible for various metabolic needs of the whole animal (e.g. glucose output from glycogen stores, maintenance of many plasma proteins, etc.) under anoxia. Although studies with isolated hepatocytes indicated a strong metabolic suppression in liver cells under anoxia (Hochachka et al., 1996), the current results indicate that in the short term, at least, liver protein synthesis appears to be maintained or even enhanced over the early hours of anoxic submergence. Hence, overall, the results seen in this chapter for p70 S6K and S6 correlate with a suppression of ribosomal complex assembly in the muscle but activation in the liver. 
Next, I examined the phosphorylation state of downstream targets, 4E-BP1 and eIF4E. 4E-BP1 is a translational repressor of eIF4E in its dephosphorylated state and interacts with eIF4E to prevent its binding to eIF4G. The inhibition of the eIF4 complex prevents the formation of the cap-dependent translational complex (Storey, 2005). In its hyperphosphorylated form, $4 \mathrm{E}-\mathrm{BP} 1^{\text {Thr37 }}$ releases eIF4E and allows the formation of the eIF4 complex and the initiation of translation. FIG 4.5B shows an increase in phosphorylated 4E-BP1 in the liver after both 5 and 20 hours of anoxic submergence which suggests reduced inhibition eIF4E and thereby promotes an increase in translation initiation. Conversely, FIG 4.5A revealed no significant change in phosphorylation state of 4E-BP1 in white muscle under anoxia as compared with control values. This suggests that $4 \mathrm{E}-\mathrm{BP} 1$ releases eIF4E from inhibition and allows it to form the initiation complex. The phosphorylation state of eIF4E $\mathrm{E}^{\mathrm{Ser} 209}$ supports the ideas above (FIG 4.6). In order to bind to the ribosomal complex and begin translational initiation, eIF4E must be phosphorylated by MNK at Ser-209 (Müller et al., 2013). The phosphorylation state of eIF4E ${ }^{\text {Ser209 }}$ revealed a progressive significant increase in liver during anoxic submergence but no significant change in white muscle (FIG 4.6). These results correlate with those obtained from (FIG 4.5) for phosphorylated 4E-BP1. 4E-BP1 appears to be highly phosphorylated in the liver which allows eIF4E to be released. By contrast, the white muscle revealed no significant change in $4 \mathrm{E}-\mathrm{BP} 1^{\mathrm{Th} 37}$ in accordance with phosphorylated eIF4E ${ }^{\text {Ser209 }}$. This suggests that the translational complex is activated in the liver during the early hours of anoxic submergence but not in skeletal muscle.

The Poly-A-binding protein (PABP) associates with the 3' tail of the mRNA and is also involved in recognition of the $5^{\prime}$ mRNA cap structure. PABP has many functions 
including translation initiation, mRNA stabilization and turnover (Caponigro and Parker, 1995; Sachs and Davis, 1989). Phosphorylation of PABP has been shown to enhance RNA binding and subsequently translation initiation. Figure 4.7 shows the state of total PABP, which shows an increase in both white muscle and liver tissues. This increase in total PABP would suggest a lack of activation of translational machinery but a change in RNA binding. In white muscle, a 2-fold increase was seen in hypoxia whereas in liver tissues, a similar 3-fold increase was observed after 5 hours of hypoxia, although expression levels returned to control values after 20 hours of anoxia. The phosphorylation state of PABP indicates its function with respect to translation and its specificity is determined by its interaction with initiation factors. RNA binding activity of phosphorylated PABP is enhanced when bound to eIF4B, whereas the RNA binding activity of hypophosphorylated PABP is enhanced when bound to eIF4F. Further, eIFiso4F enhanced its binding activity in either phosphorylation state (Le et al., 2000). Therefore, because total PABP levels were measured and do not give any indication as to the phosphorylation state, its effects on translation cannot conclusively be deduced.

The general trend for downstream targets of mTOR shown by the data in this chapter is suppression of ribosomal complex assembly but maintenance of cap-dependent initiation in the white skeletal muscle tissues but a strong upregulation of both processes in the liver.

These results are similar to those obtained for 13-lined ground squirrels during hypometabolism associated with hibernation; the translational complex was also downregulated in cardiac and skeletal muscle when animals entered torpor (Wu and Storey, 2012). It can be suggested that the lack of translational activation may be due to a lack of 
use of the skeletal muscle in the hibernating squirrel and anoxic turtle. The study by $\mathrm{Wu}$ and Storey (2012) revealed a suppression of downstream effectors 4E-BP1, p70 S6K, and S6 during hibernation and a subsequent reversal and increase during arousal. These results are mirrored in the turtle skeletal muscle where the data show significant suppression in $\mathrm{p} 70 \mathrm{~S} 6 \mathrm{~K}$ protein and S6 proteins under anoxia. It can be suggested that because the liver is the main source of glucose, that protein synthesis might be maintained at higher levels in order to supply the entire organism with energy and nutrients required during anoxia (Brooks and Storey, 1989).

In conclusion, the present study examined the regulation of the mTOR signaling pathway and revealed that the downstream pathway is differentially regulated during anoxia in white muscle and liver. The data indicate that depression of the mTOR pathway occurs in white skeletal muscle and that this regulation plays a central role in ribosomal complex assembly and cap-dependent protein synthesis. The phosphorylation status of downstream targets p70 S6K, 4E-BP1 and eIF4E are all consistent with inhibition of protein synthesis during anoxia in muscle. In contrast, the liver demonstrated indicators of activated mTOR signaling levels during hypoxia and anoxia in some cases. The data support the theory that protein synthesis is required/maintained, at least during the early hours when turtles transition through hypoxia and into anoxia. The phosphorylation status of p70 S6K, 4E-BP1, eIF4E and PABP are consistent with an activation of protein synthesis in the liver at these times. The differential regulation of the liver versus white muscle therefore indicates different physiological requirements for the tissues during the hypometabolic response. 


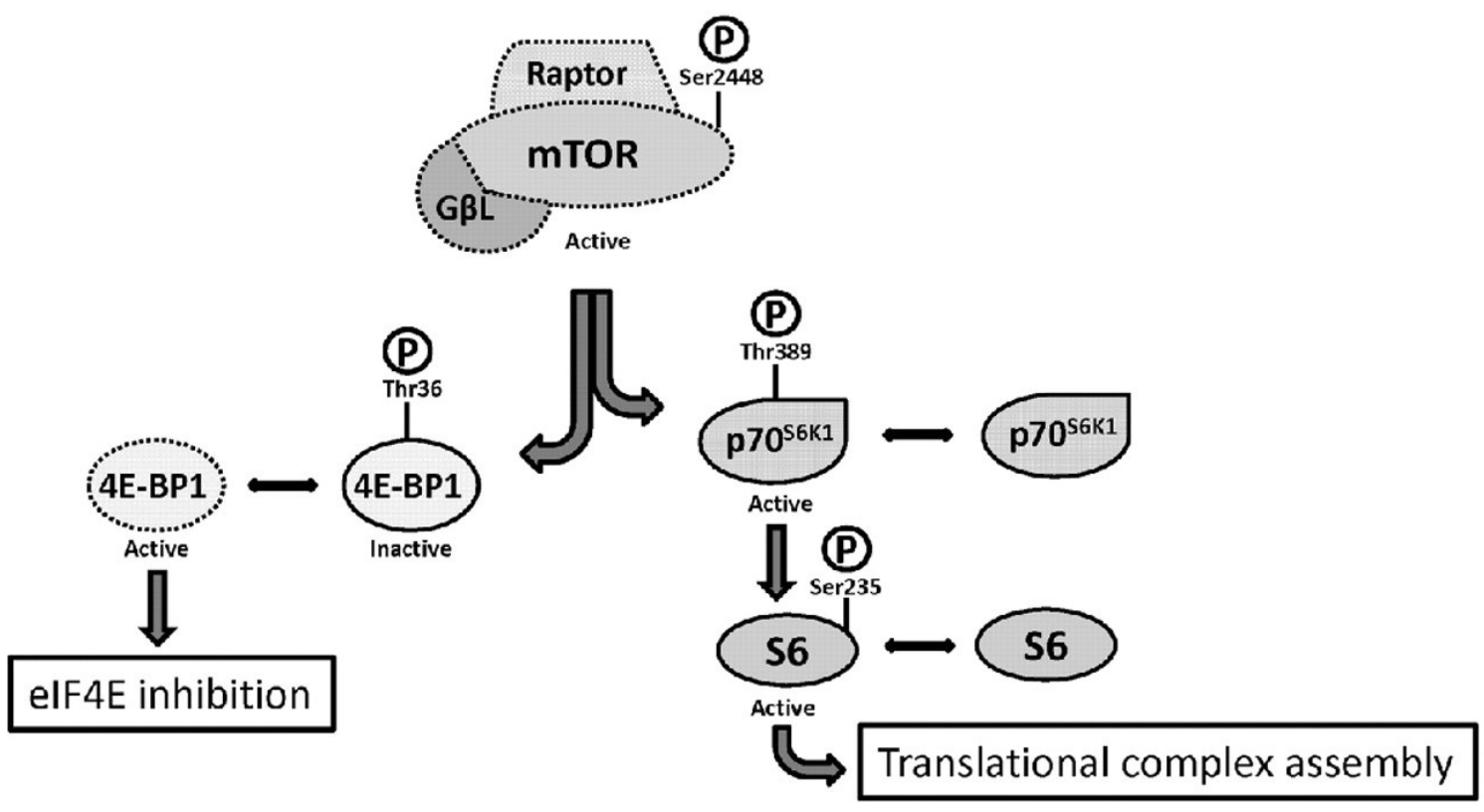

Figure 4.1 The downstream mTOR signaling pathway.

mTOR phosphorylates downstream targets p70 S6K and 4E-BP1 which activate the ribosomal protein S6 and eIF4E, respectively. S6 begins the formation of the ribosomal complex and upon release from inhibition by 4E-BP1, eIF4E begins translation initiation. (Figure adapted from Hay and Sonenberg, 2004) 
(A)

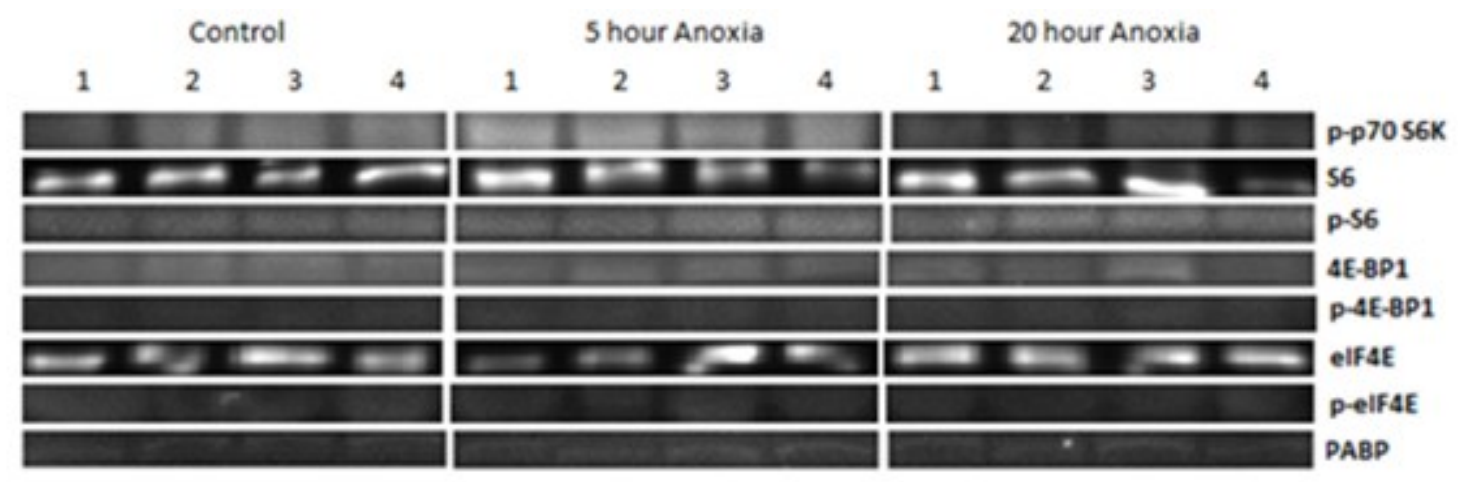

(B)

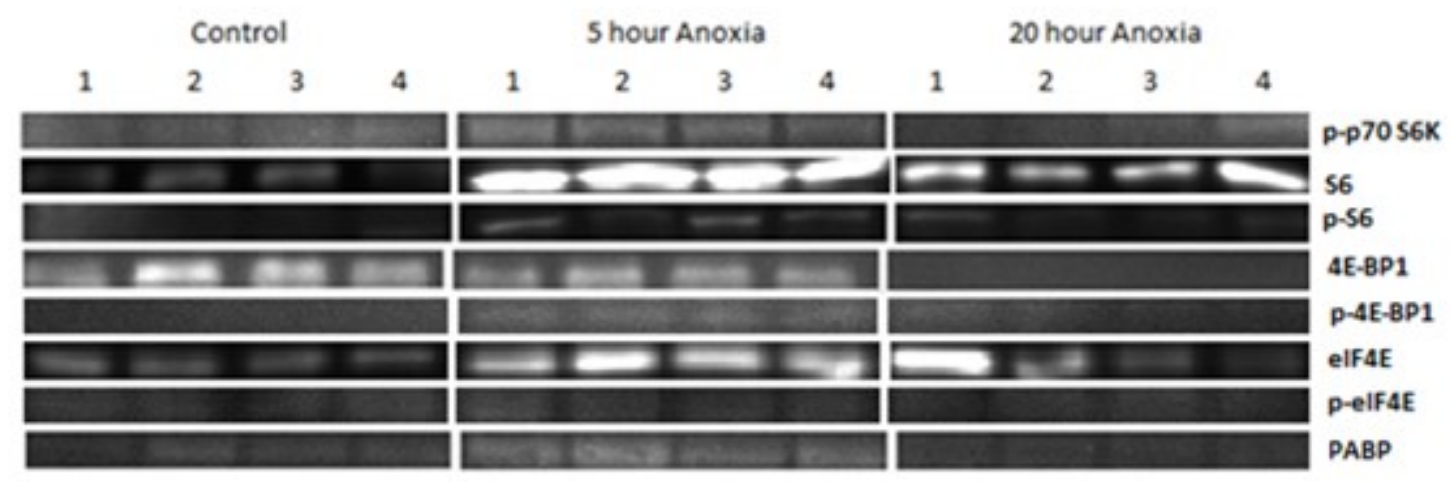

Figure 4.2 Immunoblots of downstream mTOR signaling pathway proteins in white skeletal muscle (A) and liver (B) tissues. 


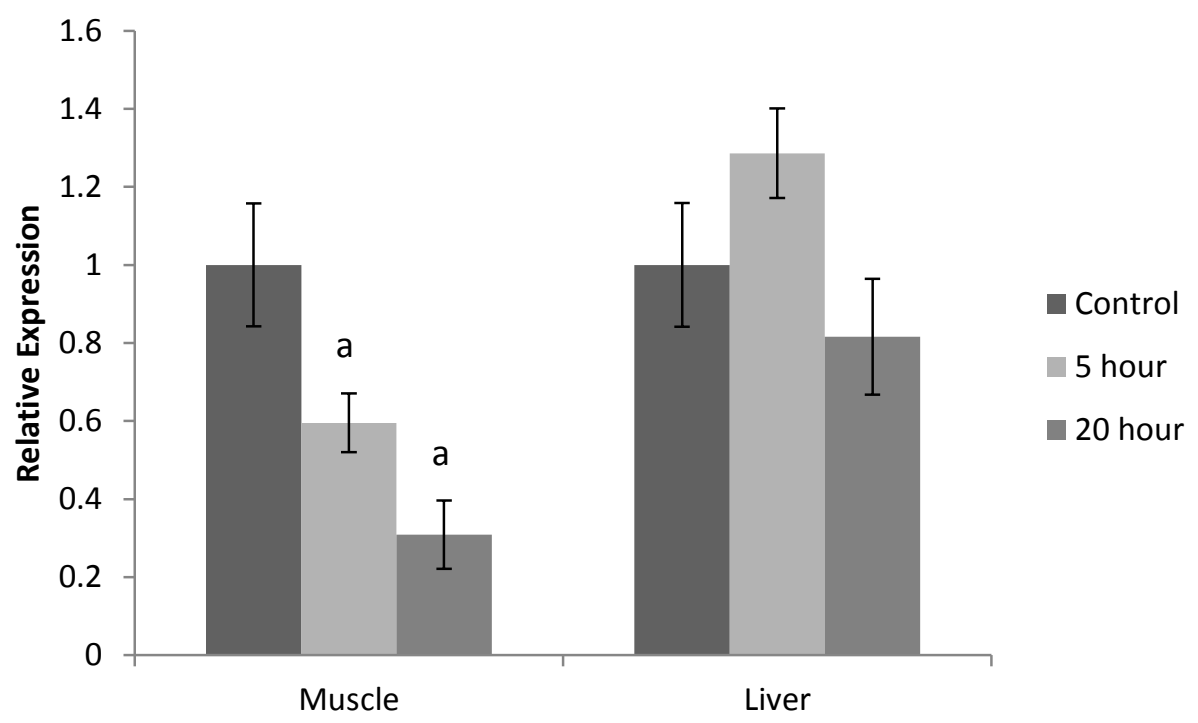

Figure 4.3. Regulation pattern of $\mathrm{p70} \mathrm{S6K}$ in white skeletal muscle and liver tissues of Trachemys scripta elegans determined by Western Immunoblotting.

Relative expression levels of phospho-p70S6K $\mathrm{K}^{\text {Thr389 }}$ during 5 hours of hypoxia and 20 hours of anoxia in white muscle and liver of the red-eared slider turtle. Representative bands were detected at $\sim 70 \mathrm{kDa}$. a- significantly different from corresponding control values $(P<0.05$, ANOVA, Tukey post hoc test). 
(A)

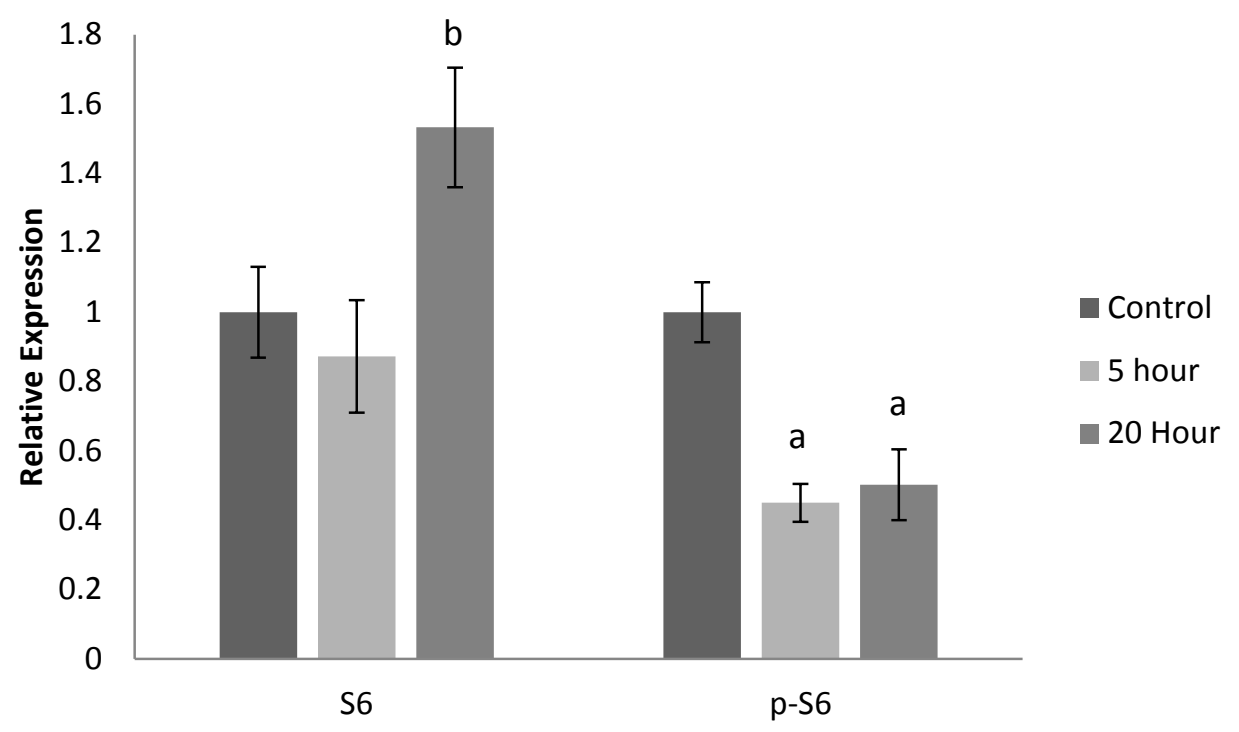

(B)

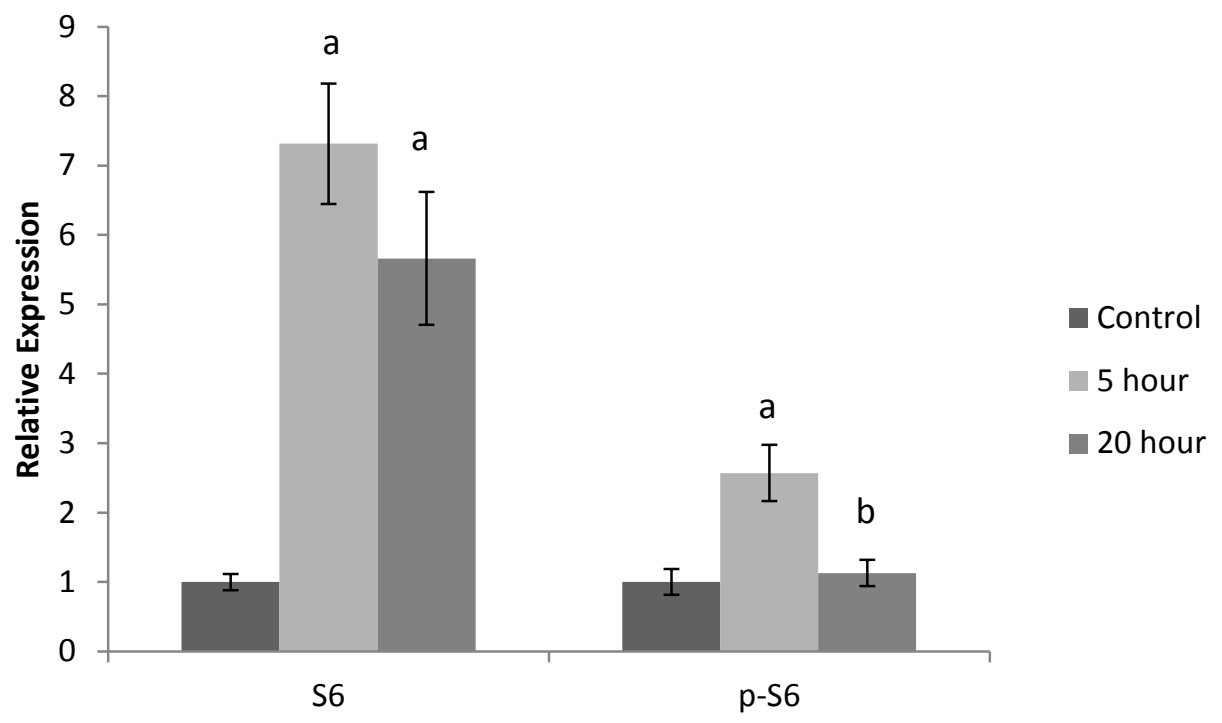

Figure 4.4 Regulation pattern of S6 protein in white skeletal muscle and liver tissues of Trachemys scripta elegans determined by Western Immunoblotting.

Relative expression levels of S6 and phospho-S6 $6^{\text {Ser235 }}$ during 5 hours of hypoxia and 20 hours of anoxia in white muscle (A) and liver (B) of the red-eared slider turtle. Representative bands were detected at $\sim 32 \mathrm{kDa}$. a- significantly different from corresponding control values, b- significantly different from corresponding 5 hour values. $(P<0.05$, ANOVA, Tukey post hoc test $)$. 
(A)

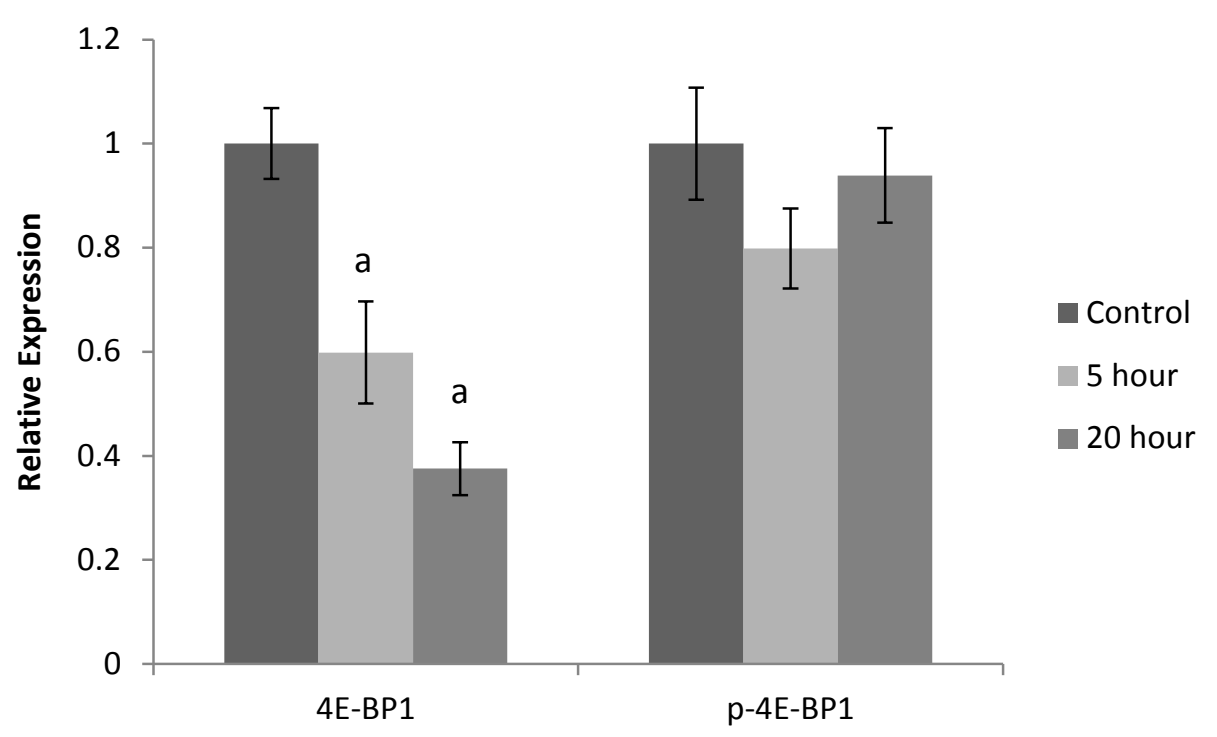

(B)

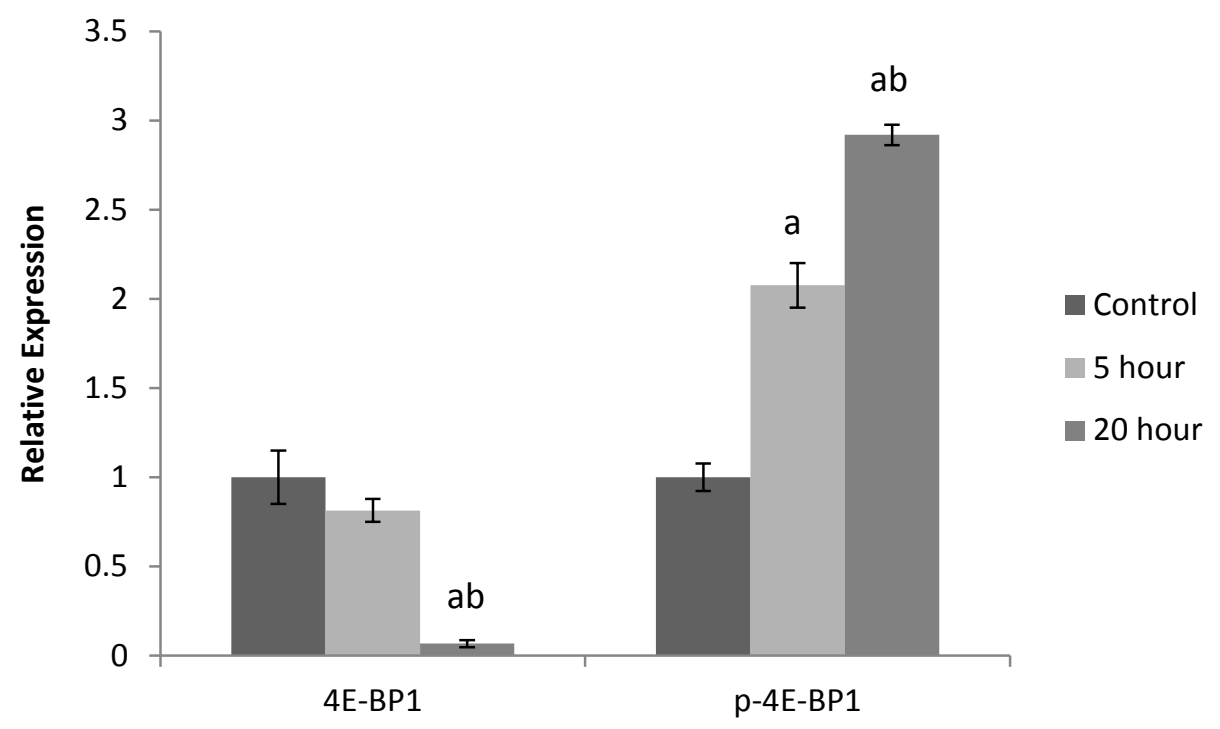

Figure 4.5 Regulation pattern of 4E-BP1 in white skeletal muscle and liver tissues of Trachemys scripta elegans determined by Western Immunoblotting.

Relative expression levels of 4E-BP1 and phospho-4E-BP $1^{\text {Thr } 37 / 46}$ during 5 hours of hypoxia and 20 hours of anoxia in white muscle (A) and liver (B) of the red-eared slider turtle. Representative bands were detected at $\sim 18 \mathrm{kDa}$. a- significantly different from corresponding control values, b- significantly different from corresponding 5 hour values. $(P<0.05$, ANOVA, Tukey post hoc test $)$. 
(A)

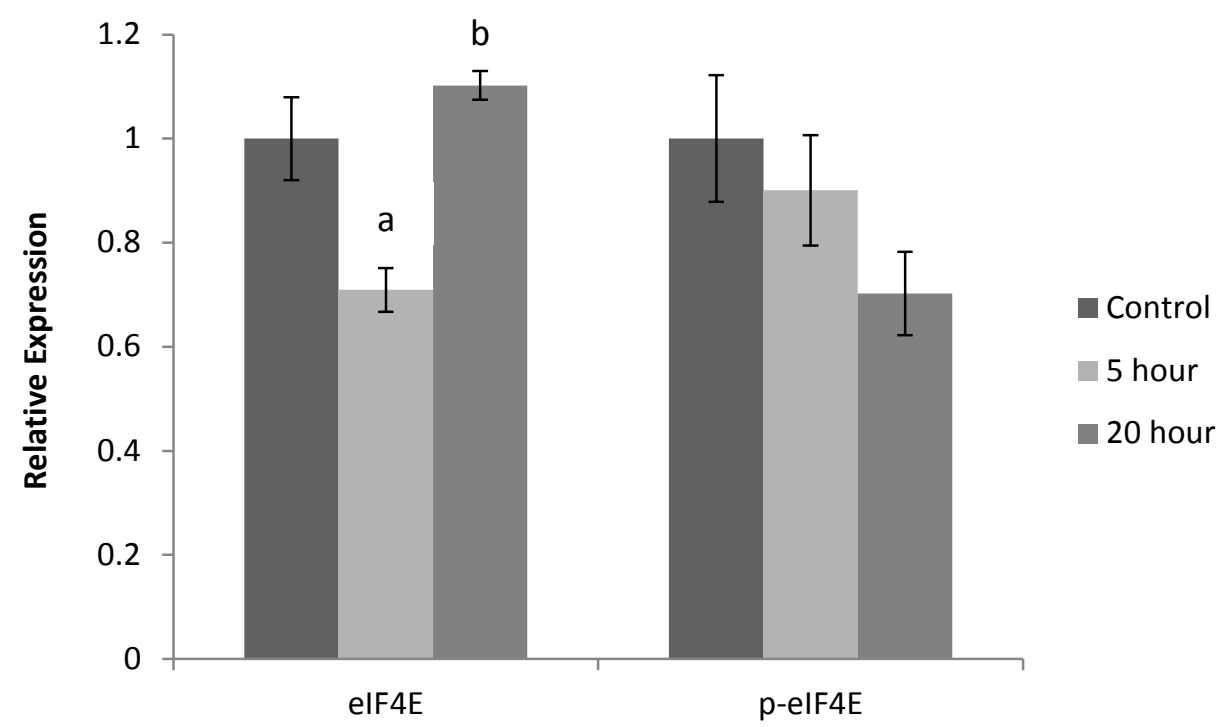

(B)

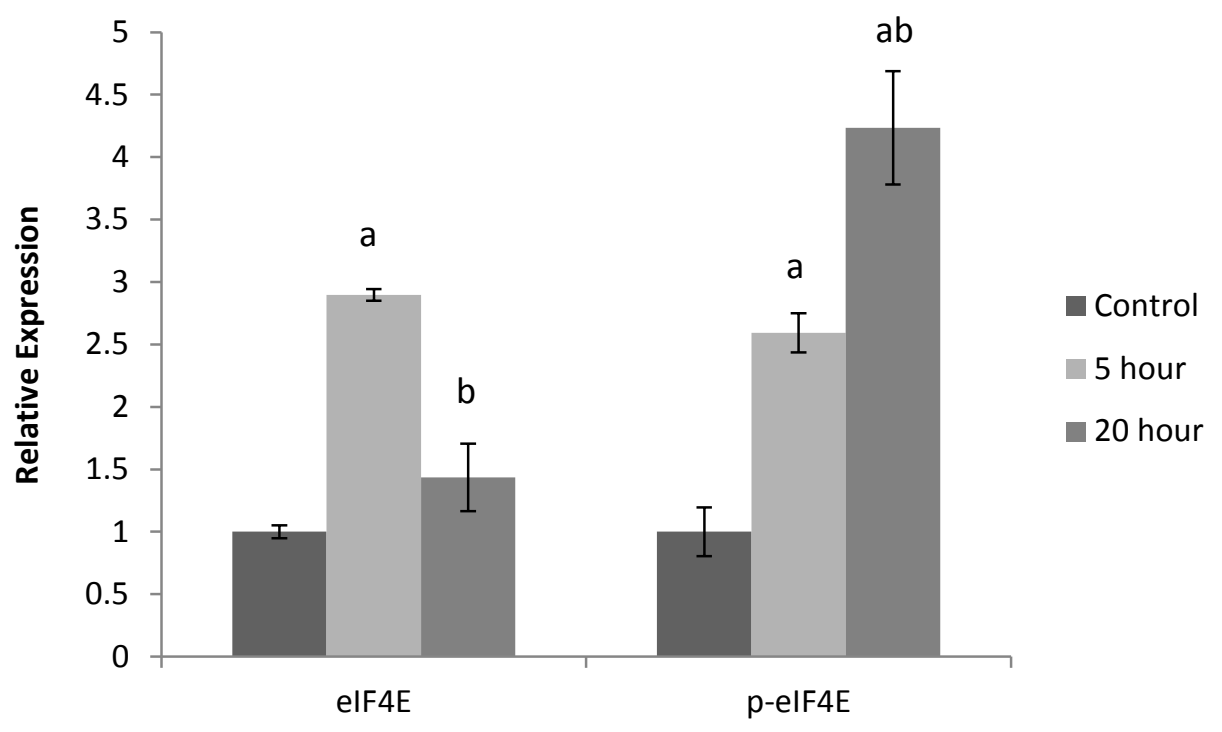

Figure 4.6 Regulation pattern of eIF4E in white skeletal muscle and liver tissues of Trachemys scripta elegans determined by Western Immunoblotting.

Relative expression levels of eIF4E and phospho-eIF4E $\mathrm{E}^{\text {Ser209 }}$ during 5 hours of hypoxia and 20 hours of anoxia in white muscle (A) and liver (B) of the red-eared slider turtle. Representative bands were detected at $\sim 25 \mathrm{kDa}$. a- significantly different from corresponding control values, b- significantly different from corresponding 5 hour values. $(P<0.05$, ANOVA, Tukey post hoc test $)$. 


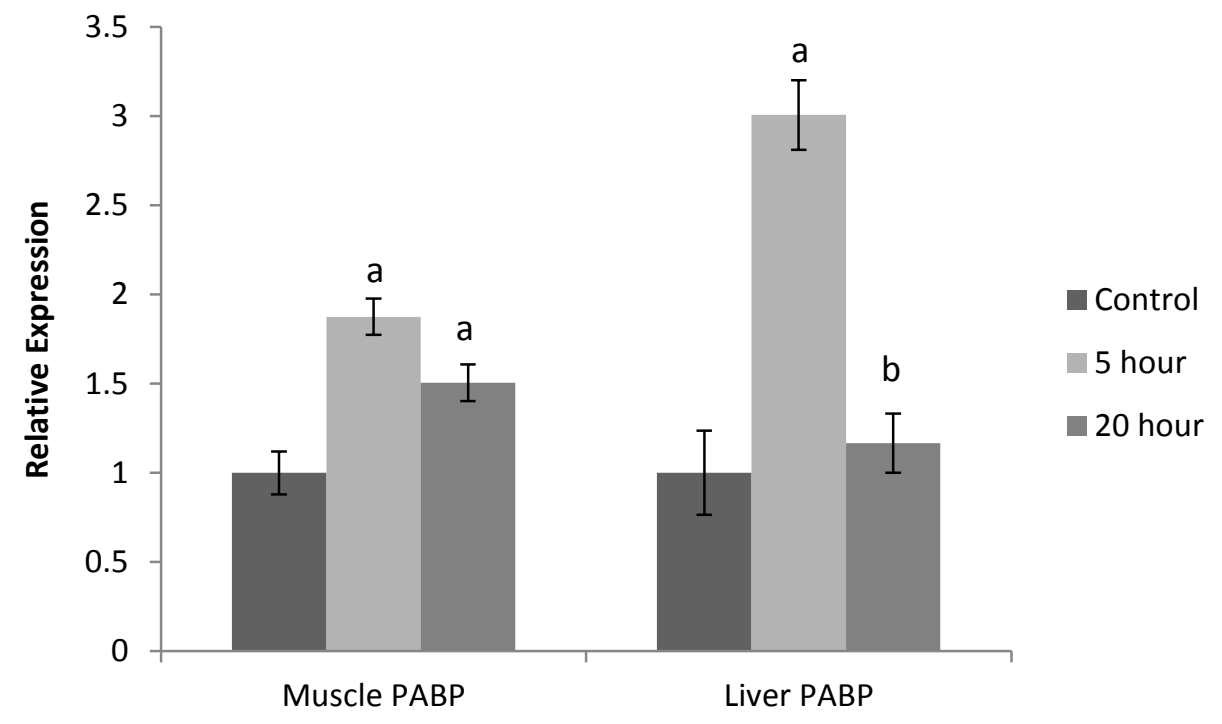

Figure 4.7 Regulation pattern of PABP in white skeletal muscle and liver tissues of Trachemys scripta elegans determined by Western Immunoblotting.

Relative expression levels of PABP during 5 hours of hypoxia and 20 hours of anoxia in white muscle and liver of the red-eared slider turtle. Representative bands were detected at $\sim 71 \mathrm{kDa}$. a- significantly different from corresponding control values, b- significantly different from corresponding 5 hour values. $(P<0.05$, ANOVA, Tukey post hoc test). 


\section{CHAPTER 5}

\section{GENERAL DISCUSSION}




\subsection{General Discussion}

The red-eared slider turtle is a champion facultative anaerobe capable of enduring long periods of time in waters devoid of oxygen and under conditions (e.g. ice cover) where it is not able to surface to breathe. It has developed several strategies to deal with this type of environmental stress. One is the accumulation of large glycogen reserves in the liver to supply the turtle with enough fermentable fuel to sustain energy needs over the winter months. Another is the ability to buffer toxic by-products produced from anaerobic glycolysis, such as lactic acid, by the release of carbonate minerals and taking up lactate into the shell and bones. However, the most significant adaptation is the turtle's ability to strongly depress its metabolic rate to reach a new state of homeostasis between energy supply and demand.

In this thesis, a major signaling pathway was examined in relation to its involvement with protein synthesis. Key upstream regulators of the mTOR signaling pathway were found to be suppressed in the white muscle of turtles but up-regulated in the liver in response to anoxic submergence (Chapter 3). Also, the mTORC1 complex itself showed no significant change in the muscle but was strongly activated in the liver. It was hypothesized that because protein synthesis is a metabolically expensive process, that it would be down-regulated in both tissues. Therefore, responses of downstream mTORC1 targets were examined in order to observe the effects of anoxia on protein synthesis. The findings of Chapter 4 revealed a similar suppression of downstream targets in the muscle as was observed upstream and a similar up-regulation of downstream liver targets, parallel to the results observed for upstream targets. The same pattern was observed in the thirteen-lined ground squirrel during hibernation (cycles of torpor- 
arousal) (Wu, 2014). Cardiac muscle and skeletal muscle were examined and the responses of mTOR pathway components indicated suppression of protein synthesis in skeletal muscle during the torpor phase of hibernation. In addition, other studies examining the effects of whole body freezing on mTOR signaling in the freeze tolerant wood frog revealed similar results with the protein expression levels of several mTOR targets increased in the liver but decreased in the skeletal muscle. Therefore, it can be postulated that the liver is a key organ required for survival in a hypometabolic state.

Generally, targets found upstream of the mTORC1 complex followed a similar trend according to their tissue of origin. However, one protein showed similar results in both the white muscle and liver. Phosphorylated AKT was not suppressed in the muscle as other targets were shown to do. Instead, AKT was found to be activated in both the liver and muscle. This may be related to the fact that AKT has been shown to be of central importance during metabolic rate depression as it is a key regulator of antiapoptosis (Igney and Krammer, 2002; Sen et al., 2003; Cheng et al., 2005). Activated AKT has been shown to activate pro-survival mechanisms either directly through phosphorylation of the protein BAD (Datta et al., 1997), or indirectly through inhibition of the transcription factor FOXO (Kops et al., 2002) and p38 signaling (del Peso et al., 1997) by imposing negative effects on apoptosis (Zhang et al, 2011). Moreover, in addition to stimulating glucose uptake through stimulation of GLUT4 translocation (Kohn et al., 1996) and glycogenesis via inhibition of GSK3ß (Ali et al., 2001; Elstrom et al., 2004), the PI3K/AKT/mTOR signaling pathway is pivotal to energy metabolism and survival in many forms of metabolic rate depression. Therefore, since the function of 
$\mathrm{AKT} / \mathrm{PKB}$ is multifaceted, we can assume that this would explain the increase in active AKT in both liver and muscle.

This study focused only on the initial hours of anoxic submergence as turtles move through the hypoxic transition into anoxia. The 20 hour time point was the longest time point used because I was interested in elucidating the mechanisms used to create a state of metabolic rate depression. However, the turtle can survive for many weeks in this state and a decrease in protein synthesis may happen in longer term hypometabolism and would predictably show a suppression of mTOR signaling. Therefore, although the results reveal a tissue specific response, there may also be a time component whereby liver protein synthesis is needed to help mediate the transition into anoxia, but may ultimately be suppressed over a longer time scale.

\subsection{The "Insulin" Signaling Pathway}

The catabolism of macromolecules such as carbohydrates, lipids and proteins produces energy required for normal cellular function. The ATP produced is used to drive energy-requiring processes. Various types of stress such as lack of oxygen cause a decrease in the amount of available energy to drive these metabolic processes. Therefore, various pathways employ energy 'sensing' mechanisms in order to regulate their function based on energy and nutritional availability. The mTOR signaling pathway, regulated by the central kinase mTORC1, integrates a variety of stimuli from various pathways in order to regulate several signaling processes such as protein synthesis. The availability of sufficient levels of mitogens and nutrients such as amino acids will result in its activation or suppression. 
The role of insulin in the 'insulin signaling pathway' is twofold. Firstly, insulin increases glucose uptake into muscle and adipose tissue and also inhibits hepatic glucose production thus serving as a primary regulator of blood glucose concentration (Saltiel and Kahn, 2001). Secondly, insulin stimulates cell growth and differentiation, promotes glycogen and protein synthesis, and inhibits glycogenolysis and protein breakdown (Saltiel and Kahn, 2001). However, the insulin signaling pathway also integrates other stimuli such as energy and amino acid availability, which are much more pertinent to the current study. During this long-term hypometabolic period of hypoxia or anoxia, the turtle must regulate protein synthesis based on ATP and amino acid availability. Therefore, the "insulin" signaling pathway must also 'sense' these changes.

Various targets of the mTORC1 signaling pathway, such as AMPK, 'sense' energy availability in the cell. Once activated by falling ATP availability, AMPK promotes ATP production by increasing the expression of proteins involved in fuel catabolism while, at the same time, conserving energy by switching off other nonessential energy-consuming metabolic processes (Hardie et al., 2012). The AMPactivated protein kinase (AMPK) is an activator of TSC2 and an inhibitor of mTORC1 through RAPTOR (Hardie et al., 2012). ATP depletion activates AMPK, which in turn phosphorylates and activates TSC2, leading to the inhibition of mTORC1 activity (HahnWindgassen et al., 2005). Therefore, the mTOR signaling pathway is regarded more as a part of an 'energy signaling' pathway rather than an 'insulin signaling' pathway with respect to its regulation of protein synthesis during hypoxic or anoxic stress.

The differential regulation of muscle and liver tissues is most likely dependent on their physiological roles in response to anoxic stress since the muscle is essentially 
unused but the liver must hydrolyze glycogen into glucose for export. The white skeletal muscle is from the neck retractor of the turtle, is a fast-twitch muscle and is a site of high levels of glycolysis. When the supply of oxygen is insufficient, whether due to the ATP demands of muscle contraction or to anoxic submergence, the muscle produces energy by anaerobic metabolism and produces lactic acid. This byproduct can then be shuttled to the liver and converted back to glucose and then shuttled back to the muscle in a process known as the Cori cycle. However, this process cannot be sustained indefinitely due to the high cost of gluconeogenesis in the liver. Hence, in situations of long term anoxia, the metabolic rate is suppressed and anaerobic glycolysis becomes the sole provider of energy. During winter months, the red-eared slider undergoes long periods of skeletal muscle disuse. Remaining glycogen stores in muscle are used up over time and ultimately, most turtle tissues may come to rely on glucose released from liver glycogen stores as their main substrate. Unlike other anoxia-tolerant animals such as the carp, the turtle is probably quiescent for the anoxic duration. Therefore, we would expect a decreased rate of protein synthesis during hypometabolism. It can be stipulated that protein synthesis is required at basal levels in the muscle but is required in higher levels the liver.

Conversely, in the liver, regulation of protein synthesis by the mTOR pathway appeared to be significantly increased over the early hours of anoxic submergence. This is supported by the data since several targets were found to be up-regulated such as AKT and mTOR (FIGs 3.7 and 3.3). The increase in AKT activity may support an increase in protein synthesis for the production of targets needed to sustain anaerobiosis. As the liver is the turtle's largest organ, and the source of glycogen stores for anaerobic glycolysis, 
the results obtained correlate with what is to be expected. Glycogen supplies from other organs are rapidly exhausted and long term anaerobiosis is fueled by blood glucose supplied from the liver glycogen reserves (Clark and Miller, 1973). As anaerobic glycolysis in the liver and other organs also produces lactic acid, the turtle must buffer the acidic by-products by releasing carbonate minerals from the shell into the extracellular fluid thus buffering the $\mathrm{pH}$. Any remaining by-products are taken up and stored in the shell and in the bones.

In summary, it may be suggested that the rate of protein synthesis is suppressed in white muscle but activated in the liver when turtles transition into an anoxic state. Any up-regulation of translation is likely essential for synthesis of new proteins required for the long-term maintenance under anoxic conditions.

\section{Final Conclusions}

The process of gene expression and protein translation is metabolically very costly. When faced with extreme environmental stress (e.g. oxygen deprivation) that compromises their ability to maintain cellular energetics and meet the demands of the many ATP-dependent processes in cells, many animals undergo extensive metabolic reprioritization in order to survive. Therefore, the costly process of protein synthesis must be heavily suppressed in order to maintain homeostasis between energy supply and demand during anoxia. This thesis provides an in-depth analysis of the possible mechanisms contributing to translational suppression in the anoxia tolerant turtle Trachemys scripta elegans. Chapters 3 and 4 illustrate the mechanisms and regulation employed by the turtle to control one of the most energy-expensive metabolic processes, 
protein synthesis, so that basal energy levels can be reprioritized towards important processes required for maintenance at a hypometabolic state. Results from Chapter 3 demonstrated the general regulation by reversible phosphorylation of upstream mTOR targets where suppression was observed in white skeletal muscle but not in liver. Chapter 4 revealed mechanisms through which ribosomal complex assembly and translational initiation was activated in the liver and maintained in skeletal muscle. Overall, the results from this thesis indicate that both the liver and white muscle undergo reprioritization of protein synthesis during hypoxia/anoxia but do so differently likely due to different functional demands on these two tissues in the anoxic state.

\section{Future directions}

This thesis characterized the regulatory process of reversible protein phosphorylation with respect to protein translation in anoxic turtles. The action of the insulin pathway was differentially regulated in the proliferative versus non-proliferative tissues (liver and muscle, respectively).

AMP-activated protein kinase (AMPK) was found to be an inhibitor of the insulin signaling pathway by phosphorylating RAPTOR. The phosphorylation of RAPTOR on Ser722/792 of the RAPTOR-containing mTORC1 complex induces cell cycle arrest when the cell is stressed for energy (Gwinn et al., 2008). AMPK plays a key role as a regulator of cellular energy homeostasis in response to stresses that deplete energy supplies such as low glucose, ischemia, heat shock and hypoxia. As a cellular energy sensor, AMPK positively regulates signaling pathways that replenish energy stores including fatty acid oxidation and autophagy and shuts down pathways that consume 
excess cellular energy such as gluconeogenesis, and lipid and protein biosynthesis. This is achieved through phosphorylation of a number of enzymes directly involved in these processes as well as through control of various transcription factors, co-activators and corepressors. Therefore, as an important future direction, I would like to extend my research to examine the regulation of AMPK itself and the AMPK pathway to see which cellular process are down-regulated under anoxic conditions in the turtle and whether there is a similar tissue-specific response to the one observed in the insulin signaling pathway. 


\section{APPENDICES}


Appendix A1. List of Antibodies

\begin{tabular}{|c|c|c|c|}
\hline Antibody & Type & Company & Stock \# \\
\hline mTOR & Total & Cell Signal & 2983 \\
\hline mTOR & Phospho Ser-2448 & Cell Signal & 2971 \\
\hline Akt & Total & Cell Signal & 2938 \\
\hline Akt & Phospho Ser-473 & Cell Signal & 9270 \\
\hline PDK1 & Total & Cell Signal & 3062 \\
\hline PDK1 & Phospho Ser-241 & Cell Signal & $3438 P$ \\
\hline PTEN & non-phospho & Cell Signal & 7960 \\
\hline PTEN & Phospho Ser-380/Thr-382/Thr-383 & Cell Signal & $9549 P$ \\
\hline TSC2 & Phospho Thr-1462 & Cell Signal & 3617 \\
\hline PRAS40 & Phospho Thr-246 & Cell Signal & 13175 \\
\hline GßL & Total & Cell Signal & 3274 \\
\hline Raptor & Total & Cell Signal & 2280 \\
\hline p70 S6K & Phospho Thr-389 & Gen Script & A00527 \\
\hline eIF4E & Total & Cell Signal & 2067 \\
\hline eIF4E & Phospho Ser-209 & Cell Signal & 9741 \\
\hline S6 & Total & Gen Script & A00465-100 \\
\hline S6 & Phospho Ser-235/Ser-236 & Gen Script & A00315-100 \\
\hline 4E-BP1 & Total & Gen Script & A00461-100 \\
\hline 4E-BP1 & Phospho Thr-37/46 & Gen Script & A00328-100 \\
\hline
\end{tabular}


Appendix A2. List of immunoblotting conditions

\begin{tabular}{|c|c|c|c|c|c|c|c|}
\hline Antibody & Type & $\begin{array}{l}\text { Gel } \\
(\%)\end{array}$ & $\begin{array}{c}\text { MW } \\
\text { (kDa) }\end{array}$ & [Primary] & Reactivity & [Secondary] & Notes \\
\hline mTOR & Total & 6 & 289 & $1: 1000$ & Anti-Rabbit & $1: 5000$ & $60 \mathrm{~m}$ run$/ 4 \mathrm{~h}$ transfer \\
\hline mTOR & phospho & 6 & 289 & $1: 1000$ & Anti-Rabbit & $1: 5000$ & $60 \mathrm{~m}$ run/4h transfer \\
\hline Akt & Total & 10 & 60 & $1: 1000$ & Anti-Rabbit & $1: 4000$ & - \\
\hline Akt & phospho & 10 & 60 & $1: 1000$ & Anti-Rabbit & $1: 4000$ & - \\
\hline PDK1 & Total & 10 & $56-68$ & $1: 1000$ & Anti-Rabbit & $1: 4000$ & - \\
\hline PDK1 & phospho & 10 & $56-68$ & $1: 1000$ & Anti-Rabbit & $1: 4000$ & - \\
\hline PTEN & Non-P & 10 & 54 & $1: 1000$ & Anti-Rabbit & $1: 5000$ & - \\
\hline PTEN & phospho & 10 & 54 & $1: 1000$ & Anti-Rabbit & $1: 5000$ & - \\
\hline TSC2 & phospho & 6 & 200 & $1: 1000$ & Anti-Rabbit & $1: 4000$ & $2 \mathrm{~h}$ transfer \\
\hline PRAS40 & phospho & 10 & 40 & $1: 1000$ & Anti-Rabbit & $1: 4000$ & - \\
\hline $\mathrm{G} \beta \mathrm{L}$ & Total & 10 & 37 & $1: 1000$ & Anti-Rabbit & $1: 6000$ & - \\
\hline Raptor & Total & 6 & 150 & $1: 1000$ & Anti-Rabbit & $1: 4000$ & $2 \mathrm{~h}$ transfer \\
\hline p70 S6K & phospho & 10 & 70 & $1: 1000$ & Anti-Goat & $1: 6000$ & - \\
\hline eIF4E & Total & 15 & 25 & $1: 1000$ & Anti-Rabbit & $1: 5000$ & 0.2 um PVDF \\
\hline S6 & Total & 8 & 32 & $1: 1000$ & Anti-Rabbit & $1: 5000$ & - \\
\hline S6 & phospho & 8 & 32 & $1: 1000$ & Anti-Rabbit & $1: 5000$ & - \\
\hline 4E-BP1 & Total & 15 & $15-20$ & $1: 1000$ & Anti-Rabbit & $1: 5000$ & 0.2 um PVDF \\
\hline 4E-BP1 & phospho & 15 & $15-20$ & $1: 1000$ & Anti-Rabbit & $1: 5000$ & 0.2 um PVDF \\
\hline PABP & Total & 10 & 71 & $1: 1000$ & Anti-Rabbit & $1: 4000$ & 0.2 um PVDF \\
\hline
\end{tabular}




\section{REFERENCES}


Bickler, P.E. and L.T. Buck. 2007. Hypoxia tolerance in reptiles, amphibians and fishes: life with variable oxygen availability. Annual Review of Physiology. 69: 145-170.

Biggar, K.K., A.G. Groom, and K.B. Storey. 2011. 4. Hypometabolism and turtles: Physiological and molecular strategies of anoxic survival. In: Hypometabolism: Strategies of Survival in Vertebrates and Invertebrates. (Nowakowska, A. and Caputa, M., eds.), Research Signpost, Kerala, India, pp. 57-94.

Biggar, K.K. and K.B. Storey. 2011. The emerging roles of microRNAs in the molecular responses of metabolic rate depression. Journal of Molecular Cell Biology. 3(3): 167175.

Bodine, S.C., T.N. Stitt, M. Gonzalez, W.O. Kline, G.L. Stover, R. Bauerlein, E. Zlotchenko, A. Scrimgeour, J.C. Lawrence, D.J. Glass, and G.D. Yancopoulos. 2001. $\mathrm{Akt} / \mathrm{mTOR}$ pathway is a crucial regulator of skeletal muscle hypertrophy and can prevent muscle atrophy in vivo. Nature Cell Biology. 3: 1014-1019.

Brooks, S.P.J. and K.B. Storey. 1989. Regulation of glycolytic enzymes during anoxia in the turtle Pseudemys scripta. The American Physiological Society. 257: 278-283.

Brooks S.P.J., and K.B. Storey. 1992. Mechanisms of glycolytic control during hibernation in the ground squirrel Spermophilus lateralis. The Journal of Comparative Physiology [B]. 162: 23-28.

Brooks, S.P.J. and Storey, K.B. 1994. Patterns of protein synthesis and phosphorylation during anoxia in the land snail Otala lactea. Canadian Journal of Zoology. 72: 856-862.

Brown, J.M. 2007. Tumor hypoxia in cancer therapy. Methods in Enzymology. 435: 297321.

Brown, C. E., and A.B. Sachs. 1998. Poly (A) tail length control in Saccharomyces cerevisiae occurs by message-specific deadenylation. Molecular and Cellular Biology. 18(11): 6548-6559.

Brugarolas, J. K. Lei, R. L. Hurley, B. D. Manning, J. H. Reiling, E. Hafen, L. A. Witters, L. W. Ellisen, and W. G. Kaelin, Jr. 2004. Regulation of mTOR function in response to hypoxia by REDD1 and the TSC1/TSC2 tumor suppressor complex. Genes \& Development. 18: 2893-2904.

Caponigro G. and R. Parker. 1995 Multiple functions for the poly(A)-binding protein in mRNA decapping and deadenylation in yeast. Genes \& Development. 19:2421-32.

Chagpar, R.B., P.H. Links, M.C. Pastor, L.A. Furber, A.D. Hawrysh, M.D. Chamberlain, D.H. Anderson and J.E. Dixon. 2010. Direct positive regulation of PTEN by the p85 subunit of phosphatidylinositol 3-kinase. Proceedings of the National Academy of Sciences of the United States of America. 107(12): 5471-5476. 
Chang, L., S.-H. Chiang, and A.R. Saltiel. 2004. Insulin signaling and the regulation of glucose transport. Molecular Medicine. 10(7-12): 65-71.

Clark, V.M., and A.T. Miller. 1973. Studies on anaerobic metabolism in the fresh water turtle (Pseudemys scripta elegans). Comparative Biochemistry and Physiology Part A: Molecular and Integrative Physiology. 44: 55-62.

Cohen, P. 2002. The origins of protein phosphorylation. Nature Cell Biology. 4: 127-130.

Dufner, A. and G. Thomas. 1999. Ribosomal S6 kinase signaling and the control of translation. Experimental Cell Research. 253(1): 100-109.

Dunlop, E.A. and A.R. Tee. 2009. Mammalian target of rapamycin complex 1: signaling inputs, substrates and feedback mechanisms. Cell Signal. 6: 827-835.

Eaton, S.L., S.L. Roche, M.L.Hurtado, K.J. Oldknow, C. Farquharson, T.H. Gillingwater and T.M. Wishart. 2013. Total protein analysis as a reliable loading control for quantitative fluorescent western blotting. Public Library of Science. 8(8): 1-9.

Fähling, M. 2009. Surviving hypoxia by modulation of mRNA translation rate. Journal of Cellular and Molecular Medicine. 13(9a): 2770-2779.

Fayard, E., L.A. Tintignac, A. Baudry and B.A. Hemmings. 2005. Protein kinase B/Akt at a glance. Journal of Cell Science. 118: 5675-5678.

Fedorov, V.B. , A. V. Goropashnaya, Ø. Tøien, N. C. Stewart, C. Chang, H. Wang, J. Yan, L. C. Showe, M. K. Showe, and B. M. Barnes. 2011 Modulation of gene expression in heart and liver of hibernating black bears (Ursus americanus). Biomed Central Genomics. 12: 171-186.

Feng, Z., and A.J. Levine. 2010. The regulation of energy metabolism and the IGF1/mTOR pathways by the p53 protein. Trends in Cell Biology. 20(7): 427-434.

Fingar, D.C., C.J. Richardson, A.R. Tee, L. Cheatham, C. Tsou, and J. Blenis. 2004. mTOR controls cell cycle progression through its cell growth effectors S6K1 and 4EBP1/eukaryotic translation initiation factor 4E. Molecular and Cellular Biology. 24(1): 200-216

Fritsche L, C. Weigert, H.U. Häring and R. Lehmann. 2008. How insulin receptor substrate proteins regulate the metabolic capacity of the liver - implications for health and disease. Current Medicinal Chemistry. 15(13): 1316-1329.

Gwinn, D.M.,D. B. Shackelford, D. F. Egan, M. M. Mihaylova, A. Mery, D. S. Vasquez, B. E. Turk, and R. J. Shaw. 2008. AMPK phosphorylation of Raptor mediates a metabolic checkpoint. Molecular Cell. 30: 214-226.

Hay N, and N. Sonenberg. 2004. Upstream and downstream of mTOR. Genes and Development. 18(16):1926-1945. 
Haar, E.V., S.-I. Lee, S. Bandhakavi, T.J. Griffin, and D.-H. Kim. 2007. Insulin signaling to mTOR mediated by the Akt/PKB substrate PRAS40. Nature Cell Biology. 9: 316-323.

Hahn-Windgassen, A. V. Nogueira, C.-C. Chen, J.E. Skeen, N. Sonenberg, and N. Hay. 2005. Akt activates mTOR by regulating cellular ATP level and AMPK activity. The Journal of Biological Chemistry. 280(37): 32081-32089.

Hardie, D.G., F.A. Ross, and S.A. Hawley. 2012. AMPK: a nutrient and energy sensor that maintains energy homeostasis. Nature Reviews Molecular Cell Biology. 13: 251-262.

Herbert, C.V. and D.C. Jackson, 1985. Temperature effects on the responses to prolonged submergence in the turtle Chrysemys picta bellii. II. Metabolic rate, blood acid-base and ionic changes and cardiovascular function in aerated and anoxic water. Physiological Zoology. 58(6): 670-681.

Hermes-Lima, M., J.M. Storey and K.B. Storey. 1998. Antioxidant defenses and metabolic depression. The hypothesis of preparation for oxidative stress in land snails. Comparative Biochemistry and Physiology Part B: Biochemistry and Molecular Biology. 120(3): 437-448.

Hemmings, B.A. and D.F. Restuccia. 2012. PI3K-PKB/Akt pathway. Cold Spring Harbor Perspectives in Biology. 4(9).

Hochachka, P.W., L.T. Buck, C.J. Doll, and S.C. Land. 1996. Unifying theory of hypoxia tolerance: molecular/metabolic defense and rescue mechanisms for surviving oxygen lack. Proceedings of the National Academy of Sciences of the United States of America. 93(18): 9493-9498.

Huang, J. and B.D. Manning. 2009. A complex interplay between Akt, TSC2 and the two mTOR complexes. Biochemical Society Transactions. 37(1): 217-222.

Hutchinson, J.A., N.P. Shanware, H. Chang, and R.S. Tibbetts. 2011. Regulation of ribosomal protein $\mathrm{S} 6$ phopshorylation by casein kinase 1 and protein phosphatase 1. The Journal of Biological Chemistry. 286: 8688-8696.

Inoki, K., Y. Li, T. Zhu, J. Wu, and K-L Guan. 2002. TSC2 is phosphorylated and inhibited by Akt and suppresses mTOR signaling. Nature cell Biology. 4: 648-657.

Jackson, D.C. 2002. Hibernating without oxygen: physiological adaptations of the painted turtle. Journal of Physiology. 543: 731-737.

Jackson, D.C. and G.R. Ultsch. 2010. Physiology of hibernation under the ice by turtles and frogs. Journal of Experimental Zoology. 313: 311-327.

Jackson, R.J. and N. Standart. 1990. Do the poly(A) tail and 3' untranslation region control mRNA translation? Cell. 62: 15-24. 
Kim D.H., D.D. Sarbassov, S.M. Ali, R.R. Latek, K.V. Guntur, H. ErdjumentBromage, P. Tempst, D.M. Sabatini. 2003. GbetaL, a positive regulator of the rapamycinsensitive pathway required for the nutrient-sensitive interaction between raptor and mTOR. Molecular Cell. 4: 895-9004.

Knaup, K.X., K. Jozefowski, R. Schmidt, W. M. Bernhardt, A. Weidemann, J. S. Juergensen, C. Warnecke, K.-U. Eckardt and M. S. Wiesener. 2009. Mutual regulation of hypoxia-inducible factor and mammalian target of rapamycin as a function of oxygen availability. Molecular Cancer Research. 7(1): 88-98.

Krivoruchko, A. and K.B. Storey. 2013a. Activation of the unfolded protein response during anoxia exposure in the turtle Trachemys scripta elegans. Molecular Cell Biochemistry. 374: 91-103.

Krivoruchko, A. and K.B. Storey, K.B. 2013b. Anoxia-responsive regulation of the FoxO transcription factors in freshwater turtles, Trachemys scripta elegans. Biochimica et Biophysica Acta. 1830(11): 4990-4998.

Kroese, F.G.M. and N.V. Rooijen. 1982. The architechture of the spleen of the red-eared slider, Chrysemys scripta elegans (Reptilia, Testudines). Journal of Morphology. 173(3): 279-284.

Lant, B. 2011. The anoxia tolerant crayfish: a profile of stress response. Ph.D Thesis. Carleton Univerity, Ottawa ON.

Laplante, M. and D.M. Sabatini. 2009. mTOR signaling at a glance. The Journal of Cell Science. 122: 3589-3594.

Larade, K. and K.B. Storey. 2002a. A profile of the metabolic responses to anoxia in marine invertebrates. In: Cell and Molecular Responses to Stress (Storey, K.B. and Storey, J.M., eds.), Vol. 3: Sensing, Signaling and Cell Adaptation. Elsevier Press, Amsterdam, pp. 27-46.

Larade, K. and K.B. Storey. 2002b. Reversible suppression of protein synthesis in concert with polysome disaggregation during anoxia exposure in Littorina littorea. Molecular and Cellular Biochemistry. 232: 121-127.

Le, H., R.L. Tanguay, M.L. Balasta, C.C. Wei, K.S. Browning, A.M. Metz, D.J. Goss, and D.R. Gallie. 1997. Translation initiation factors eIF-iso4G and eIF-4B interact with the poly(A)-binding protein and increase its RNA binding activity. The Journal of Biological Chemistry. 272(26):16247-55.

Le, H., K.S. Browning, and D.R. Gallie. 2000. The phosphorylation state of poly (A)binding protein specifies its binding to poly (A) RNA and its interaction with eukaryotic initiation factor (eIF) 4F, eIFiso4F, and eIF4B. Journal of Biological Chemistry, 275(23): $17452-17462$ 
Leclerc G.M., G.J. Leclerc, G. Fu, and J.C. Barredo. 2010. AMPK-induced activation of Akt by AICAR is mediated by IGF-1R dependent and independent mechanisms in acute lymphoblastic leukemia. Journal of Molecular Signaling. 5: 1-13.

Liu, P., M. Begley, W. Michowski, H. Inuzuka, M. Ginzberg, D. Gao, P. Tsou, W. Gan, A. Papa, B. M. Kim, L. Wan, A. Singh, B. Zhai, M. Yuan, Z. Wang, S. P. Gygi, T. H. Lee, K.-P. Lu, A. Toker, P. P. Pandolfi, J. M. Asara, M. W. Kirschner, P. Sicinski, L. Cantley and W. Wei. 2014. Cell-cycle-regulated activation of Akt kinase by phosphorylation at its carboxyl terminus. Nature Letters. 1: 1-8.

Long, X., F. Müller, and J. Avruch. 2004. TOR action in mammalian cells and in Caenorhabditis elegans. Current Topics in Microbiology and Immunology. 279: 115-138.

Lutz, P.L. and G.E. Nilsson. 2004. Vertebrate brains and the pilot light. Respiratory Phyiology and Neurobiology. 141(3): 285-296.

Luu, B. 2013. Regulation of protein translation and cell cycle processes by reversible protein phosphorylation in response to dehydration in the African clawed frog. M.Sc. Thesis. Carleton University, Ottawa ON.

Martorell, L., M. Gentile, J. Rius, C. Rodríguez, J. Crespo, L. Badimon, and J. MartínezGonzález. 2009. The hypoxia-inducible factor 1/NOR-1 axis regulates the survival response of endothelial cells to hypoxia. Molecular and Cellular Biology. 29(21):58285842.

Müller, D., C. Lasfargues, S.E. Khawand, A. Alard, R.J. Schneider, C. Bousquet, S. Pyronnet, and Y. Martineau. 2013. 4E-BP restrains eIF4E phosphorylation. Proceedings of the National Academy of Sciences of the United States of America. 75: 4843-4849.

Mylonis, I., H. Sembongi, C. Befani, P. Liakos, S. Siniossoglou, and G. Simos. 2012. Hypoxia causes triglyceride accumulation by HIF-1-mediated stimulation of lipin 1 expression. Journal of Cell Science. 125: 3485-3493.

Nayak, G.H., H.M. Prentice, S.L. Milton. 2011. Neuroprotective signaling pathways are modulated by adenosine in the anoxia-tolerant turtle. The Journal of Cerebral Blood Flow \& Metabolism. 31(2): 467-475.

Nielsen P.J., G. Thomas, J.L. Maller. 1982. Increased phosphorylation of ribosomal protein S6 during meiotic maturation of Xenopus oocytes. Proceedings of the National Academy of Sciences of the United States of America. 79(9): 2937-2941.

Nilsson, G.E. and G.M.C. Renshaw. 2004. Hypoxic survival strategies in two fishes: extreme anoxia tolerance in the North European crucian carp and natural hypoxic preconditioning in a coral-reef shark. The Journal of Experimental Biology. 217(10): 3131-3139. 
Parker, P. J., Caudwell, F.B., and Cohen, P. 1983. Glycogen synthase from rabbit skeletal muscle; effect of insulin on the state of phosphorylation of the seven phosphoserine residues in vivo. European Journal of Biochemistry. 130: 227-234.

Richter J.D. and N. Sonenberg. 2005. Regulation of cap-dependent translation by eIF4E inhibitory proteins. Nature. 433: 477-480.

Rosner M., N. Siegel, A. Valli, C. Fuchs, and M. Hengstschlager. 2009. mTOR phosphorylated at S2448 binds to raptor and rictor. Amino Acids. 38(1): 223-228.

Ruvinsky, I. and O. Meyuhas. 2006. Ribosomal protein S6 phosphorylation: from protein synthesis to cell size. Trends in Biochemical Sciences, 31(6): 342-348

Sachs A.B. and R.W. Davis RW.1989. The poly(A) binding protein is required for poly(A) shortening and $60 \mathrm{~S}$ ribosomal subunit-dependent translation initiation. Cell. 58(5): $857-867$.

Schick V., M. Majores, G. Engels, W. Hartmann, C.E. Elger, J. Schramm, S. Schoch, A.J. Becker. 2007. Differential PI3K-pathway activation in cortical tubers and focal cortical dysplasias with balloon cells. Brain Pathology. 2: 165-173.

Schwanhäusser, B., D. Busse, N. Li, G. Dittmar, J. Schuchhardt, J. Wolf, W. Chen and M. Selbach. 2011. Global Quantification of mammalian gene expression control. Nature. 473(7347): 337-342.

Soley, M., R. Chieri, and E. Harrera. 1983. Liver glucose, glycogen and lipid synthesis in fed and 24-hour fasted rats soon after a pulse of $\left[3-{ }^{14} \mathrm{C}\right]$ pyruvate through the portal vein. The International Journal of Biochemistry. 15(1): 45-49.

Sonenberg, N., and A.C. Gingras. 1998. The mRNA 5' cap-binding protein eIF4E and control of cell growth. Current Opinion in Cell Biology, 10(2): 268-275.

Song, M.S., L. Salmena, and P.P. Pandolfi. 2012. The functions and regulation of the PTEN tumor suppressor. Nature Reviews Molecular Cell Biology. 13: 283-296.

Stensløkken, K.-O., S. Ellefsen, J.A.W. Stecyk. M.B. Dahl, G.E. Nilsson, and J. Vaage 2008. Differential regulation of AMP-activated kinase and AKT kinase in response to oxygen availability in crucian carp (Carassius carassius). American Journal of Physiology Regulatory, Integrative and Comparative Physiology. 295: 1803-1814.

Stitt T.N., D. Drujan, B.A. Clarke, F. Panaro, Y. Timofeyva, W.O. Kline, M. Gonzalez, G.D. Yancopoulos, D.J. Glass. 2004. The IGF-1/PI3K/Akt pathway prevents expression of muscle atrophy-induced ubiquitin ligases by inhibiting FOXO transcription factors. Molecular Cell. 14(3):395-403. 
Storey, K.B. 1996. Metabolic adaptations supporting anoxia tolerance in reptiles: Recent advances. Comparative Biochemistry and Physiology Part B: Biochemistry and Molecular Biology. 113(1): 23-35.

Storey, K.B. 1997. Metabolic regulation in mammalian hibernation: Enzyme and protein adaptations. Comparative Biochemistry and Physiology Part A: Physiology. 118(4): 1115-1124.

Storey, K.B. 2003. Mammalian hibernation: transcriptional and translational controls. In: Hypoxia: Through the Lifecycle (Roach, R.C., Wagner, P.D., Hackett, P.H., eds.) Kluwer/Plenum Academic, New York. pp.21-38.

Storey, K.B. 2004. Functional Metabolism. Regulation and Adaptation. John Wiley \& Sons, New York.

Storey, K.B. 2007. Anoxia tolerance in turtles: Metabolic regulation and gene expression. Comparative Biochemistry and Physiology, Part A. 147: 263-276.

Storey, K.B. and J.M. Storey. 1984. Biochemical adaptation for freezing tolerance in the wood frog, Rana sylvatica. Journal of Comparative Physiology B. 155: 29-36.

Storey, K.B. and J.M. Storey. 1990. Metabolic rate depression and biochemical adaptation in anaerobiosis, hibernation and estivation. The Quarterly Review of Biology. 65: $145-174$.

Storey, K.B., and J.M. Storey. 2004a. Metabolic rate depression in animals: transcriptional and translational controls. Biological Reviews of the Cambridge Philosophical Society. 79: 207-233.

Storey, K.B. and J.M. Storey. 2004b. Oxygen limitations and metabolic rate depression. In: Functional Metabolism: Regulation and Adaptation. (Storey, K.B., ed.) John Wiley \& Sons, New York. pp.415-442.

Storey, K.B. and J.M. Storey. 2007a. Metabolic rate depression in animals: transcriptional and translational controls. Biological Reviews. 79(1): 207-233.

Storey, K.B. and J.M. Storey. 2007b. Tribute to P.L. Lutz: putting life on 'pause' molecular regulation of hypometabolism. The Journal of Experimental Biology. 210: $1700-1714$.

Storey, K.B. and T.P. Mommsen. 1994. Effects of temperature and freezing on hepatocytes isolated from a freeze-tolerant frog. American Journal of Physiology. 266: R1477-R1482.

Ultsch, G.R. 2006. The ecology of overwintering among turtles: where turtles overwinter and its consequences. Biological Reviews. 81: 339-367 
Vaupel, P. and A. Mayer. 2007. Hypoxia in cancer: significance and impact on clinical outcome. Cancer Metastasis Review. 2: 225-239.

Wan, X. and L.J. Helman. 2003. Levels of PTEN protein modulate AKT phosphorylation on serine 473, but not on threonine 308, in IGF-II-overexpressing rhabdomyosarcomas cells. Oncogene. 22: 8205-8211.

Wang, X., and C.G. Proud. 2006. The mTOR pathway in the control of protein synthesis. Physiology. 21: 362-269.

Wang L, T.E. Harris, and J.C. Lawrence. 2008. Regulation of proline-rich Akt substrate of $40 \mathrm{kDa}$ (PRAS40) function by mammalian target of rapamycin complex 1 (mTORC1)mediated phosphorylation. The Journal of Biological Chemistry. 283(23): 15619-15627.

Wang, L., T.E. Harris, R.A. Roth, and J.C. Lawrence. 2007. PRAS40 regulates mTORC1 kinase activity by functioning as a direct inhibitor of substrate binding. Journal of Biological Chemistry. 282: 20036 - 20044.

Wasserman, K. 1999. Critical capillary $\mathrm{PO}_{2}$ and the role of lactate production in oxyhemoglobin dissociation during exercise. Advances in Experimental Medicine and Biology. 471: 321-333.

Watanabe, R., L. Wei, and J. Huang. 2011. mTOR signaling, function, novel inhibitors and therapeutic targets. Journal of Nuclear Medicine. 4: 497-500.

Weng, Q.P., K. Andrabi, A. Klippel, M.T. Kozlowski, L.T. Williams, and J. Avuch. 1995. Phosphatidylinositol 3-kinase signals activation of p70 S6 kinase in situ through site-specific p70 phosphorylation. Proceedings of the National Academy of Sciences of the United States of America. 92(12): 5744-5748.

Wilkie, G.S., K.S. Dickson, and N.K. Gray. 2003. Regulation of mRNA translation by 5'and 3'-UTR-binding factors. Trends in Biochemical Sciences. 28(4): 182-188.

Willmore, W.G., K.J. Cowan, K.B. Storey. 2001. Effects of anoxia exposure and aerobic recovery on metabolic enzyme activities in the freshwater turtle Trachemys scripta elegans. Canadian Journal of Zoology. 79: 1822-1828.

Wise, G., J.M. Mulvey, and G.M.C. Renshaw. 1998. Hypoxia tolerance in the epaulette shark (Hemiscyllium ocellatum). The Journal of Experimental Zoology. 281: 1-5.

Wouters, B.G. and M. Koritzinsky. 2008. Hypoxia signaling through mTOR and the unfolded protein response in cancer. Nature Reviews Cancer. 8: 851-864.

Wu, C.-W. 2014. Molecular adaptations of mammalian hibernation: roles of metabolic signaling regulation in the torpor-arousal cycle. Ph.D Thesis. Carleton Univerity, Ottawa. 
Wu, C-W and K.B. Storey. 2012. Regulation of the mTOR signaling networks in hibernating thirteen-lined ground squirrels. The Journal of Experimental Biology. 215: 1720-1727.

Xiong, Z.J. and K.B. Storey. 2012. Regulation of liver lactate dehydrogenase by reversible phosphorylation in response to anoxia in a freshwater turtle. Comparative Biochemistry and Physiology B: Biochemistry and Molecular Biology. 163(2): 221-228.

Zhang, J., K.K. Biggar, and K.B. Storey. 2013. Regulation of p53 by reversible posttranscriptional and post-translational mechanisms in liver and skeletal muscle of an anoxia tolerant turtle, Trachemys scripta elegans. Gene 513: 147-155.

Zhang, J. and K.B. Storey. 2013. Akt signaling and freezing survival in the wood frog, Rana sylvatica. Biochimica et Biophysica Acta. 1830(10): 4828-4837.

Zhang, J., S.N. Tessier, and K.B. Storey. 2011. PI3K-Akt regulation as a molecular mechanism of the stress response during aerobic dormancy. In: Hypometabolism: Strategies of Survival in Vertebrates and Invertebrates. (Nowakowska, A. and Caputa, M., eds.), Research Signpost, Kerala, India, pp. 147-182. 